\title{
Transition metal complexes with functionalized silyl-substituted cyclopentadienyl and related ligands: synthesis and reactivity
}

\author{
Tomás Cuenca, Pascual Royo * \\ Departamento de Química Inorgánica, Universidad de Alcalá, Campus Universitario, \\ Edificio de Farmacia, 28871-Alcalá de Henares, Madrid, Spain
}

Received 7 January 1999; received in revised form 12 March 1999; accepted 19 April 1999

\section{Contents}

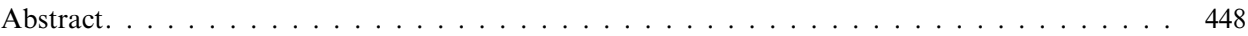

1. Introduction . . . . . . . . . . . . . . . . . . . . . . . . . 449

2. Hydro-silyl-cyclopentadienyl metal complexes (type I) . . . . . . . . . . . . . . . 451

2.1 Synthetic methods . . . . . . . . . . . . . . . . . . 451

2.1.1 Synthesis of hydro-silyl-cyclopentadiene and related derivatives and their alkali and thallium salts .................... 451

2.1.2 Synthesis of monocyclopentadienyl-type derivatives using diene-reagents . . . . . 452

2.1.3 Synthesis of dicyclopentadienyl-type derivatives using dienyl-reagents . . . . . . . 453

2.1.4 Metallation of coordinated cyclopentadienyl ligands . . . . . . . . . . . . . . . . . . . . . . . . . . 454

2.1 .5 Use of doubly silyl-bridged cyclopentadiene . . . . . . . . . . . . . . 455

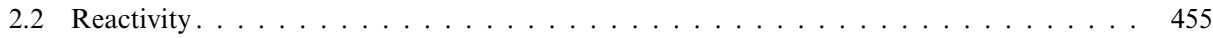

3. Halo-silyl-cyclopentadienyl metal complexes (type II) . . . . . . . . . . . . . . . . 457

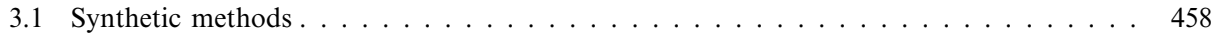

3.1.1 Transfer of the halosilyl-cyclopentadienyl ring to a transition metal . . . . . 458

3.1.1.1 Alkali and thallium salts of the halo-silyl-cyclopentadienide. . . . . . . 459

3.1.1.2 Use of disilycyclopentadienes . . . . . . . . . . . . . . . 460

3.1.1.3 Use of doubly silyl-bridged dicyclopentadiene. . . . . . . . . . . . . 462

3.1.1.4 Use of halo-silylcyclopentadiene . . . . . . . . . . . . . 463

3.1.2 Halogenation of silyl-cyclopentadienyl metal complexes . . . . . . . . . . . . 465

3.2 Reactivity. . . . . . . . . . . . . . . . . . . . . 465

* Corresponding author. Tel.: + 34-91-8854765; fax: + 34-91-8854683.

E-mail address: proyo@inorg.alcala.es (P. Royo) 
3.2.1 Reactions of halo-silyl cyclopentadienyl metal complexes with water

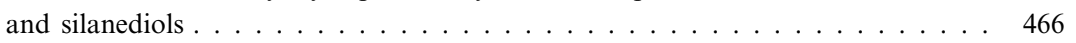

3.2 .2 Reactions with $\mathrm{LiOH} \ldots \ldots \ldots \ldots \ldots$. . . . . . . . . . . . . 468

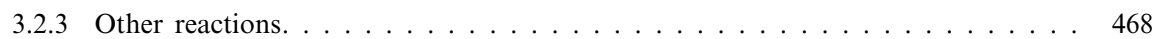

4. Oxo-silyl-cyclopentadienyl metal complexes (type III) . . . . . . . . . . . . . . . . . . . 469

4.1 Synthetic procedures . . . . . . . . . . . . . . . . . . . . . . 469

4.1.1 Transfer of oxo-silyl functionalized cyclopentadienyl rings . . . . . . . . . . . 469

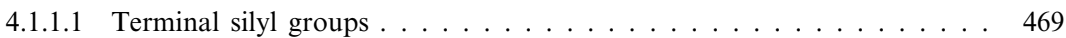

4.1 .1 .2 Bridging alkoxo-silyl groups . . . . . . . . . . . . . . . 473

4.1.1.3 Bridging siloxane groups . . . . . . . . . . . . . . . 473

4.1.2 Transformation of chloro-silyl into oxo-silyl functionalized cyclopentadienyl metal complexes . . . . . . . . . . . . . . . . . 476

4.1.3 Transformation of amido-silyl into oxo-silyl cyclopentadienyl metal

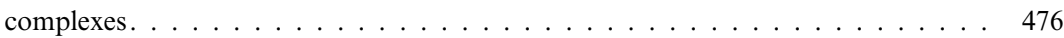

5. Amino - and amido-silyl-cyclopentadienyl metal complexes (type IV) . . . . . . . . . . 478

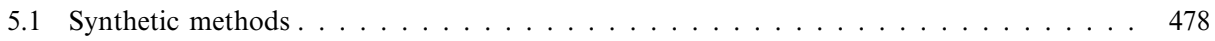

5.1 .1 Transfer of functionalized cyclopentadienyl rings . . . . . . . . . . . . . 478

5.1.2 Transformation of chloro-silyl into amido-silyl functionalized cyclopentadienyl metal complexes . . . . . . . . . . . . . . . . . . 478

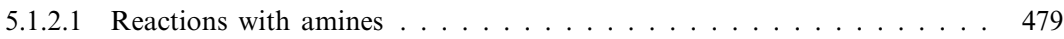

5.1.2.2 Reactions with amides $\mathrm{LiNR}_{2}$ and LiNHR . . . . . . . . . . . 480

6. Alkyl-silyl-cyclopentadienyl metal complexes (type V) . . . . . . . . . . . . . . . . . . . 482

6.1 Silyl-bridged di- and poly-cyclopentadienyl metal complexes . . . . . . . . . . . . 483

6.1 .1 Synthetic procedures . . . . . . . . . . . . . . . . . . 484

6.1.1.1 Transfer of the silyl-cyclopentadienyl ring to a transition metal using an alkali salt. . . . . . . . . . . . . . . . . 484

6.1.1.1.1 Mononuclear compounds . . . . . . . . . . . . . 484

6.1.1.1.2 Dinuclear compounds. . . . . . . . . . . . . . . . 486

6.1.1.1.3 Polynuclear compounds . . . . . . . . . . . . . . . 488

6.1.1.2 Alcoholysis of silicon-silicon bonds . . . . . . . . . . . . . . 489

6.2 Alkenyl-silyl-cyclopentadienyl metal complexes . . . . . . . . . . . . . . . . . . 490

7. Boron-silyl-cyclopentadienyl metal complexes (type VI) . . . . . . . . . . . . . . . . . 491

8. Structural aspects . . . . . . . . . . . . . . . . . . . . . . . 491

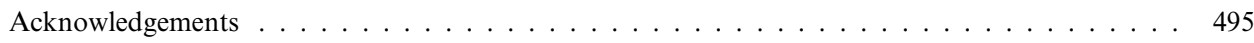

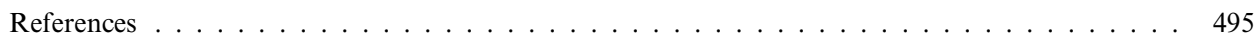

\section{Abstract}

Interest in modifying transition metal complexes using substituted cyclopentadienyl rings has been stimulated in the last years by their potential synthetic and catalytic applications in different processes. This review will feature mono- and dicyclopentadienyl-transition metal complexes containing silyl-cyclopentadienyl and related indenyl and fluorenyl ligands. All of these compounds contain silyl-substituted functionalities which are able to coordinate the metal center or used to introduce such a type of ligating moieties. The synthesis and chemical behaviour of these types of compounds are strongly emphasized. Compounds discussed are all those containing silicon-bound substituents which include: (a) hydrosilyl ( $\mathrm{Si}-\mathrm{H})$; (b) halosilyl ( $\mathrm{Si}-\mathrm{X})$; oxosilyl (Si-O); (c) amino- and amido-silyl (Si-N); (d) alkyl- and alkenyl-silyl (Si-C) and (d) boron-silyl ( $\mathrm{Si}-\mathrm{B})$ compounds. A brief remark on their most significant structural characteristics is also included. (C) 1999 Elsevier Science S.A. All rights reserved. 


\section{Introduction}

Since the discovery of ferrocene [1], cyclopentadienyls have been among the most important ligands in organo-transition metal chemistry because they form a wide range of stable complexes whose steric and electronic properties can easily be tailored by varying the ring substituents. An enormous number of mono- and dicyclopentadienyl-transition metal complexes have been reported [2] in recent years, and articles reviewing the chemistry of cyclopentadienyl metal complexes have been published [3].

There has been special and intense research interest in early transition metal cyclopentadienyl-type compounds usually containing one or two cyclopentadienyl (Cp), indenyl (Ind) or fluorenyl (Flu) moieties.

The $\eta^{5}$-cyclopentadienyl and related early transition metal derivatives have played an important role in structural, synthetic and catalytic organometallic chemistry. They are useful compounds which have found applications as reagents in organic chemistry [4], as soluble Ziegler-Natta catalysts [3e, 4b, 5] and as cancerostatic compounds $[3 \mathrm{e}, 4 \mathrm{~b}, 6]$.

During the past few years, functionalized cyclopentadienyl systems, which do not act just as innocent spectator ligands, have become very attractive. The influence of different substituents in the cyclopentadienyl ring on the chemical behaviour of compounds of this type has been widely studied [7]. Replacement of one or more of the cyclopentadienyl ring hydrogens with various different substituents has resulted in significant changes in reactivity, stability, catalytic activity and other properties, due to changes in both steric and electronic effects at the metal centre.

The interest in modifying early transition metal complexes using substituted cyclopentadienyl rings is related to their potential application in various olefin conversion processes and with their wider synthetic applications. In particular, the immobilization of homogeneous catalysts is of increasing interest and their coordination via cyclopentadienyl anchoring ligands offers a possible route to heterogeneous catalysts using organic or inorganic supports. This process requires the funtionalization of the cyclopentadienyl ring. Good candidates for anchoring ligands could be silyl-functionalized cyclopentadienyl derivatives. The catalytic properties of heterogeneous complexes synthesized in this way are significantly affected by the length of the spacer separating the support surface from the anchoring ligand.

It has been extensively demonstrated that the catalytic activity of Group 4 metallocene complexes in olefine polymerization processes is increased by silyl groups directly bonded to the cyclopentadienyl ligand. This effect has been justified on the basis of electronic and steric reasoning [5a]. Particularly useful are the so-called ansa-metallocenes formed by silyl bridges between two cyclopentadienyl rings.

More recently interest has been focused on cyclopentadienyl-silyl-amido complexes which provided the well-known Exxon-Dow catalysts [8].

For all of these reasons a considerable number of cyclopentadienyl-silanes have been prepared and used to isolate new types of mono- and di-cyclopentadienyl 
complexes, mainly of the early transition metals, and numerous studies concerning their synthesis and their chemical and structural behaviour have been reported [2,3].

Two basic approaches have been used to synthesize substituted cyclopentadienyl metal complexes. The first method is based on the synthesis of the functionalized ligand followed by its transformation into the metallated reagent used to transfer the ring to the transition metal compound. This approach is the most versatile, since many different metal centers can coordinate the functionalized ligands. The second method results in the functionalization of the ring while it is a part of the organometallic compound. This approach works well with ferrocene and a few other less reactive $\eta^{5}$-cyclopentadienyl metal compounds. However most $\eta^{5}$-cyclopentadienyl metal compounds do not undergo ring substitution, instead other competing reactions may occur under the reaction conditions.

This review is concerned with those complexes formed using functionalized silyl-substituted cyclopentadienyl ligands and related indenyl and fluorenyl derivatives. We will not therefore include compounds containing trialkylsilyl-cyclopentadienyl ligands $\mathrm{C}_{5} \mathrm{H}_{4}-\mathrm{SiR}_{3}$, unless at least one of the alkyl groups is functionalized by some coordinatively significant group. Good examples of compounds of this type are the dialkylsilyl-dicyclopentadienyl derivatives used to prepare the dialkylsilyl-bridged ansa-metallocenes $\mathrm{C}_{5} \mathrm{R}_{4}-\mathrm{SiR}_{2}^{\prime}-\mathrm{C}_{5} \mathrm{R}_{4}$ and $\mathrm{C}_{5} \mathrm{R}_{3}-$ $\left(\mathrm{SiR}_{2}^{\prime}\right)_{2}-\mathrm{C}_{5} \mathrm{R}_{3}$. They will be included in this article to illustrate only those aspects of reactivity immediately related to other functionalized silyl compounds. Detailed studies on these compounds have been reported and reviewed [2,3,9].

This review will focus on the Group 4-6 transition metal compounds containing ligands with substituted rings of the type $\mathrm{C}_{5} \mathrm{R}_{4}-\mathrm{SiR}_{2}-\mathrm{X}$ which contain at least one $\eta^{5}$-cyclopentadienyl or related indenyl or fluorenyl rings, and one functional X group bonded to silicon. The study of compounds of this type has been one of the main objectives of our research group, particularly in relation to general principles on synthesis, structural characterization and reactivity of $\pi$ complexes with silyl substituted cyclopentadienyl ligands.

Compounds discussed will be classified according to the nature of the functional X groups into the types of Scheme 1 .

It is well known that cyclopentadienylsilanes show fluxional NMR behaviour. Metallotropic (degenerate) and prototropic (non-degenerate) shifts result in interconversion to different isomers ( $\mathrm{Si}$-allyl and $\mathrm{Si}$-vinyl). The energy barrier for the prototropic shift is in the range of $24-168 \mathrm{~kJ} \mathrm{~mol}^{-1}$, suitable for studies using variable temperature NMR spectroscopy. Coalescence leads to broadening of several resonances at room temperature in the ${ }^{1} \mathrm{H}$ - and ${ }^{13} \mathrm{C}-\mathrm{NMR}$ spectra. This effect and the presence of different isomers complicate the assignment of the signals, especially in the ${ }^{13} \mathrm{C}-\mathrm{NMR}$ spectra. Recording the spectra in the region of slow or fast exchange removes the problem of line broadening but is impracticable for routine work [10]. 

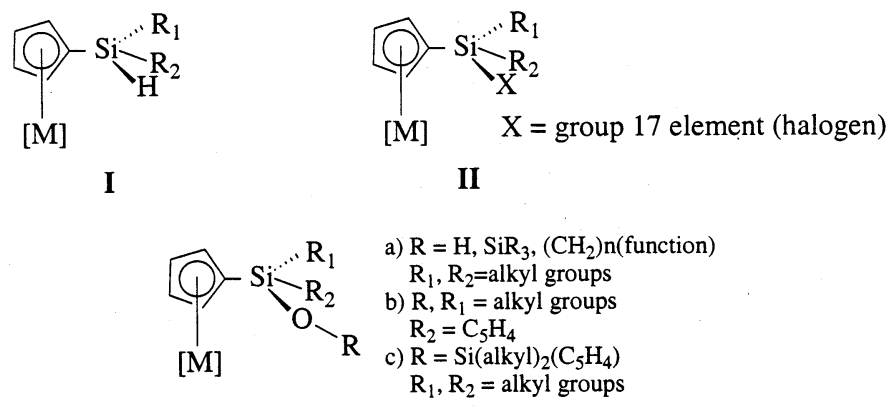

III<smiles></smiles>

[M]

$$
\mathrm{X}=\mathrm{N} \text { (amine; amide), } \mathrm{P}
$$

IV

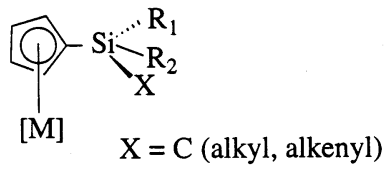

V<smiles></smiles>

VI

Scheme 1.

\section{Hydro-silyl-cyclopentadienyl metal complexes (type I)}

The $\mathrm{Si}-\mathrm{H}$ bond, which is relatively strong and of low polarity, does not normally react spontaneously with unsaturated molecules. It is necessary to use a catalyst to obtain successful hydrosilylation reactions. The cyclopentadienyl metal derivatives supporting a $\mathrm{Si}-\mathrm{H}$ unit such as a cyclopentadienyl ring substituent provide convenient systems to introduce functionalized pendant chains into the cyclopentadienyl ring and therefore to provide new organometallic compounds.

\subsection{Synthetic methods}

\subsubsection{Synthesis of hydro-silyl-cyclopentadiene and related derivatives and their} alkali and thallium salts

Dimethylsilylyclopentadiene $\mathrm{C}_{5} \mathrm{H}_{5} \mathrm{SiMe}_{2} \mathrm{H}$ is conveniently prepared by the reaction of a benzene solution of $\mathrm{SiClMe}_{2} \mathrm{H}$ with $\mathrm{C}_{5} \mathrm{H}_{5} \mathrm{MgBr}$ [11], or alternatively with $\mathrm{NaC}_{5} \mathrm{H}_{5}$ in hexane [12]. Its sodium, lithium or thallium salts are obtained by treatment with $\mathrm{NaH}$, LinBu or TlOEt (Scheme 2).

Following a similar procedure, indene was reacted with buthyllithium to give a white precipitate of $\mathrm{Li}\left(\mathrm{C}_{9} \mathrm{H}_{7}\right)$, which was then reacted with $\mathrm{SiClMe}_{2} \mathrm{H}$ to give the 


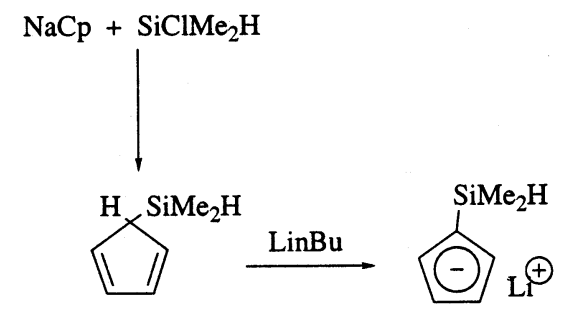

Scheme 2.

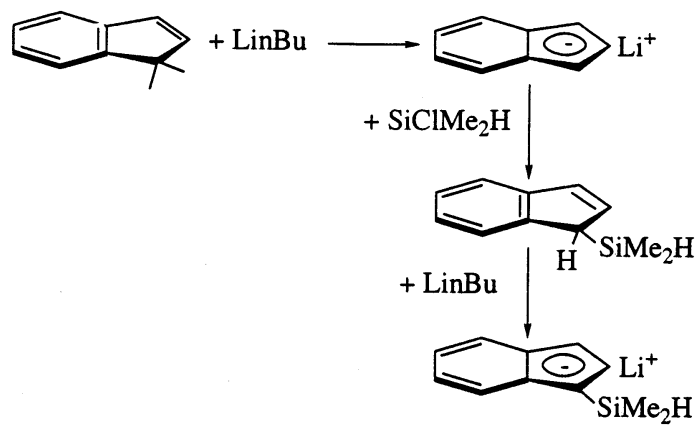

Scheme 3.

dimethylsilylindene derivative $\mathrm{C}_{9} \mathrm{H}_{7} \mathrm{SiMe}_{2} \mathrm{H}$. Treatment of this indene with $\mathrm{LinBu}$ affords the lithium salt $\mathrm{Li}\left(\mathrm{C}_{9} \mathrm{H}_{6} \mathrm{SiMe}_{2} \mathrm{H}\right)$ [13] (Scheme 3).

The bis-silyl derivatives $\mathrm{C}_{5} \mathrm{H}_{4}\left(\mathrm{SiMe}_{2} \mathrm{H}\right)_{2}, \mathrm{C}_{5} \mathrm{H}_{4}\left(\mathrm{SiMe}_{3}\right)\left(\mathrm{SiMe}_{2} \mathrm{H}\right), \mathrm{C}_{9} \mathrm{H}_{6}\left(\mathrm{SiMe}_{2} \mathrm{H}\right)_{2}$ and $\mathrm{C}_{9} \mathrm{H}_{6}\left(\mathrm{SiMe}_{3}\right)\left(\mathrm{SiMe}_{2} \mathrm{H}\right)$ can then be conveniently prepared (Scheme 4$)$.

\subsubsection{Synthesis of monocyclopentadienyl-type derivatives using diene-reagents}

The reaction of $\mathrm{ZrCl}_{4}$ with one equivalent of the ligand $\mathrm{C}_{5} \mathrm{H}_{4}\left(\mathrm{SiMe}_{2} \mathrm{H}\right)_{2}$ in toluene produced the monocyclopentadienyl derivative $\mathrm{Zr}\left[\mathrm{C}_{5} \mathrm{H}_{4}\left(\mathrm{SiMe}_{2} \mathrm{H}\right)\right] \mathrm{Cl}_{3}$ as pale yellow crystals in moderate yield (Scheme 5). When the reaction is carried out for a longer period of time, substitution of the $\mathrm{Si}-\mathrm{H}$ hydrogen by chlorine occurs affording $\mathrm{Zr}\left[\mathrm{C}_{5} \mathrm{H}_{4}\left(\mathrm{SiMe}_{2} \mathrm{Cl}\right)\right] \mathrm{Cl}_{3}$, previously prepared by an alternative method (see Section 3.1.2). This behaviour contrasts with that observed for the analogous

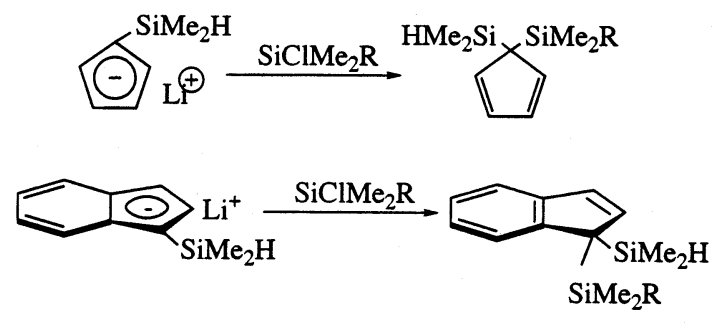

$\mathrm{R}=\mathrm{H}, \mathrm{Me}$

Scheme 4 . 

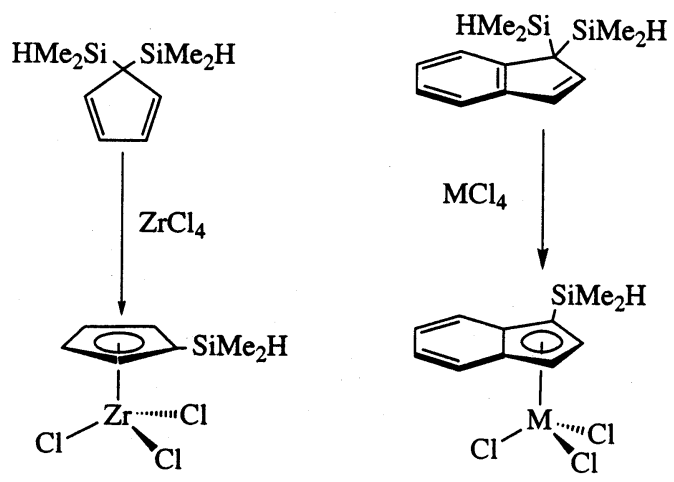

$\mathrm{M}=\mathrm{Ti}, \mathrm{Zr}$

Scheme 5 .

dicyclopentadienyl derivatives where the $\mathrm{Si}-\mathrm{H}$ bond remains unchanged. Attempts to prepare $\mathrm{Zr}\left[\mathrm{C}_{5} \mathrm{H}_{4}\left(\mathrm{SiMe}_{2} \mathrm{H}\right)\right] \mathrm{Cl}_{3}$ from the known ligand $\mathrm{C}_{5} \mathrm{H}_{4}\left(\mathrm{SiMe}_{2} \mathrm{H}\right)\left(\mathrm{SiMe}_{3}\right)$ in the reaction with $\mathrm{ZrCl}_{4}$ gave mainly a mixture of $\mathrm{Zr}\left[\mathrm{C}_{5} \mathrm{H}_{4}\left(\mathrm{SiMe}_{2} \mathrm{H}\right)\right] \mathrm{Cl}_{3}$ and the well characterized compound $\mathrm{Zr}\left[\mathrm{C}_{5} \mathrm{H}_{4}\left(\mathrm{SiMe}_{3}\right)\right] \mathrm{Cl}_{3}$ [12].

The monoindenyl derivatives $\mathrm{M}\left[\mathrm{C}_{9} \mathrm{H}_{6}\left(\mathrm{SiMe}_{2} \mathrm{H}\right)\right] \mathrm{Cl}_{3}(\mathrm{M}=\mathrm{Ti}, \mathrm{Zr})$ are obtained in the same way [13] (Scheme 5).

The monocyclopentadienyl complex $\mathrm{Zr}\left[\mathrm{C}_{5} \mathrm{H}_{4}\left(\mathrm{SiMe}_{2} \mathrm{H}\right)\right] \mathrm{Cl}_{3}$ is found to be very moisture sensitive in contrast to the bis(cyclopentadienyl) derivatives which can be handled in air for a few minutes without decomposition. However, they can be stored under rigorously dry conditions. They are soluble in aromatic hydrocarbons and chlorinated solvents but insoluble in alkanes.

\subsubsection{Synthesis of dicyclopentadienyl-type derivatives using dienyl-reagents}

Treatment of $\mathrm{ZrCl}_{4}$ with two equivalents of $\mathrm{Li}\left[\mathrm{C}_{5} \mathrm{H}_{4}\left(\mathrm{SiMe}_{2} \mathrm{H}\right)\right]$ in a mixture of toluene/THF at room temperature gave the expected dicyclopentadienyl complex $\mathrm{Zr}\left[\mathrm{C}_{5} \mathrm{H}_{4}\left(\mathrm{SiMe}_{2} \mathrm{H}\right)\right]_{2} \mathrm{Cl}_{2}$, while reaction of one equivalent of the lithium salt with $\mathrm{Zr}\left(\mathrm{C}_{5} \mathrm{H}_{5}\right) \mathrm{Cl}_{3}$ afforded the mixed metallocene $\mathrm{Zr}\left(\mathrm{C}_{5} \mathrm{H}_{5}\right)\left[\mathrm{C}_{5} \mathrm{H}_{4}\left(\mathrm{SiMe}_{2} \mathrm{H}\right)\right] \mathrm{Cl}_{2}$, both as white microcrystals in ca. 70-75\% yield [12] (Scheme 6).
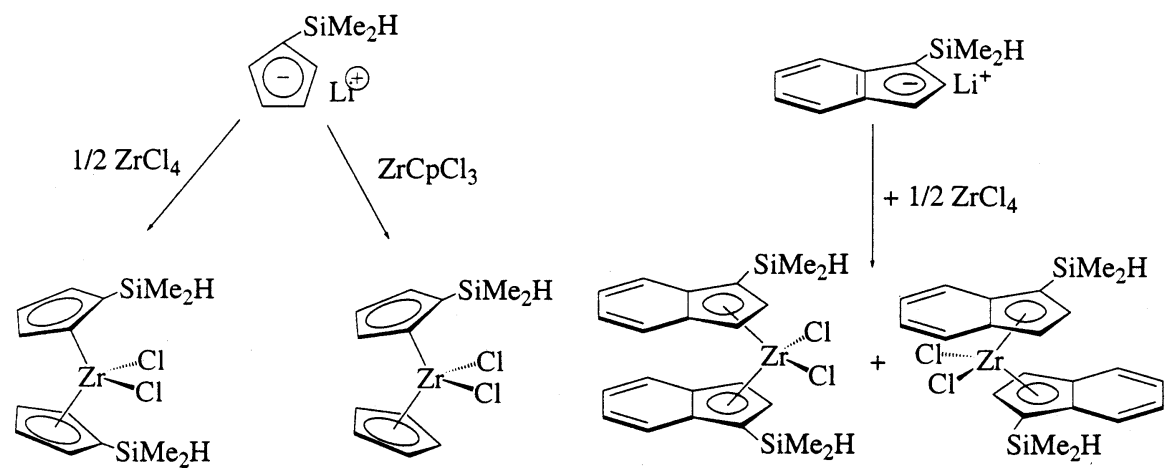

Scheme 6. 


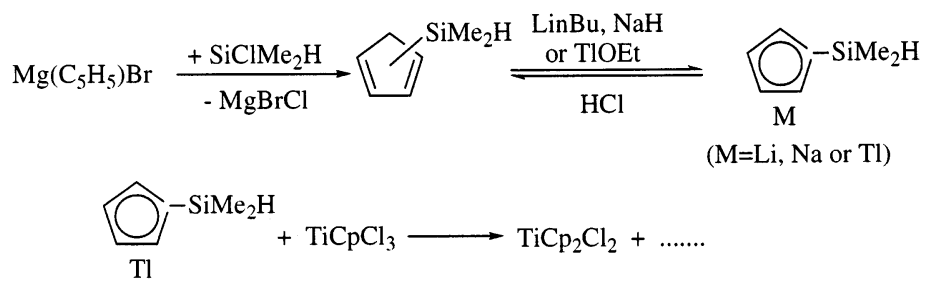

Scheme 7.

The bis-indenyl derivative $\mathrm{Zr}\left[\mathrm{C}_{9} \mathrm{H}_{6}\left(\mathrm{SiMe}_{2} \mathrm{H}\right)\right]_{2} \mathrm{Cl}_{2}$ is obtained in the same way, as a mixture of isomers [13] (Scheme 6).

However the reaction of these salts with titanium halides led to cleavage of the $\mathrm{Cp}-\mathrm{Si}$ bond [14] (Scheme 7).

\subsubsection{Metallation of coordinated cyclopentadienyl ligands}

Hydro-silyl-cyclopentadienyl derivatives of late transition metals have been obtained by an indirect method, which involves metallation of the coordinated cyclopentadienyl ring in metal complexes followed by reaction with $\mathrm{SiClMe}_{2} \mathrm{H}$. Examples are shown in Scheme 8.

Similar derivatives $\mathrm{Mn}\left[\mathrm{C}_{5} \mathrm{X}_{4}\left(\mathrm{SiMe}_{2} \mathrm{H}\right)\right](\mathrm{CO})_{3}(\mathrm{X}=\mathrm{Cl}, \mathrm{Br}, \mathrm{H})$ are obtained by reaction of $\mathrm{Mn}\left(\mathrm{C}_{5} \mathrm{X}_{4} \mathrm{Br}\right)(\mathrm{CO})_{3}$ with $\mathrm{LinBu}$ and $\mathrm{SiClMe}_{2} \mathrm{H}$ [15].

Metal complexes with completely substituted cyclopentadienyl groups are of particular interest, since the effect of substituents on chemical and physical properties should be maximized. Polysilylated cyclopentadienyl ligands have been of interest in recent years because increasing the number of silyl substituents is believed to enhance their solubility in non-polar solvents, their volatility and their kinetic stability. However, attempts to introduce more than three $\mathrm{SiMe}_{3}$ groups into the cyclopentadienyl ring have been unsuccessful. Five-fold silylated cyclopentadienyl ligands can be obtained by this method when $\mathrm{SiMe}_{2} \mathrm{H}$ is used [16] (Scheme 9).

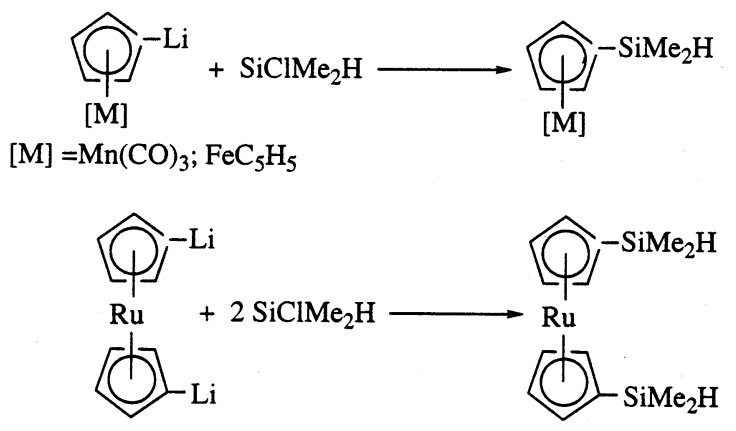

Scheme 8 . 


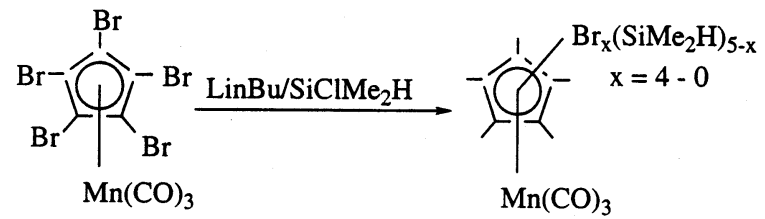

Scheme 9.

\subsubsection{Use of doubly silyl-bridged cyclopentadiene}

The synthesis of the doubly bridged cyclopentadiene system $\left(\mathrm{Me}_{2} \mathrm{Si}_{2}\right)_{2}$ $\left(\mathrm{C}_{5} \mathrm{H}_{3} \mathrm{SiMe}_{3}\right)\left(\mathrm{C}_{5} \mathrm{H}_{3} \mathrm{SiMe}_{2} \mathrm{H}\right)$ derived from 2,2,8,8-tetramethyl-2,8-disilatricyclo [7.3.0.0 $0^{3,7}$ ]dodeca-3,5,9,11-tetraene has been published [17]. The reaction of this reagent with $\mathrm{LinBu}$ yields the corresponding mono lithiated derivative which reacts with 0.5 equivalents of $\mathrm{TiCl}_{4}$ to form the titanocene dichloride $\mathrm{Ti}\left[\left(\mathrm{Me}_{2} \mathrm{Si}\right)_{2}\left(\eta^{5}-\right.\right.$ $\left.\left.\mathrm{C}_{5} \mathrm{H}_{2} \mathrm{SiMe}_{3}\right)\left(\mathrm{C}_{5} \mathrm{H}_{3} \mathrm{SiMe}_{2} \mathrm{H}\right)\right]_{2} \mathrm{Cl}_{2}$ (Scheme 10).

\subsection{Reactivity}

Complexes with silylated cyclopentadienyl $\mathrm{C}_{5} \mathrm{H}_{4}\left(\mathrm{SiMe}_{2} \mathrm{H}\right)$ or related rings might be used for further functionalizations. These silicon-containing compounds have potential as assembling ligands through reactions with metal carbonyls [14] (Scheme 11).

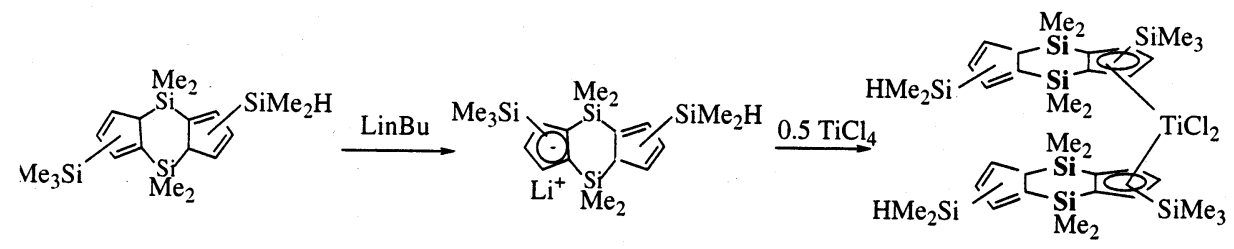

Scheme 10 .

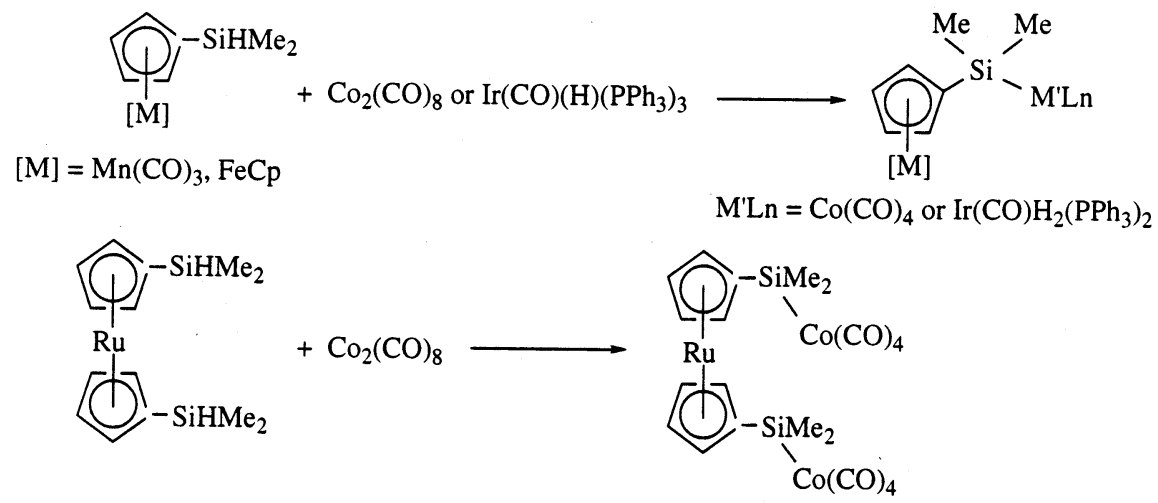

Scheme 11 
Hydrosilylation reactions of alkynes have been described [18]. Reactions of $\mathrm{Zr}\left[\mathrm{C}_{5} \mathrm{H}_{4}\left(\mathrm{SiMe}_{2} \mathrm{H}\right)\right] \mathrm{Cl}_{3}$ with lithium amides have been studied [12]. Treatment of this compound with one equivalent of $\mathrm{Li}\left[\mathrm{N}\left(\mathrm{SiMe}_{3}\right)_{2}\right]$ in hexane gave the amido compound $\mathrm{Zr}\left[\mathrm{C}_{5} \mathrm{H}_{4}\left(\mathrm{SiMe}_{2} \mathrm{H}\right)\right]\left[\mathrm{N}\left(\mathrm{SiMe}_{3}\right)_{2}\right] \mathrm{Cl}_{2}$ as a yellow oil in $80 \%$ yield. The compound was very moisture sensitive and thermally stable; no decomposition was observed even on heating in a $\mathrm{C}_{6} \mathrm{D}_{6}$ solution at $100^{\circ} \mathrm{C}$. An identical reaction occurred when $\mathrm{Zr}\left[\mathrm{C}_{5} \mathrm{H}_{4}\left(\mathrm{SiMe}_{2} \mathrm{H}\right)\right] \mathrm{Cl}_{3}$ reacted with one equivalent of $\mathrm{Li}\left[\mathrm{NH}\left(\mathrm{C}_{6} \mathrm{H}_{3} \mathrm{Me}_{2}\right)\right]$ to afford $\mathrm{Zr}\left[\mathrm{C}_{5} \mathrm{H}_{4}\left(\mathrm{SiMe}_{2} \mathrm{H}\right)\right]\left[\mathrm{NH}\left(\mathrm{C}_{6} \mathrm{H}_{3} \mathrm{Me}_{2}\right)\right] \mathrm{Cl}_{2}$ as a pale brown oil also in high yield. However when $\mathrm{Zr}\left[\mathrm{C}_{5} \mathrm{H}_{4}\left(\mathrm{SiMe}_{2} \mathrm{H}\right)\right] \mathrm{Cl}_{3}$ was treated with $\mathrm{Li}\left(\mathrm{NH}^{t} \mathrm{Bu}\right)$, the previously reported silyl-amido derivative $\operatorname{Zr}\left(\eta^{5}: \eta^{1}\right.$ $\left.\mathrm{C}_{5} \mathrm{H}_{4} \mathrm{SiMe}_{2} \mathrm{~N}^{t} \mathrm{Bu}\right) \mathrm{Cl}_{2}$ was obtained in moderate yield, probably via a nucleophilic substitution reaction with subsequent evolution of dihydrogen (Scheme 12).

The distinct behaviour shown by the amido reagents could be due to intramolecular coordination of the zirconium-bonded nitrogen atom to silicon to give a penta-coordinate silane, which would enhance the reactivity of the silicon atom. The steric hindrance imposed by the presence of more bulky $\mathrm{SiMe}_{3}$ and $\mathrm{Me}_{2} \mathrm{C}_{6} \mathrm{H}_{3}$ groups and the lower basicity of their amido fragments may prevent nitrogen coordination in the case of the other two zirconium complexes.

The bis-(silylindenyl) zirconium complexes $\mathrm{Zr}\left(\eta^{5}-\mathrm{C}_{9} \mathrm{H}_{6} \mathrm{SiMe}_{2} \mathrm{H}\right)_{2} \mathrm{X}_{2}$ reacted with

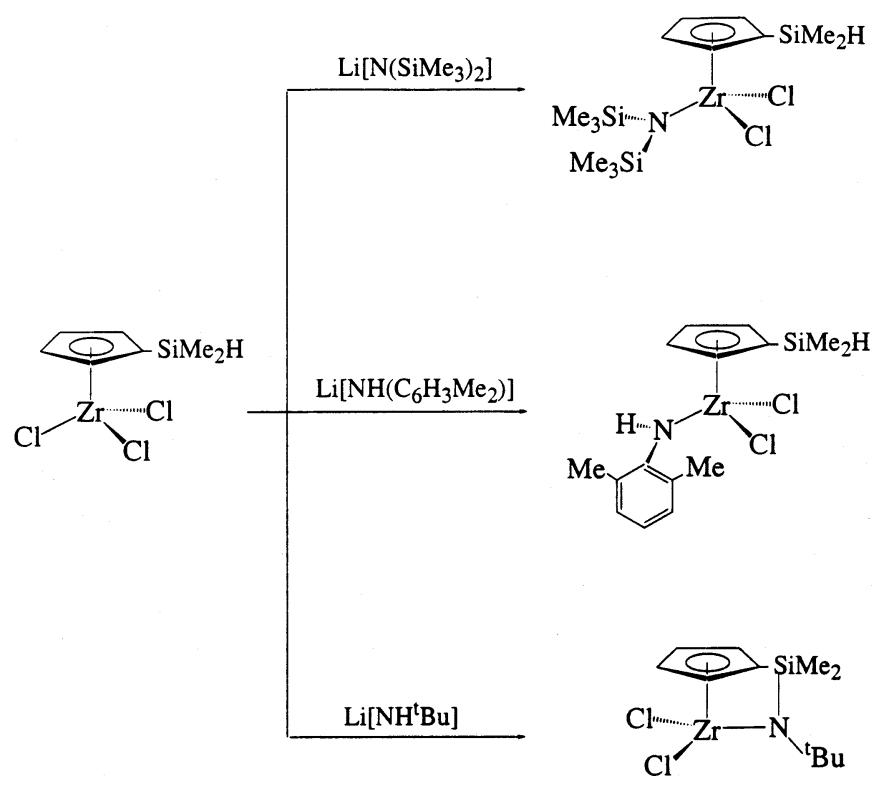

Scheme 12 . 


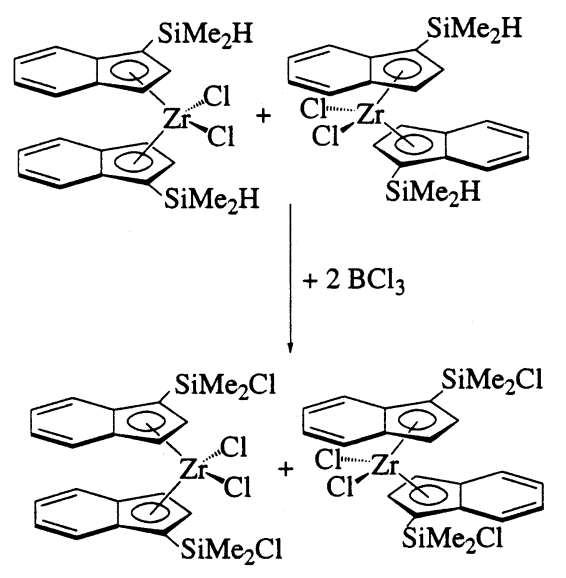

Scheme 13 .

$\mathrm{BCl}_{3}$ to give the corresponding bis-(chlorosilylindenyl) derivatives $\mathrm{Zr}\left(\eta^{5}-\mathrm{C}_{9} \mathrm{H}_{6} \mathrm{Si}\right.$ $\mathrm{Me}_{2} \mathrm{Cl}_{2} \mathrm{X}_{2}$ [13] (Scheme 13).

Treatment of $\mathrm{Mn}\left[\mathrm{C}_{5} \mathrm{X}_{4}\left(\mathrm{SiMe}_{2} \mathrm{H}\right)\right](\mathrm{CO})_{3} \quad(\mathrm{X}=\mathrm{Cl}, \mathrm{Br}, \mathrm{H})$ and $\mathrm{Mn}\left[\mathrm{C}_{5} \mathrm{Br}_{3}-\right.$ $\left.\left(\mathrm{SiMe}_{2} \mathrm{H}\right)_{2}\right](\mathrm{CO})_{3}$ with $\mathrm{PdCl}_{2}$ yields the corresponding chlorosilanes $\mathrm{Mn}\left[\mathrm{C}_{5} \mathrm{X}_{4}\right.$ $\left.\left(\mathrm{SiMe}_{2} \mathrm{Cl}\right)\right](\mathrm{CO})_{3}$ and $\mathrm{Mn}\left[\mathrm{C}_{5} \mathrm{Br}_{3}\left(\mathrm{SiMe}_{2} \mathrm{Cl}\right)_{2}\right](\mathrm{CO})_{3}$. The chlorosilanes react with alcohols, $\mathrm{C}_{n} \mathrm{H}_{2 n+1} \mathrm{OH} \quad(n=1-10)$, to give the cymantrenyl-alkoxosilanes $\mathrm{Mn}\left[\mathrm{C}_{5} \mathrm{X}_{4}\left(\mathrm{SiMe}_{2} \mathrm{OR}\right)\right](\mathrm{CO})_{3}$ and $\mathrm{Mn}\left[\mathrm{C}_{5} \mathrm{Br}_{3}\left(\mathrm{SiMe}_{2} \mathrm{OR}\right)_{2}\right](\mathrm{CO})_{3}[15]$.

It was found that the titanocene dichloride $\mathrm{Ti}\left[\left(\mathrm{SiMe}_{2}\right)_{2}\left(\eta^{5}-\mathrm{C}_{5} \mathrm{H}_{2} \mathrm{SiMe}_{3}\right)-\right.$ $\left.\left(\mathrm{C}_{5} \mathrm{H}_{3} \mathrm{SiMe}_{2} \mathrm{H}\right)\right]_{2} \mathrm{Cl}_{2}$ polymerizes ethene, but does not react with propene, although ethene and propene were successfully copolymerized [17].

\section{Halo-silyl-cyclopentadienyl metal complexes (type II)}

Metal complexes containing halo-silyl substituted cyclopentadienyl ligands comprise a particularly important group of compounds due to the reactivity of the $\mathrm{Si}-\mathrm{X}$ bond. They are useful precursors to supported catalysts for olefin polymerization and excellent reagents for introducing different functionalities into the cyclopentadienylsilyl moiety. However this reactivity means that they are more difficult to isolate.

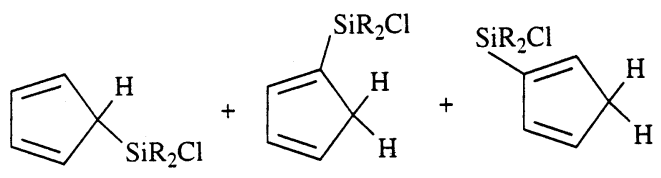

Scheme 14 . 


\subsection{Synthetic methods}

Basically there are two synthetic routes to these compounds.

\subsubsection{Transfer of the halosilyl-cyclopentadienyl ring to a transition metal}

A great number of chloro-silyl cyclopentadiene compounds have been reported. They are classified in Table 1 as those containing one terminal chloro-silyl group and those in which the chloro-silyl substituent is a bridging group bound to unsubstituted or substituted cyclopentadiene, indene and fluorene.

Table 1

\section{A) Terminal chloro silyl group}

$$
\mathrm{Cp}^{\prime}-\mathrm{Si}^{\prime} \stackrel{\mathrm{Y}}{{ }_{\mathrm{Cl}}^{\mathrm{X}}}
$$

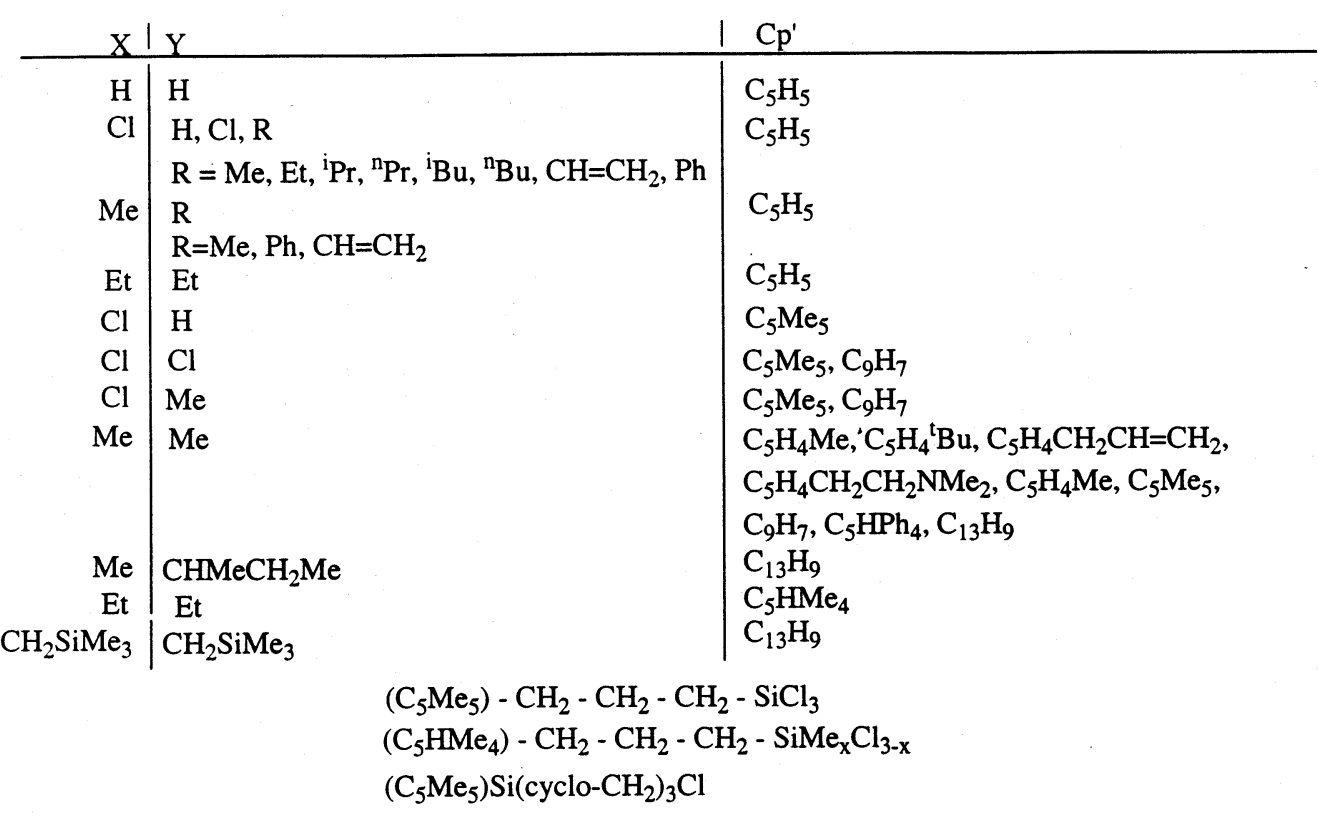

\section{B) Bridging chloro silyl group}

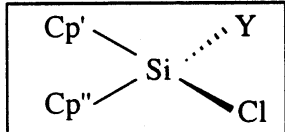

\begin{tabular}{r|l|l|l}
$\mathrm{Y}$ & $\mathrm{Cp}^{\prime}=\mathrm{Cp}^{\prime \prime}$ & $\mathrm{Cp}^{\prime}$ & $\mathrm{Cp}$ \\
\hline $\mathrm{H}$ & $\mathrm{C}_{5} \mathrm{H}_{5}$ & & \\
$\mathrm{Cl}$ & $\mathrm{C}_{5} \mathrm{H}_{5}$ & & \\
& $\mathrm{C}_{5} \mathrm{HMe}_{4}$ & & \\
& $\mathrm{C}_{9} \mathrm{H}_{7}$ & & \\
$\mathrm{Me}$ & $\mathrm{C}_{13} \mathrm{H}_{9}$ & & \\
$\mathrm{Cl}$ & $\mathrm{C}_{9} \mathrm{H}_{7}$ & & \\
$\mathrm{C}_{5} \mathrm{H}_{5}$ & $\mathrm{C}_{5} \mathrm{H}_{5}$ & $\mathrm{C}_{9} \mathrm{H}_{7}$ & $\mathrm{C}_{13} \mathrm{H}_{9}$
\end{tabular}




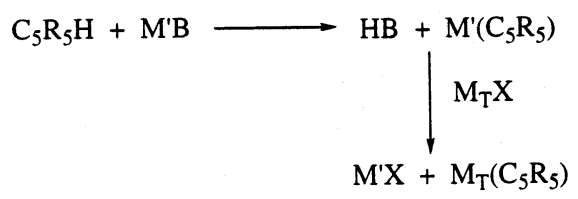

Scheme 15 .

Methods of synthesis for all these compounds have been reported and are based on reactions of the metallated cyclopentadienyl with $\mathrm{SiCl}_{2} \mathrm{R}_{2}, \mathrm{SiCl}_{2} \mathrm{RR}^{\prime}$ or $\mathrm{SiCl}_{3} \mathrm{R}$ [8a, 10d, 10e, 19]. The resulting silyl-cyclopentadienes are always a mixture of different isomers produced by sila- and/or proto-tropic shifts, which can be identified by NMR spectroscopy (Scheme 14).

The principal methods used to transfer the derived cyclopentadienyl, indenyl and fluorenyl rings to the metal are discussed below (Sections 3.1.1.1, 3.1.1.2, 3.1.1.3 and 3.1.1.4).

3.1.1.1. Alkali and thallium salts of the halo-silyl-cyclopentadienide. A general method useful to prepare a wide variety of carbon-functionalized cyclopentadienyl complexes involves metallation of the cyclopentadiene by reaction with a deprotonating reagent $\mathrm{M}^{\prime} \mathrm{B}$ (alkaline salt, TlOEt) to give a nucleophilic salt $\mathrm{M}^{\prime} \mathrm{Cp}\left(\mathrm{M}^{\prime}=\right.$ alkali metal, $\mathrm{Tl}$ ), which reacts with an electrophilic transition metal halide $\mathrm{M}_{\mathrm{T}} \mathrm{X}^{\prime}$ to eliminate the alkali or thallium halide and give the cyclopentadienyl transition metal complex $\mathrm{M}_{\mathrm{T}}\left(\mathrm{C}_{5} \mathrm{R}_{5}\right)$ (Scheme 15).

However, for the chloro-silyl-cyclopentadiene molecules this procedure has serious limitations:

1. competition from a substitution reaction of the chloro atom in the $\mathrm{Si}-\mathrm{Cl}$ bond of the $\mathrm{C}_{5} \mathrm{R}_{4} \mathrm{H}(\mathrm{SiClXY})$ species

2. $\left[\mathrm{C}_{5} \mathrm{R}_{4}(\mathrm{SiClXY})\right]$ compounds have very low stability.

The salts $\mathrm{M}^{\prime}\left(\mathrm{C}_{5} \mathrm{H}_{4}-\mathrm{SiClXY}\right)$ resulting from deprotonation of $\mathrm{C}_{5} \mathrm{H}_{5}-\mathrm{SiClXY}$ with basic reagents $\left(\mathrm{M}^{\prime} \mathrm{B}\right)$ such as LiR or TlOEt are unstable and easily eliminate the alkali or thallium halide $\mathbf{M}^{\prime} \mathrm{X}$ to give an intermediate silylene. These then dimerize to afford doubly silyl-bridged compounds with simultaneous sila- or proto-tropic rearrangement [20,21] (Scheme 16).

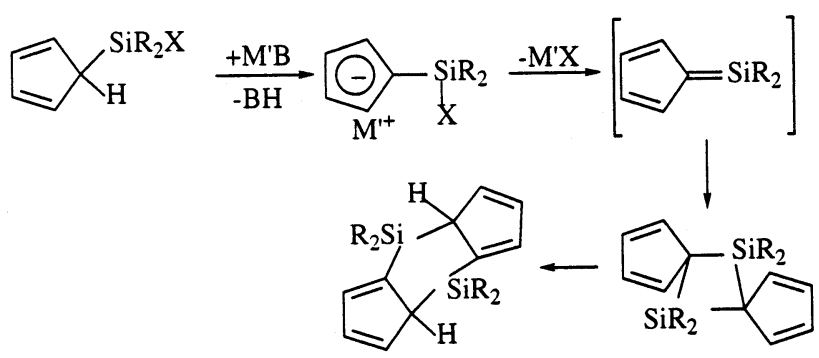

Scheme 16. 


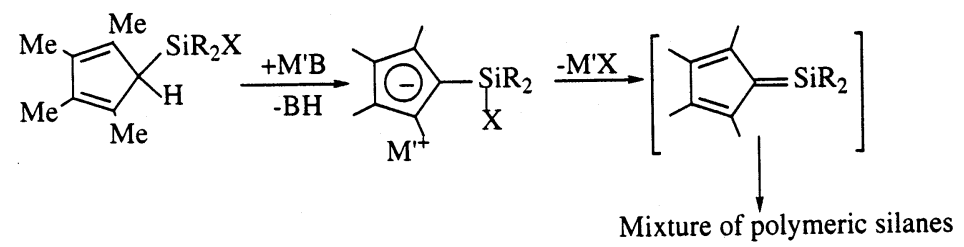

Scheme 17.

The same reaction occurs even when substituted cyclopendienyl derivatives are used, leading to a mixture of polymeric silanes (Scheme 17).

This method, which is based on a nucleophilic route via substitution of halide from $\mathrm{M}_{\mathrm{T}} \mathrm{X}$, has therefore rarely been used to prepare these functionalized halosilyl-cyclopentadienyl metal compounds.

Stable chlorosilylcyclopentadienide type anions can be isolated if extremely bulky rings and chloro substituents are used, or alternatively by deprotonation of the chlorosilylcyclopentadiene with phosphoranes [19j, 19p, 22, 23].

3.1.1.2. Use of disilycyclopentadienes. A well known method to transfer a cyclopentadienyl ring to a transition metal is based on the reaction of a metal halide $\mathrm{M}_{\mathrm{T}} \mathrm{X}^{\prime}$ with trimethylsilyl-cyclopentadiene $\mathrm{C}_{5} \mathrm{R}_{5} \mathrm{SiMe}_{3}$ or related $\mathrm{C}_{5} \mathrm{R}_{5} \mathrm{ER}_{x}^{\prime}(\mathrm{E}=\mathrm{Ge}, \mathrm{Sn}$, $x=3 ; \mathrm{E}=\mathrm{As}, \mathrm{Sb}, x=2$ ) derivatives. The reaction takes place with elimination of a halosilane or related halo compounds $\mathrm{EXR}_{x}^{\prime}$.

Improved routes to mono and dicyclopentadienyl transition metal complexes by direct reaction of silicon-substituted cyclopentadiene and analogous rings have been reported [3b, 24, 25].

The reactivity of element-substituted cyclopentadienes $\mathrm{C}_{5} \mathrm{H}_{4}\left(\mathrm{XMe}_{2}\right)\left(\mathrm{YMe}_{3}\right)(\mathrm{X}=$ $\mathrm{As}, \mathrm{Sb} ; \mathrm{Y}=\mathrm{Si}, \mathrm{Ge}, \mathrm{Sn}$ ) with titanium tetrachloride to give the cyclopentadienyl titanium trichlorides Ti $\left[\mathrm{C}_{5} \mathrm{H}_{4}\left(\mathrm{XMe}_{2}\right)\right] \mathrm{Cl}_{3}$ or Ti $\left[\mathrm{C}_{5} \mathrm{H}_{4}\left(\mathrm{YMe}_{3}\right)\right] \mathrm{Cl}_{3}$, has been studied and compared. The following order of reactivity was found: $\mathrm{AsMe}_{2}<\mathrm{SiMe}_{3}<\mathrm{GeMe}_{3}<$ $\mathrm{SbMe}_{2}<\mathrm{SnMe}_{3}$ [24d, 26].

Replacement of silyl groups in the reaction of di- or polisilyl substituted cyclopentadienes with transition metal halides can be an appropriate method to give silyl-substituted cyclopentadienyl transition metal complexes (Scheme 18).

The required di- or poly-silyl cyclopentadienes can easily be prepared following the reactions indicated in Scheme 19. Introducing the silyl groups into the cyclopentadienyl ring in subsequent steps, firstly the halogen-free group $\mathrm{SiR}_{3}$ and finally the halosilyl group SiClXY (via (A)) prevents the formation of silylene by-products as

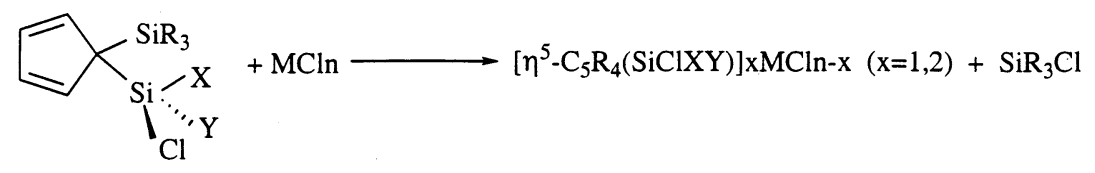




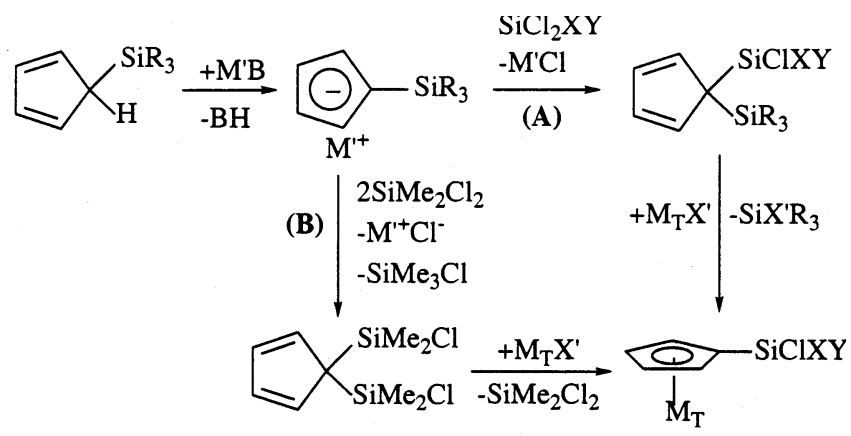

Scheme 19.

discussed above. Subsequentely, the $\mathrm{C}_{5} \mathrm{H}_{4}(\mathrm{SiClXY})\left(\mathrm{SiR}_{3}\right)$ derivative reacts with the $\mathrm{M}_{\mathrm{T}} \mathrm{X}^{\prime}$ molecule to give the desired product $\mathrm{M}_{\mathrm{T}}\left[\mathrm{C}_{5} \mathrm{H}_{4}(\mathrm{SiClXY})\right]$.

Exchange between trimethylsilyl and dichlorodimethylsilyl groups in the cyclopentadienyl ring has been observed [27] when two equivalents of $\mathrm{SiMe}_{2} \mathrm{Cl}_{2}$ were used, leading to the di-functionalized silyl derivative $\mathrm{C}_{5} \mathrm{H}_{4}\left(\mathrm{SiMe}_{2} \mathrm{Cl}_{2}\right)_{2}$ (via (B)) which reacts with metal halides in a similar manner. However similar reactions are not possible when totally substituted cyclopentadienyl rings $\mathrm{C}_{5} \mathrm{Me}_{4} \mathrm{H}$ are used.

Compared with cyclopentadienyl donors such as electropositive metal cyclopentadienides, silylcyclopentadiene reagents have several advantages:

1. These reagents are more conveniently used to prepare halodimethylsilylated monocyclopentadienyl type complexes because they give much higher yields and much cleaner products in their reactions with metal halides (monocyclopentadienyl complexes of Group 4 elements show reactivity profiles that differ considerably from those of their dicyclopentadienyl counterparts). It is therefore not surprising that these complexes have assumed an increasingly important role in synthetic and mechanistic endeavors. Despite increasing interest in these reagents, few practical routes for their preparation as pure compounds have been reported. The synthesis of halodimethylsilylated monocyclopentadienyl type complexes by this route is essentially quantitative after short reaction times (sometimes under reflux). It seems to be established that titanium tetrachloride reacts with one equivalent of silylated cyclopentadienes to afford the monocyclopentadienyl derivatives as the sole products under any conditions and this is an efficient route to monocyclopentadienyl titanium complexes [20, 28b]. The $\mathrm{SiMe}_{2} \mathrm{Cl}$ fragment exhibits extraordinary immobility (Scheme 20). In contrast, the related reactions with zirconium and hafnium tetrachlorides afford the mono- or dicyclopentadienyl dichloride depending on the conditions.

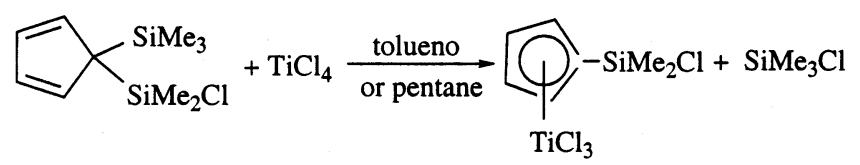


2. The silyl-cyclopentadiene is a much poorer reducing agent than the alkali salts.

3. The silyl reagents are easily obtained and manipulated since they are air-stable and liquid.

4. The products are easily separated by filtration or sublimation.

These reactions are unexpectedly complex. This synthetic strategy is based on electrophilic attack at the cyclopentadienyl group with cleavage of the silicon-carbon bond [25]. Cyclopentadienyl-, indenyl and fluorenyl-silicon bonds are easier to cleave than any other silicon-hydrocarbon bonds. Thus the cyclopentadienylsilicon bond can be cleaved even with manganese pentacarbonyl halides and dimanganese decacarbonyl itself [29].

$\mathrm{C}_{5} \mathrm{H}_{4}\left(\mathrm{SiR}_{3}\right)(\mathrm{SiClXY})$ possesses two $\mathrm{Si}-\mathrm{Cp}$ bonds. These compounds could be expected to form two different products under the action of $\mathrm{MCl}_{4}$ (Scheme 21) according to reaction (a) or (b).

Groups 4 and 5 transition metal chloro-silyl-cyclopentadienyl derivatives can be prepared by this method $[28,30]$ (Scheme 22).

However this method is not suitable when the halosilyl group is a preferential leaving group such as $\mathrm{SiXX}^{\prime} \mathrm{R}_{2}$ instead of $\mathrm{SiX}^{\prime} \mathrm{R}_{3}$. Preferential reactions of the silyl group are not only governed by the nature of the substituents bound to silicon but also by the nature of the transition metal and its substituents.

Even alcoxo-, siloxo-, amido- and imido-functionalized cyclopentadienyl compounds have been synthesized by the trimethylsilyl extrusion route [31].

3.1.1.3. Use of doubly silyl-bridged dicyclopentadiene. A process intimately related to that discussed above based on the elimination of chloromethylsilane derivatives uses doubly silyl bridged dicyclopentadiene. Few examples of reactions of transition metal halides with doubly silyl-bridged dicyclopentadiene, in which transfer of halide to silicon takes place leading directly to the halosilyl functionalized cyclopentadienyl metal derivative, have been reported (Scheme 23).

(a)

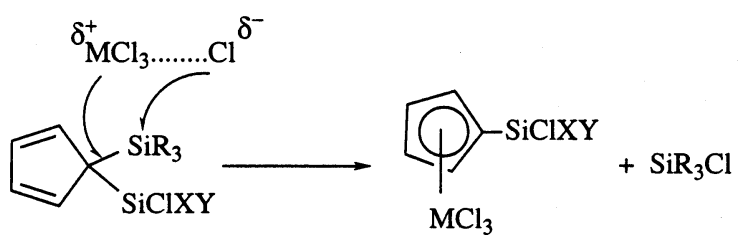

(b)

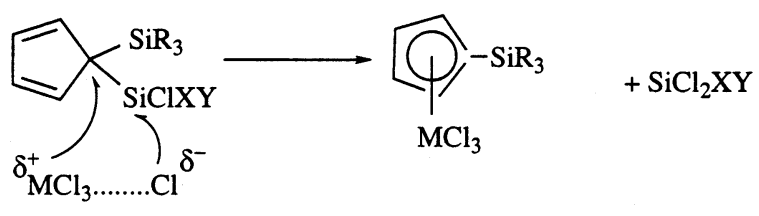

Scheme 21 . 

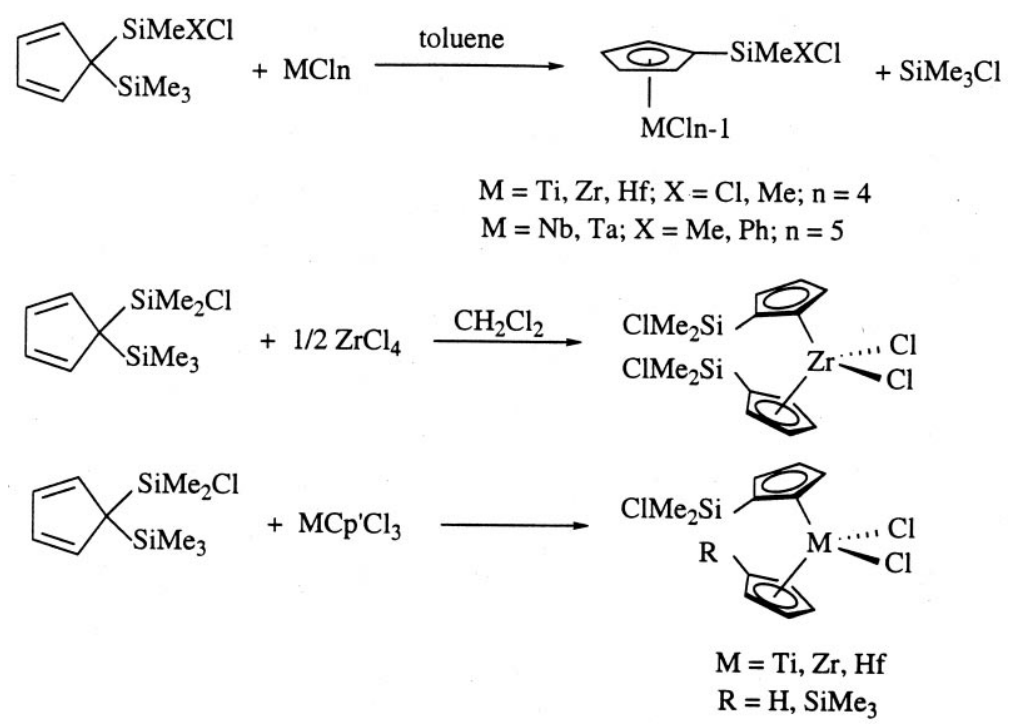

Scheme 22 .

$\left(\mathrm{SiMe}_{2} \mathrm{C}_{5} \mathrm{H}_{4}\right)_{2}$ is a disilylated dicyclopentadiene with silicon atoms simultaneously linked to the allyl and vinyl positions of each ring. The $\mathrm{Si}-\mathrm{Cp}$ bonds can be cleaved to give various types of products (Scheme 24). It reacts with $\mathrm{MCl}_{4}$ to give the intermediate A. Treatment of $\left(\mathrm{SiMe}_{2} \mathrm{C}_{5} \mathrm{H}_{4}\right)_{2}$ with $\mathrm{MCl}_{4}(\mathrm{M}=\mathrm{Ti}, \mathrm{Zr}$, Hf) (molar ratio 1:1) in pentane or toluene, but in a significantly longer reaction time $(5-10 \mathrm{~h})$ affords the trichloro-derivatives $\mathrm{M}\left(\mathrm{C}_{5} \mathrm{H}_{4} \mathrm{SiMe}_{2} \mathrm{Cl}\right) \mathrm{Cl}_{3}$. When $\mathrm{M}=\mathrm{Zr}$ or $\mathrm{Hf}$ the presence of significant amounts of $\mathrm{M}\left(\mathrm{C}_{5} \mathrm{H}_{4} \mathrm{SiMe}_{2} \mathrm{Cl}\right)_{2} \mathrm{Cl}_{2}$ is observed. According to these results the inter- or intramolecular cleavage of the $\mathrm{RMe}_{2} \mathrm{Si}-\mathrm{Cp}(\mathrm{R}=\mathrm{Me}$, $\mathrm{C}_{5} \mathrm{H}_{5}$ ) bond rather than that of $\mathrm{ClMe}_{2} \mathrm{Si}-\mathrm{Cp}$ is greatly preferred [28c].

Similar behaviour has also been observed for late transition metals.

Dicyclopentadienyl bridged heterodinuclear compounds have been isolated using Group 4 metal derivatives in which only one of the rings is coordinated [32]. Reactions of these complexes with $\left[\mathrm{RhCl}(\mathrm{CO})_{2}\right]_{2}$ take place with transfer of chloride to one of the silyl bridges [32] (Scheme 25).

Transfer of chloride from late transition metals is even more favourable than from early transition metals.

3.1.1.4. Use of halo-silylcyclopentadiene. Some transition metal complexes containing basic metal centers, such as Group 6 metal carbonyl derivatives, react with

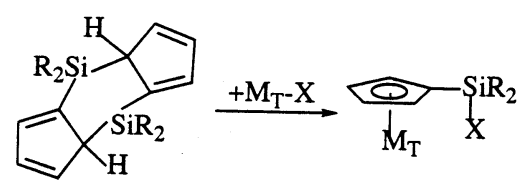

Scheme 23 . 


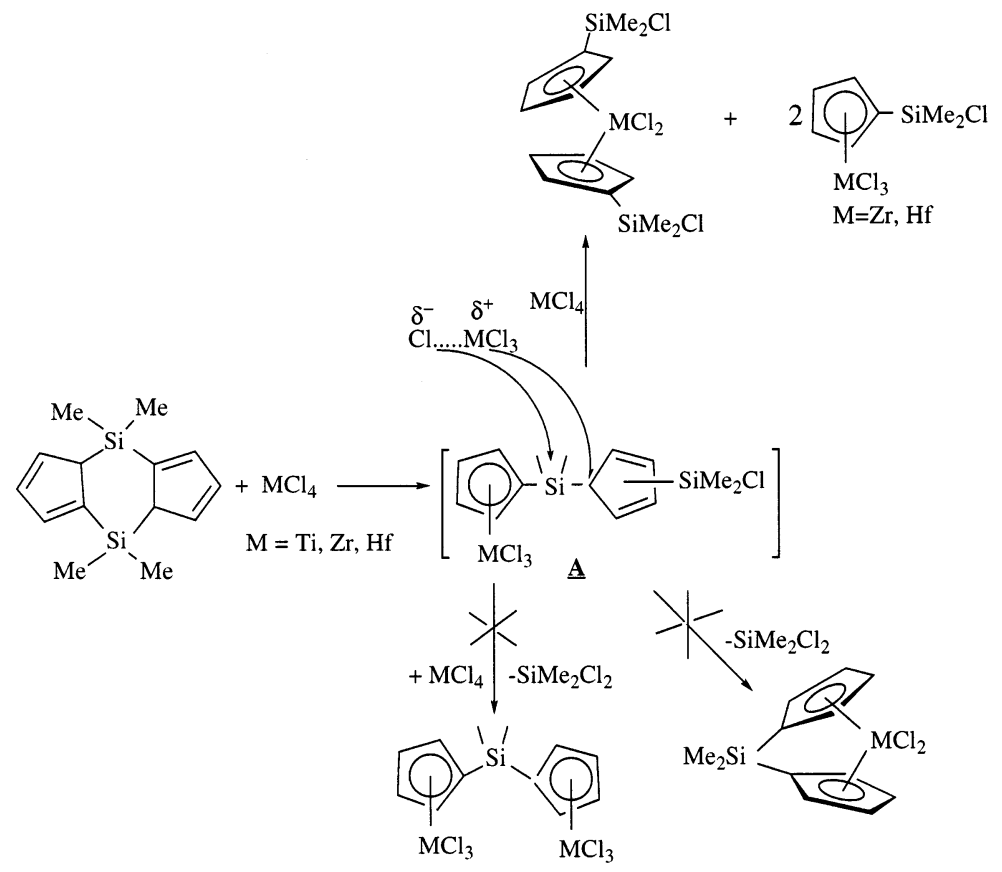

Scheme 24.

halosilylcyclopentadienes with activation of the $\mathrm{C}-\mathrm{H}$ bond and transfer of hydrogen to the metal (Scheme 26).

When more acidic metal centers are used similar deprotonation can be achieved by reacting the cyclopentadiene with metal compounds containing strongly basic substituents $\left(\mathrm{B}=\mathrm{NR}_{2}, \mathrm{OR}, \mathrm{R}\right)$ which are eliminated as $\mathrm{BH}$. Few studies have been carried out on these reactions. In some cases a metathesis reaction occurs between the metal complex $\mathrm{M}_{\mathrm{T}}-\mathrm{B}$ and the $\mathrm{Si}-\mathrm{X}$ bond leading to the metal halide derivative $\mathrm{M}_{\mathrm{T}}-\mathrm{X}$ with formation of the $\mathrm{Si}-\mathrm{B}$ product $\left(\mathrm{B}=\mathrm{NR}_{2}\right)($ Scheme 27$)$.

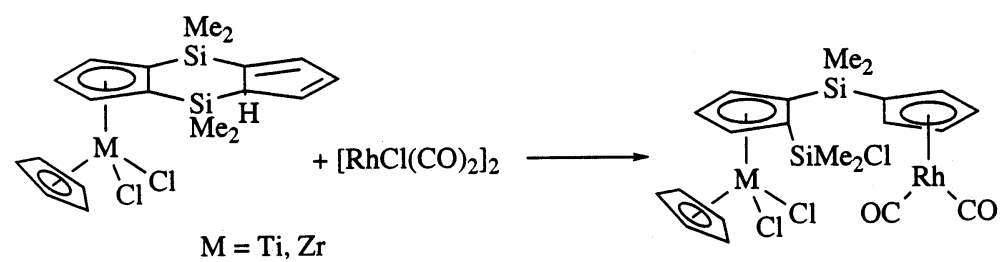

Scheme 25. 


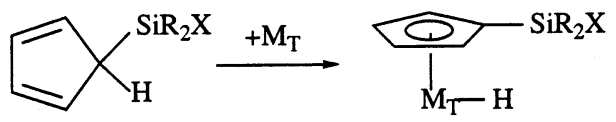

Scheme 26

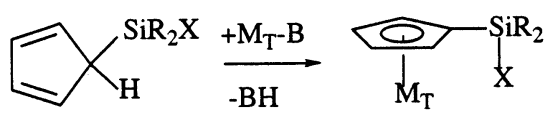

Scheme 27.

\subsubsection{Halogenation of silyl-cyclopentadienyl metal complexes}

The halodemethylation reaction of trimethylsilyl-substituted cyclopentadienyl dihalide derivatives with boron trihalides [33] is a method also used to synthesize halo-silyl-cyclopentadienyl metal complexes, according to Scheme 28.

These highly selective reactions cleave only one methyl group from rings containing between one and four trimethylsilyl substituents. This method, in which the functionality is established after metal complexation, appears more appropriate for the preparation of multiply halodimethylsililated metallocenes.

These results contrast with the behaviour observed for 1,1'-bis(trimethylsilyl)-ferrocene. The reaction of $\mathrm{Fe}\left(\eta^{5}-\mathrm{C}_{5} \mathrm{H}_{4} \mathrm{SiMe}_{3}\right)_{2}$ with excess $\mathrm{BCl}_{3}$ in $\mathrm{CH}_{2} \mathrm{Cl}_{2}$ at $-78^{\circ} \mathrm{C}$ affords, through a desilaborylation process, a mixture of metathesis products containing $\mathrm{Fe}\left(\eta^{5}-\mathrm{C}_{5} \mathrm{H}_{4} \mathrm{BCl}_{2}\right)_{2}$ and its isomer $\mathrm{Fe}\left[\eta^{5}-1,3-\mathrm{C}_{5} \mathrm{H}_{3}\left(\mathrm{BCl}_{2}\right)_{2}\right]\left(\eta^{5}-\mathrm{C}_{5} \mathrm{H}_{5}\right)$.

\subsection{Reactivity}

Metal halide complexes containing the chloro-silyl-cyclopentadienyl ligand $\mathrm{M}_{\mathrm{T}}\left(\mathrm{C}_{5} \mathrm{H}_{4} \mathrm{SiMe}_{2} \mathrm{Cl}\right) \mathrm{Cl}_{3}$ possess both metal-chloro, $\mathrm{M}-\mathrm{Cl}$ and silicon-chloro, $\mathrm{Si}-\mathrm{Cl}$ bonds with different reactivity toward several nucleophiles.
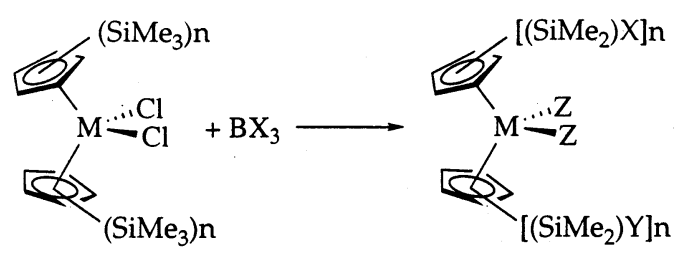

$$
\begin{aligned}
& \mathrm{M}=\mathrm{Zr} ; \mathrm{n}=\mathrm{m}=1 ; \mathrm{X}=\mathrm{Cl} ; \mathrm{Y}=\mathrm{SiMe}_{3} ; \mathrm{Z}=\mathrm{Cl} \\
& \mathrm{M}=\mathrm{Ti}, \mathrm{Zr} ; \mathrm{n}=\mathrm{m}=1 ; \mathrm{X}=\mathrm{Y}=\mathrm{Br} ; \mathrm{Z}=\mathrm{Br} \\
& \mathrm{M}=\mathrm{Zr} ; \mathrm{n}=\mathrm{m}=2 ; \mathrm{X}=\mathrm{Y}=\mathrm{Br} ; \mathrm{Z}=\mathrm{Br}
\end{aligned}
$$

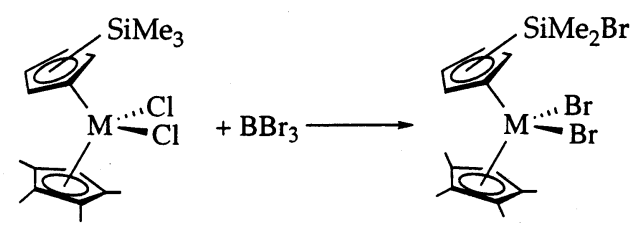

Scheme 28 . 
Selective reactions at the $\mathrm{Si}-\mathrm{Cl}$ bond in these compounds, which contain other $\mathrm{M}-\mathrm{Cl}$ or $\mathrm{M}-\mathrm{R}$ bonds, are required to introduce different functional groups onto the silicon atom of the cyclopentadienyl ring (see below). Selective reactions at the $\mathrm{M}-\mathrm{Cl}$ (or $\mathrm{M}-\mathrm{R}$ ) bonds would produce different chloro-silyl-cyclopentadienyl metal compounds. Many studies related to the relative reactivity of these bonds have been reported.

\subsubsection{Reactions of halo-silyl cyclopentadienyl metal complexes with water and silanediols}

Reactions with weak nucleophiles like water depend on the polarity and stability of the $\mathrm{M}-\mathrm{Cl}$ and $\mathrm{Si}-\mathrm{Cl}$ bonds, as illustrated by the following points.

1. For monocyclopentadienyl complexes, the reactivity of the $\mathrm{Si}-\mathrm{Cl}$ bond is comparable to that found for $\mathrm{Ti}(\mathrm{IV})-\mathrm{Cl}$ and $\mathrm{Nb}(\mathrm{V})-\mathrm{Cl}$ bonds and their reactions are not selective and take place simultaneously at both to give various oxo-silyl derivatives [28, 30b] (Schemes 29 and 30).

The same occurs in reactions with $\mathrm{SiPh}_{2}(\mathrm{OH})_{2}$ [28c] (Scheme 31).

However the reaction is highly selective at the $\mathrm{Si}-\mathrm{Cl}$ bond for the related zirconium derivative with more stable $\mathrm{Zr}-\mathrm{Cl}$ bonds [28c] (Scheme 32).

Even more selective reactions at $\mathrm{Si}-\mathrm{Cl}$ bonds are found for more basic metal centers such as carbonyl Mo(II) derivatives [28e] (Scheme 33).
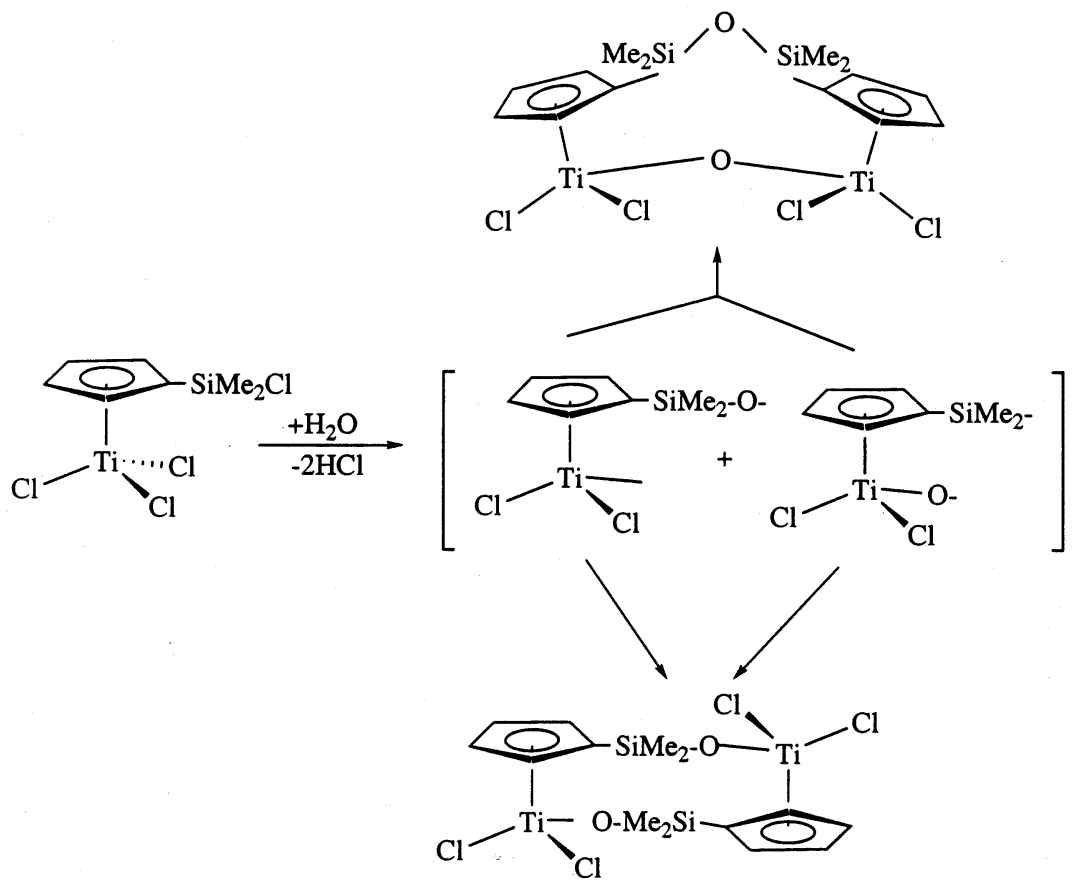

Scheme 29. 


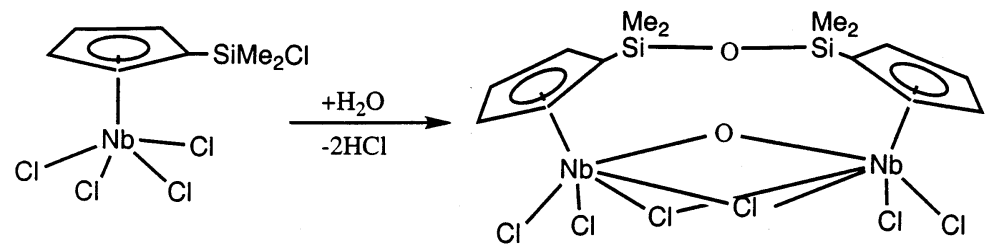

Scheme 30 .

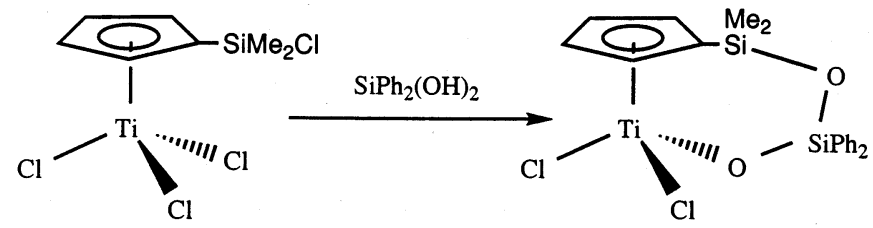

Scheme 31 .

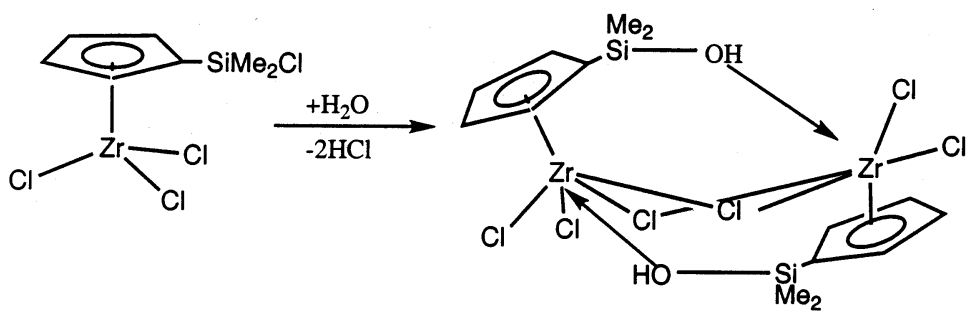

Scheme 32 .

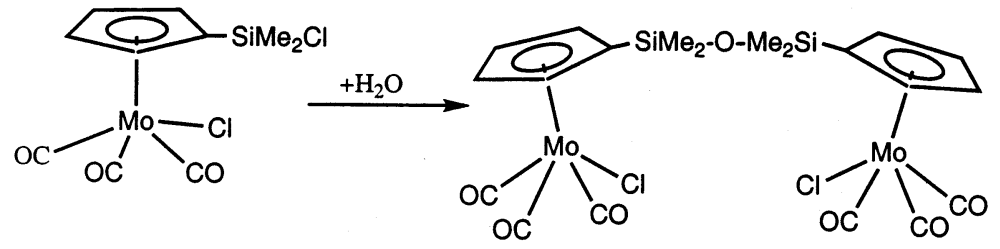

Scheme 33 .

2. For dicyclopentadienyl Group 4 metal complexes the more stable $\mathrm{M}-\mathrm{Cl}$ bonds make the attack at the $\mathrm{Si}-\mathrm{Cl}$ bond preferential and selective [28b,c] (Scheme 34).

Quantitative and selective hydrolysis by exposure of the halodimethylsily-substituted metallocene to ambient atmosphere is a standard and direct method to obtain Group 4 tetramethyldisiloxane-bridged metallocene derivatives [33] (Scheme 35).

The disiloxane structural assignment is supported by the change in the ${ }^{1} \mathrm{H}$ chemical shifts of the methyl groups in the NMR spectra compared to those of the halodimethyl substituted starting materials (0.6 ppm upfield) [28b]. 


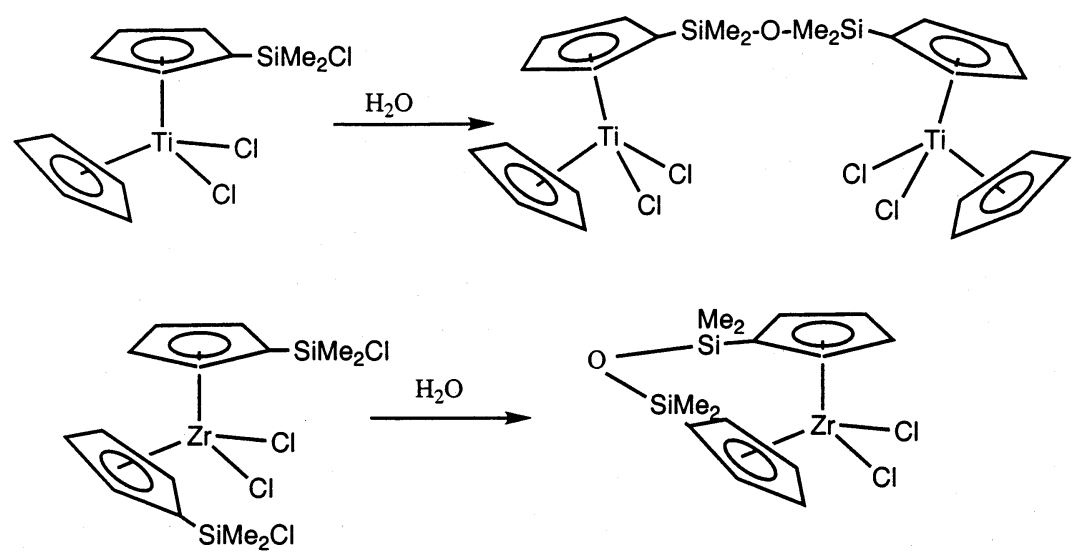

Scheme 34.

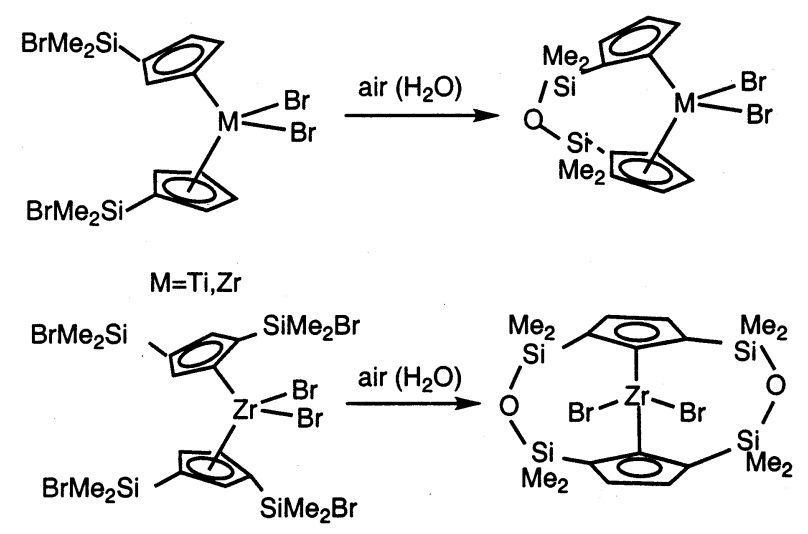

Scheme 35 .

\subsubsection{Reactions with $\mathrm{LiOH}$}

Related reactions using stronger nucleophiles $(\mathrm{LiOH})$ are selectively directed to the $\mathrm{M}-\mathrm{Cl}$ bonds in the case of the more acidic metal centers [Ti(IV)] [28c], whereas the $\mathrm{Si}-\mathrm{Cl}$ bond reacts preferentially in the case of the more basic metal centers [Mo(II)] [28e] (Scheme 36).

\subsubsection{Other reactions}

Reactions with nucleophilic alkoxo lithium or sodium salts are not selective and both $\mathrm{Zr}-\mathrm{Cl}$ and $\mathrm{Si}-\mathrm{Cl}$ bonds of the $\mathrm{Zr}\left(\eta^{5}-\mathrm{C}_{5} \mathrm{H}_{4} \mathrm{SiMe}_{2} \mathrm{Cl}\right) \mathrm{Cl}_{3}$ compound react to give unresolvable mixtures unless a stoichiometric amount of the alkoxo is used to give the totally substituted tetrasiloxo compound $\mathrm{Zr}\left(\eta^{5}-\mathrm{C}_{5} \mathrm{H}_{4} \mathrm{SiMe}_{2} \mathrm{OSiMe}_{3}\right)\left(\mathrm{OSiMe}_{3}\right)_{3}$ [30c]. Similar results are obtained when $\mathrm{Zr}\left(\eta^{5}-\mathrm{C}_{5} \mathrm{H}_{4} \mathrm{SiMe}_{2} \mathrm{Cl}\right) \mathrm{Cl}_{3}$ reacts with 

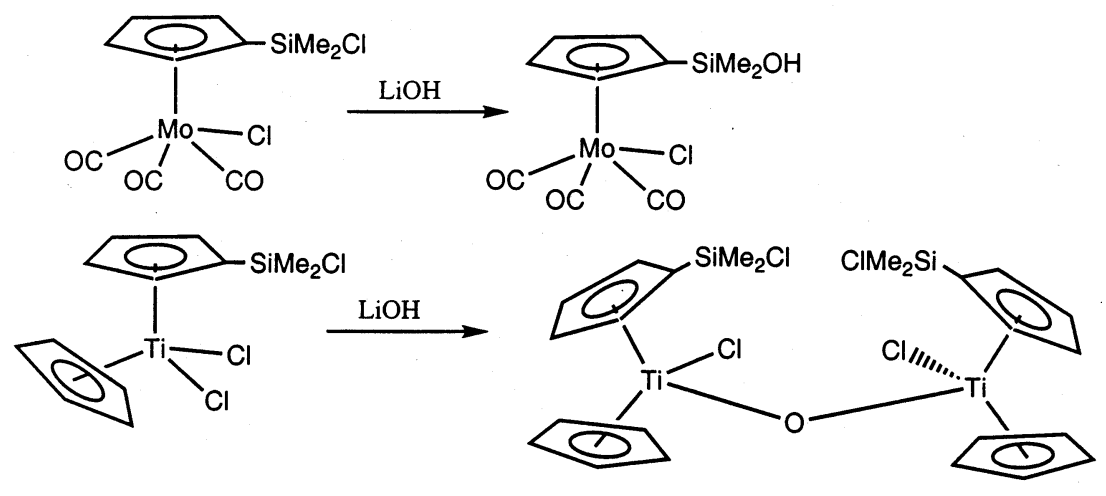

Scheme 36.

$\mathrm{MgBz}_{2} \cdot 2 \mathrm{THF}$ or $\mathrm{LiR}\left(\mathrm{R}=\mathrm{CH}_{2} \mathrm{CMe}_{2} \mathrm{Ph}, \mathrm{C}_{6} \mathrm{H}_{5}, \mathrm{C}_{6} \mathrm{~F}_{5}, \mathrm{CH}_{2} \mathrm{SiMe}_{3}\right)$ to give the tetraalkyl substituted derivatives $\mathrm{Zr}\left(\eta^{5}-\mathrm{C}_{5} \mathrm{H}_{4} \mathrm{SiMe}_{2} \mathrm{R}\right) \mathrm{R}_{3}$.

Other similar reactions with amines and lithium amides have been studied and follow the trends observed for the oxo nucleophiles discussed above. They will be presented in Section 5 as synthetic methods to prepare amino-silyl-cyclopentadienyl metal complexes.

\section{Oxo-silyl-cyclopentadienyl metal complexes (type III)}

The known oxo-silyl-cyclopentadienyl ligands $\mathrm{C}_{5} \mathrm{H}_{5}-\mathrm{Si}-\mathrm{O}-\mathrm{R}$ can be classified according to the nature of the substituent $\mathrm{R}$ bound to silicon into the types shown below.

1. Terminal oxosilyl compounds

1.1. hydroxosilyl derivatives $(\mathrm{R}=\mathrm{H})$

1.2. disiloxo derivatives $\left(\mathrm{R}=\mathrm{SiR}_{3}\right)$

1.3. alkoxosilyl compounds $\left[\mathrm{R}=\left(\mathrm{CH}_{2}\right)_{\mathrm{n}}\right.$ (Function)]. These are particularly interesting when the alkyl chain bonded to oxygen is functionalized with potential donor systems which can give rise to bidentate or tridentate (if the ring is taken into account) ligands.

2. Bridging alkoxo silyl dicyclopentadienyl derivatives $\mathrm{C}_{5} \mathrm{H}_{5}-\mathrm{Si}(\mathrm{OR}) \mathrm{R}-\mathrm{C}_{5} \mathrm{H}_{5}$.

3. Bridging disiloxanediil dicyclopentadienyl derivatives $\mathrm{C}_{5} \mathrm{H}_{5}-\mathrm{SiR}_{2}-\mathrm{O}-\mathrm{SiR}_{2}-$ $\mathrm{C}_{5} \mathrm{H}_{5}$.

\subsection{Synthetic procedures}

The strategies discussed for halo-silyl derivatives in Section 3 can be used to obtain any of these compounds.

\subsubsection{Transfer of oxo-silyl functionalized cyclopentadienyl rings}

4.1.1.1. Terminal silyl groups. Silyl-cyclopentadienes can be functionalized with a 


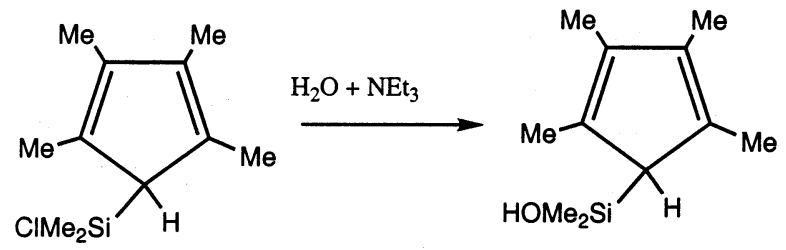

Scheme 37.

hydroxo, siloxo or alkoxo substituent and in a second step they can be transformed by metallation into their alkali or thallium salts. These are then used to transfer the ligand to a transition metal by reaction with an appropriate metal halide.

Functionalization of silyl-cyclopentadienes is usually achieved by reaction of halo-silyl-cyclopentadienes with alcohols, alkali alkoxides or water in the presence of a base.

1. Hydroxo-silyl-cyclopentadienes can be isolated when halo-silyl-cyclopentadienes are treated with water in the presence of a base (Scheme 37).

Both acidic $\mathrm{H}$ atoms can be metallated by reaction with $\mathrm{LinBu}$ to give salts which can be used to transfer the ring to the metal (Scheme 38).

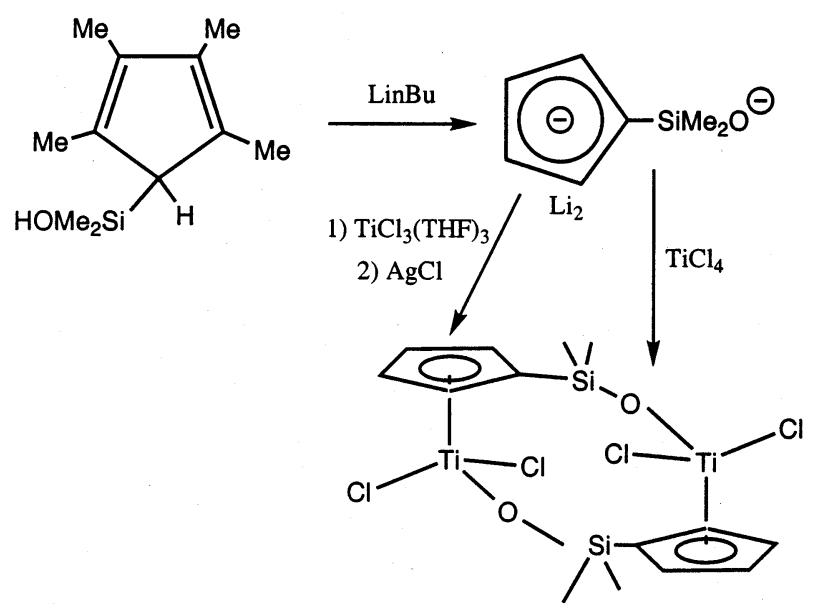

Scheme 38 .

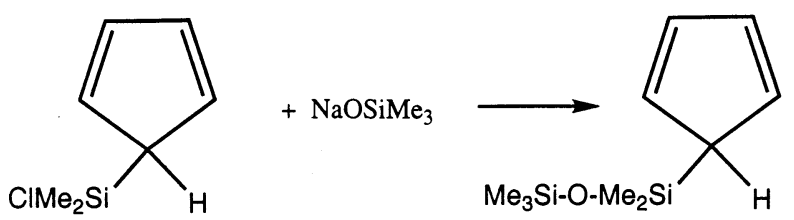

Scheme 39. 


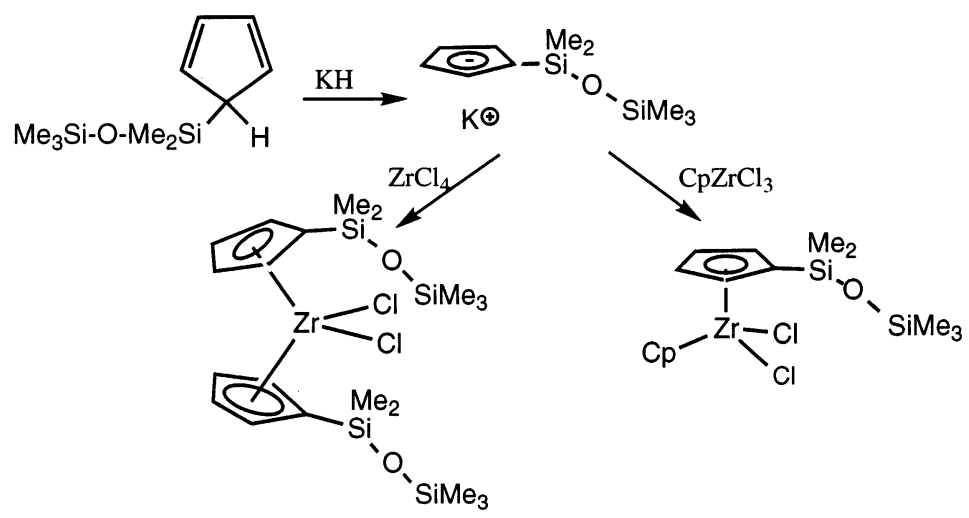

Scheme 40 .

The rigidity of the almost linear system $\mathrm{Si}-\mathrm{O}-\mathrm{M}$, due to a $\pi$-bonding contribution, avoids the formation of mononuclear compounds, and without exception all these compounds dimerize easily.

2. Similarly terminal disiloxo derivatives have normally been prepared by reactions with alkali siloxides [34] (Scheme 39).

While metallation of these compounds cannot be obtained by reaction with $\mathrm{LinBu}$, which leads to polysiloxanes, the potassium salt can easily be obtained by reaction with $\mathrm{KH}$ and then used to transfer the ligand to the transition metal (Scheme 40).

However a different reaction takes place when the thallium salt is used (Scheme 41).

3. Alcoxosilyl pendant bidentate ligands.

Homodinuclear Group 4 and 5 transition metal derivatives with $\mathrm{C}_{5} \mathrm{H}_{4} \mathrm{SiMe}_{2} \mathrm{O}$ or $\mathrm{C}_{5} \mathrm{H}_{4} \mathrm{SiMe}_{2} \mathrm{OH}$ fragments as bidentate ligands are known, and are obtained from complexes containing the $\mathrm{C}_{5} \mathrm{H}_{4} \mathrm{SiMe}_{2} \mathrm{Cl}$ unit. They were discussed in Section 3.2.1.

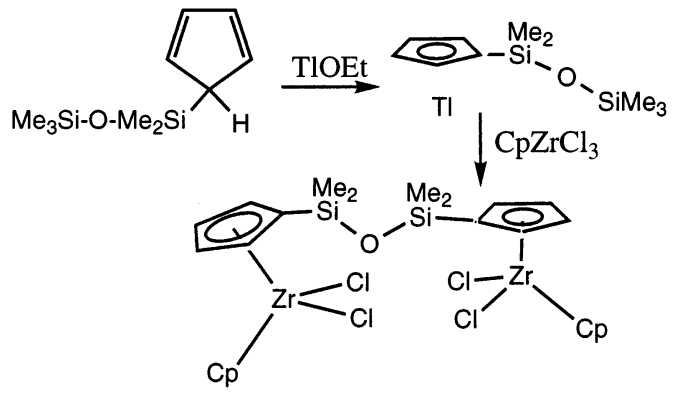

Scheme 41 . 


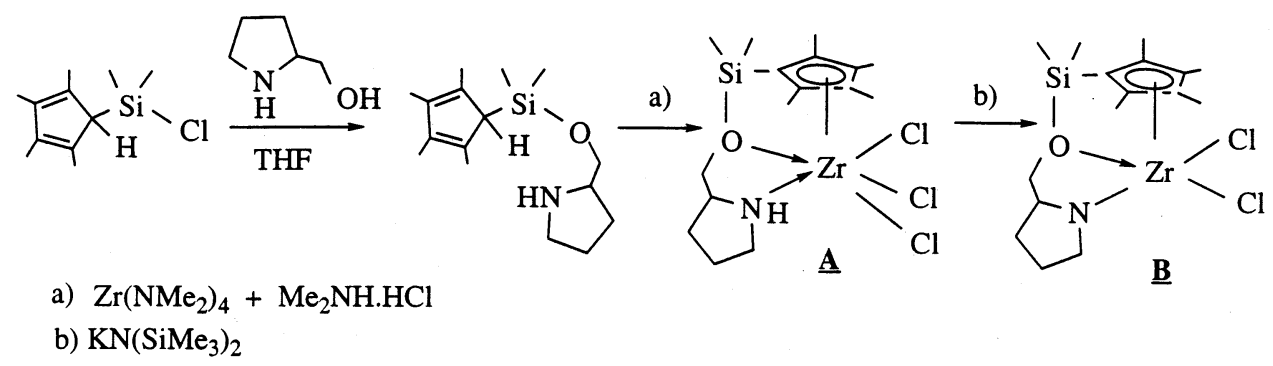

Scheme 42 .

Development in the field of homogeneous Ziegler-Natta polymerization has been rapid since Sinn and Kaminsky's discovery of the highly active zirconocene dichloride/methylaluminoxane system in 1979 [35]. Homogeneous ZieglerNatta catalysts based on Group 4 metallocene complexes have greatly improved the understanding of chain initiation, growth and termination steps during olefin polymerization on the molecular level. Progress in the development of catalysts tailored to produce specialty polymers has largely been a result of advances in the art of ligand design, since ligand architecture plays a crucial role in determining the microstructure of the polymer produced by a given catalyst. This strategy has allowed the synthesis of sophisticated ligands which have since been used to create metal complexes with potential as selective catalysts.

Treatment of dimethyl(tetramethylcyclopentadienyl)chloro silane with $S$-( - )-2pyrrolidine methanol provided the O-silylated ligand $\left(\mathrm{C}_{5} \mathrm{Me}_{4} \mathrm{H}\right) \mathrm{SiMe}_{2} \mathrm{OCH}_{2^{-}}$ $\left(\mathrm{C}_{4} \mathrm{H}_{7} \mathrm{NH}\right)\left(\mathrm{Cp}^{*} \mathrm{SiProH}_{2}\right)$ as a $90 \%$ pure oil. Reaction of this ligand with $\mathrm{Zr}\left(\mathrm{NMe}_{2}\right)_{4}$ and $\mathrm{Me}_{2} \mathrm{NH} . \mathrm{HCl}$ gave the trichloro derivative $\mathrm{Zr}(\mathrm{Cp} * \mathrm{SiProH}) \mathrm{Cl}_{3} \mathbf{A}$, obtained as a mixture of diastereomers. Deprotonation of $\mathbf{A}$ with $\mathrm{LiN}\left(\mathrm{SiMe}_{3}\right)_{2}$ produced the dichloride $\mathrm{Zr}\left(\mathrm{Cp}^{*} \mathrm{SiPro}\right) \mathrm{Cl}_{2}$ B [36] (Scheme 42).

Alkylation of either $\mathbf{A}$ or $\mathbf{B}$ resulted in $\mathrm{Si}-\mathrm{O}$ bond cleavage in the $\mathrm{Cp}^{*} \mathrm{SiPro}$ ligand to give a dimeric complex $\mathbf{C}$. Compound $\mathbf{A}$ reacts with three equivalents of methyllithium to give $\mathbf{C}$ (Scheme 43). In this reaction, each equivalent of LiMe serves a different purpose; one deprotonates the coordinated pyrrolidine ring, another attacks the silicon center on the ligand, resulting in $\mathrm{Si}-\mathrm{O}$ bond cleavage, while the last equivalent metathesizes a chloride ligand to leave a methyl group

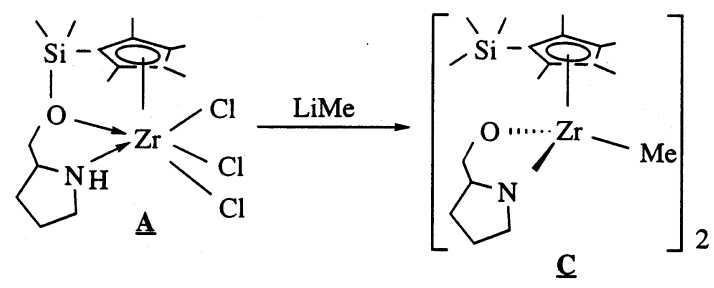

Scheme 43 . 


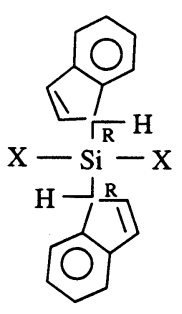

(RR/SS)

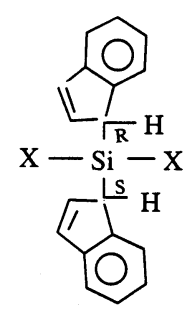

$(\mathrm{R}, \mathrm{S})$

$\left(\mathrm{X}=\mathrm{Cl}, \mathrm{CH}_{3}, \mathrm{OCH}_{3}\right)$

Scheme 44 .

bonded to zirconium. The sequence of these three steps is unknown. Preliminary experiments suggest that when activated with MAO, the compounds $\mathbf{A}$ or $\mathbf{B}$ polymerize ethylene albeit with low activities. The $\mathrm{Si}-\mathrm{O}$ functionality is probably responsible for the poor activity and thermal instability of derivatives of this Cp*SiPro type.

Recently, a series of ligands of general type $\mathrm{XSiMe}_{2}\left(\mathrm{OCH}_{2} \mathrm{CH}_{2}\right) \mathrm{nOMe}\left(\mathrm{X}=\mathrm{C}_{5} \mathrm{H}_{5}\right.$ or $\mathrm{C}_{5} \mathrm{Me}_{5}, n=2$ or 3 ) have been described. The oligethylene glycol ether substituent (tentacle) on these ligands may have various interesting effects [37].

4.1.1.2. Bridging alkoxo-silyl groups. Rausch and Chien described the synthesis of a family of compounds with the general stoichiometry $\mathrm{L}_{x} \mathrm{SiX}_{4-x}(x=1,2 ; \mathrm{L}=\mathrm{Cp}$, Ind, Flu; $\mathrm{X}=\mathrm{Cl}, \mathrm{CH}_{3}, \mathrm{OCH}_{3}$ ), in order to use these new organosilicon compounds to prepare the corresponding zirconocene and titanocene derivatives as catalyst for olefin polymerization. Two diastereomers, the $(R R / S S)$-rac and $(R, S)$-meso structures were obtained and separated for the (Ind) $)_{2} \mathrm{SiX}_{2}$ ligand (Scheme 44). Thermal diastereomerization of the racemic into the meso structure has been observed and a possible mechanism is proposed $[19 \mathrm{~m}]$.

Similar reactions produce $\mathrm{C}_{5} \mathrm{H}_{4}\left(\mathrm{SiMe}_{3}\right)\left(\mathrm{SiMe}_{2} \mathrm{OMe}\right)$ and $\mathrm{C}_{5} \mathrm{H}_{4}\left(\mathrm{SiMe}_{2} \mathrm{OMe}\right)_{2}$ [27a].

4.1.1.3. Bridging siloxane groups. As part of the numerous attempts to develop novel ansa-metallocene-based complexes of early transition metals as potentially efficient catalysts for olefin polymerization, worldwide interest has, inter alia, been focussed on complexes with tetramethyldisiloxanediyl-tethered cyclopentadienyl ligands. Thus, considerable attention has been paid to complexes of the general type $\left[\mathrm{M}\left\{\mathrm{O}\left(\mathrm{Me}_{2} \mathrm{SiC}_{5} \mathrm{H}_{4}\right)_{2}\right\} \mathrm{X}_{n}\right]_{m}(\mathrm{X}=$ halide $)[33 \mathrm{~b}, 38-44]$.

Metallocenes with two bridging groups are the subject of investigation elsewhere as catalysts for olefin polymerization [17,38,39].

The discoveries of stereoespecific $\alpha$-olefin polymerization by 14-electron ansametallocene cations of Group 4 elements have revolutionized Ziegler-Natta catalysis. Various types of ring-bridging group have been developed to investigate the influence 
of the corresponding ansa-metallocene precursor on the olefin polymerization behaviour of the catalyst derived from it. It is now generally recognized that metallocenes having a rigid single-atom bridged structure exhibit good activity and high stereoselectivity in propylene polymerization. Metallocenes with a more flexible two-atom bridge perform less well. Thus far, only a few Group 4 metallocenes with a three-atom bridge have been synthesized, including those with a trimethylene group, and none of the studies has dealt with their use as polymerization catalysts. Compared with one- or two-atom bridges, the trimethylene group is exceedingly flexible. However, another triatomic bridge, 1,1,3,3-tetramethyldisiloxanediyl, $-\mathrm{Me}_{2} \mathrm{SiOSiMe}_{2}-$ is less likely to be as flexible as $-\left(\mathrm{CH}_{2}\right)_{3}-$ in metallocene complexes, due to conformational effects caused by the four methyl substituents.

The synthesis and characterization of the disiloxane-bridged bis(indenyl)metallocenes [ $\mathrm{rac}$-1,3-bis( $\eta^{5}$-indenyl)-1,1,3,3-tetramethyldisiloxane]dichlorotitanium and zirconium $\mathrm{M}\left[\mathrm{O}\left(\mathrm{Me}_{2} \mathrm{SiC}_{9} \mathrm{H}_{6}\right)_{2}\right] \mathrm{Cl}_{2}$ was reported [40] (Scheme 45), as well as a study of their properties as ethylene and propylene polymerization catalysts.

Fischer and colleagues have more recently published their results concerning the zirconium complex, using a slightly different preparative approach and providing high-resolution ${ }^{1} \mathrm{H}-\mathrm{NMR}$ spectra and a successful single-crystal X-ray study for the zirconium compound $\mathrm{Zr}\left[\mathrm{O}\left(\mathrm{Me}_{2} \mathrm{SiC}_{9} \mathrm{H}_{6}\right)_{2}\right] \mathrm{Cl}_{2}$ [41]. While Rausch and coworkers synthesized the compound by reacting $\mathrm{ZrCl}_{4} / \mathrm{THF}$ with the dilithium salt $\mathrm{Li}_{2}\left[\mathrm{O}\left(\mathrm{Me}_{2} \mathrm{SiC}_{9} \mathrm{H}_{6}\right)\right]$ prepared in situ, Fischer and coworkers isolated and characterized the corresponding dipotassium salt which they then used in the synthesis.

These compounds polymerize ethylene only when activated with MAO and not with $\mathrm{Ph}_{3} \mathrm{C}^{+} \mathrm{B}\left(\mathrm{C}_{6} \mathrm{~F}_{5}\right)_{4}^{-}$-triisobutylaluminium. The titanium precursor does not polymerize propylene with either cocatalyst, whereas the zirconium precursor exhibited moderate activity to produce polypropylene. The catalytic behaviour suggests $\sigma$-donation from the oxygen atom of the siloxane bridge to the metal center (A). In the presence of MAO as cocatalyst a $\sigma$-complexed $\mathrm{O}-\mathrm{Al}$ structure is considered (B) (Rausch and colleagues). Other catalytic properties of these compounds have been studied [42a] and the X-ray structure of two yttrocen derivatives have been reported [42b].

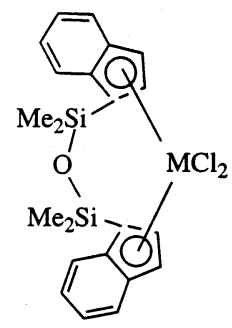

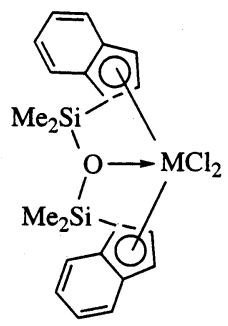

$\underline{\mathbf{A}}$

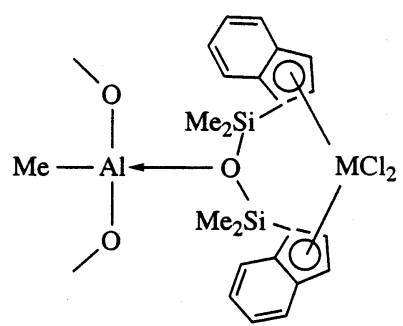

B

Scheme 45 . 
$\mathrm{Zr}\left[\mathrm{O}\left(\mathrm{Me}_{2} \mathrm{SiC}_{5} \mathrm{H}_{4}\right)_{2}\right] \mathrm{Cl}_{2}, \mathrm{Zr}\left[\mathrm{O}\left(\mathrm{Me}_{2} \mathrm{SiC}_{5} \mathrm{H}_{3}^{t} \mathrm{Bu}\right)_{2}\right] \mathrm{Cl}_{2}$ and $\mathrm{Zr}\left[\mathrm{Me}_{2} \mathrm{Si}\left(\mathrm{OMe}_{2} \mathrm{SiC}_{5} \mathrm{H}_{4}\right)_{2}\right] \mathrm{Cl}_{2}$ were prepared by reacting $\mathrm{ZrCl}_{4}$ with salts $\mathrm{K}_{2}\left[\mathrm{O}\left(\mathrm{Me}_{2} \mathrm{SiC}_{5} \mathrm{H}_{4}\right)_{2}\right], \mathrm{K}_{2}\left[\mathrm{O}\left(\mathrm{Me}_{2} \mathrm{SiC}_{5}-\right.\right.$ $\left.\left.\mathrm{H}_{3}^{t} \mathrm{Bu}\right)_{2}\right]$ and $\mathrm{K}_{2}\left[\mathrm{Me}_{2} \mathrm{Si}\left(\mathrm{OMe}_{2} \mathrm{SiC}_{5} \mathrm{H}_{4}\right)_{2}\right]$, respectively [43]. In solution, at room temperature, all three complexes are fluxional; moreover the NMR spectrum of $\mathrm{Zr}\left[\mathrm{O}\left(\mathrm{Me}_{2} \mathrm{SiC}_{5} \mathrm{H}_{3}^{t} \mathrm{Bu}\right)_{2}\right] \mathrm{Cl}_{2}$ shows resonances for two isomers. Four principally different isomers (rac and meso configurations) are possible for the non-fluxional compound $\mathrm{Zr}\left[\mathrm{O}\left(\mathrm{Me}_{2} \mathrm{SiC}_{5} \mathrm{H}_{3}^{t} \mathrm{Bu}\right)_{2}\right] \mathrm{Cl}_{2}$. Simple model considerations predict that the meso configurations will suffer more from intramolecular steric congestion (due to the eclipsed tert-butyl groups) than the racemic forms, this suggests qualitatively the sequence in configurational stability: rac $>$ meso. This compound crystallizes from $n$-hexane as a racemic mixture (single-crystal X-ray study) with exclusively 1,3-disubstituted cyclopentadienyl ligands and chloro centers oriented transoid to the $\mathrm{O}$ atoms. The considerable space demand of both ring substituents in the compound probably dictates the preference for the 1,3-isomer.

Both $\left(\mathrm{Me}_{2} \mathrm{HSi}\right)_{2} \mathrm{O}$ and $\left(\mathrm{Me}_{2} \mathrm{HSiO}\right)_{n}$ are cleanly chlorinated by a mixture of $\mathrm{Cl}_{2}$ and $\mathrm{N}_{2}$ to form the corresponding chlorides $\left(\mathrm{Me}_{2} \mathrm{ClSi}\right)_{2} \mathrm{O}$ and $\left(\mathrm{Me}_{2} \mathrm{ClSiO}\right)_{n}$ in good yield. The chlorosiloxanes react with sodium cyclopentadienide to give the cyclopentadiene siloxanes. These $\mathrm{Cp}$ derivatives are easily converted into their metallated compounds by reaction with sodium metal or $\mathrm{LinBu}$. These are then reacted with $\mathrm{TiCl}_{4} \cdot 2$ py to give the chloro titanocene complexes Ti[1, $\left.1^{\prime}-\eta^{5}-\eta^{5}-\left(\mathrm{Me}_{4} \mathrm{Si}_{2} \mathrm{O}\right)\left(\mathrm{C}_{5} \mathrm{H}_{4}\right)_{2}\right] \mathrm{Cl}_{2}$ and $\left[\mathrm{Ti}\left\{1,1^{\prime}-\eta^{5}-\eta^{5}-\left(\mathrm{Me}_{2} \mathrm{Si}_{2} \mathrm{O}_{2}\right)\left(\mathrm{C}_{5} \mathrm{H}_{4}\right)_{2}\right\} \mathrm{Cl}_{2}\right]_{n}$ (Scheme 46). The Ti[1,1'- $\eta^{5}-\eta^{5}-\left(\mathrm{Me}_{4} \mathrm{Si}_{2} \mathrm{O}\right)-$ $\left.\left(\mathrm{C}_{5} \mathrm{H}_{4}\right)_{2}\right] \mathrm{Cl}_{2}$ compound reacts with LiMe to give the corresponding dimethyltitanocene derivative, and with $\mathrm{CO}$ in the presence of aluminium to form the reduced titanocene(II) dicarbonyl complex [33b].

The NMR spectra of these compounds exhibit an $\mathrm{A}_{2} \mathrm{~B}_{2}$ spin system for the cyclopentadienyl protons. The IR spectrum of the dicarbonyl compound shows two strong $\delta(\mathrm{CO})$ bands at 1960 and $1885 \mathrm{~cm}^{-1}$. These values may be compared to those found at 1975 and $1897 \mathrm{~cm}^{-1}$ for the parent compound $\mathrm{TiCp}_{2}(\mathrm{CO})_{2}$. The $15 \mathrm{~cm}^{-1}$ shift to lower frequency reflects the electron-releasing effect of the Si-substituted ring.

The synthesis of the first disiloxane-bridged molybdenocene and tugstenocene $\mathrm{M}\left[\mathrm{O}\left(\mathrm{SiMe}_{2} \mathrm{C}_{5} \mathrm{H}_{4}\right)_{2}\right] \mathrm{Cl}_{2}(\mathrm{M}=\mathrm{Mo}, \mathrm{W})$ derivatives has been described [44]. The dichloro compounds react with sodium borohydride to give the dihydride $\mathrm{M}\left[\mathrm{O}\left(\mathrm{SiMe}_{2} \mathrm{C}_{5} \mathrm{H}_{4}\right)_{2}\right] \mathrm{H}_{2}$ and with $\mathrm{ZnMe}_{2}$ and $\mathrm{NaSEt}$ to form $\mathrm{M}\left[\mathrm{O}\left(\mathrm{SiMe}_{2} \mathrm{C}_{5} \mathrm{H}_{4}\right)_{2}\right] \mathrm{Me}_{2}$ and $\mathrm{M}\left[\mathrm{O}\left(\mathrm{SiMe}_{2} \mathrm{C}_{5} \mathrm{H}_{4}\right)_{2}\right](\mathrm{SEt})_{2}$, respectively. An X-ray crystal analysis has shown that the bridged chain blocks one of the side positions of the complex, the siloxy unit being located at one side of the $\mathrm{Me}-\mathrm{Mo}-\mathrm{Me}$ bisector.
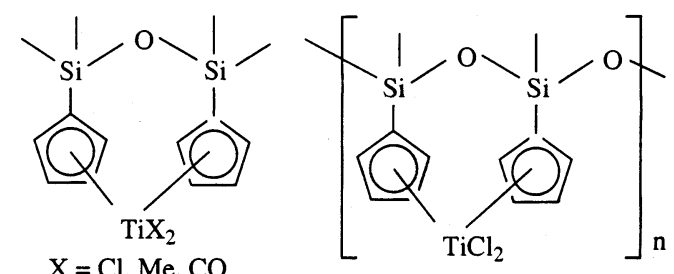

Scheme 46. 


\subsubsection{Transformation of chloro-silyl into oxo-silyl functionalized cyclopentadienyl} metal complexes

A second strategy involves the isolation of a silyl-cyclopentadienyl metal complex containing a different functional group $\mathrm{Cp}-\mathrm{Si}-\mathrm{X}$ and its subsequent transformation into the alkoxo derivative.

Selective reactions at the $\mathrm{Si}-\mathrm{Cl}$ bond of halo-silyl cyclopentadienyl metal halides are required. We have already discussed the different reactivity of these compounds with water and $\mathrm{LiOH}$ (Sections 3.2.1 and 3.2.2).

\subsubsection{Transformation of amido-silyl into oxo-silyl cyclopentadienyl metal complexes}

The first preliminary details of a novel metal mediated transformation, implying direct conversion of a coordinated silylamido group into a silyloxide fragment, was reported by Petersen [45] in the carboxylation reaction of $\operatorname{Zr}\left[\left(\eta^{5}-\mathrm{C}_{5} \mathrm{Me}_{4}\right) \mathrm{SiMe}_{2}-\right.$ $\left.\left(\mathrm{N}^{t} \mathrm{Bu}\right)\right] \mathrm{Me}_{2}$ via isocyanate elimination (Scheme 47).

The identity of this compound has been verified by an X-ray crystallographic analysis (Fig. 2) [45]. Its molecular structure shows an $O$-constrained geometry with a crystallographic center of inversion in the molecule. The two $\mathrm{Zr}$ centers are linked by a pair of bridging acetate groups and the oxygen atom of an ansa-tetramethylcyclopentadienyl siloxy ligand. The coordination sphere about each $\mathrm{Zr}$ center is completed with a single chelate acetate ligand and the appended tetramethylcyclopentadienyl ring. Of the six Zr-bound oxygen donor atoms, five are deployed in a nearly pentagonal arrangement with the sixth one lying trans to the centroid of the tetramethylcyclopentadienyl ring.

Similarly, the reaction of $\mathrm{Ti}\left(\eta^{5}-\mathrm{C}_{5} \mathrm{H}_{4} \mathrm{SiMe}_{2} \mathrm{NR}\right) \mathrm{Cl}_{2}$ and $\mathrm{Ti}\left[\eta^{5}-\mathrm{C}_{5} \mathrm{H}_{4} \mathrm{SiMe}_{2}-\right.$ $\left.\mathrm{NMe}\left(\mathrm{CH}_{2}\right)_{2} \mathrm{NMe}\right] \mathrm{Cl}_{2}$ with dry $\mathrm{CO}_{2}$ and carbonyl organic compounds gave, by oxygen abstraction, oxo-silyl cyclopentadienyl metal complexes, and the corresponding organic molecule [46] (Schemes 48-51).

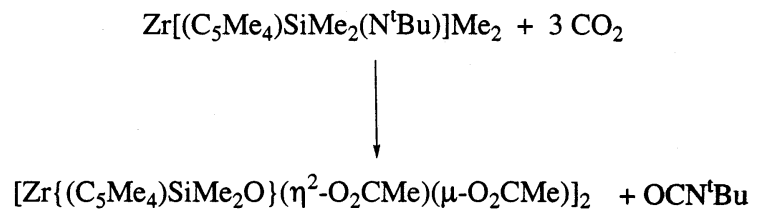

Scheme 47.

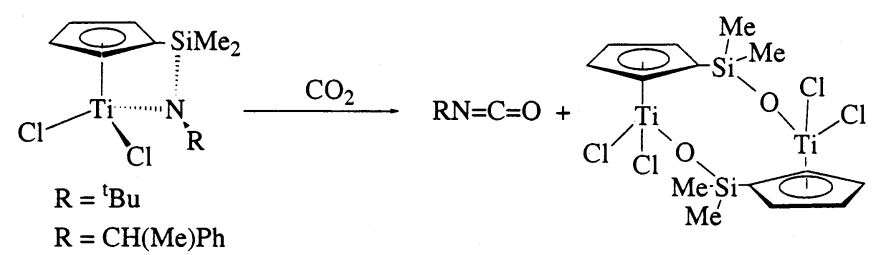

Scheme 48 . 


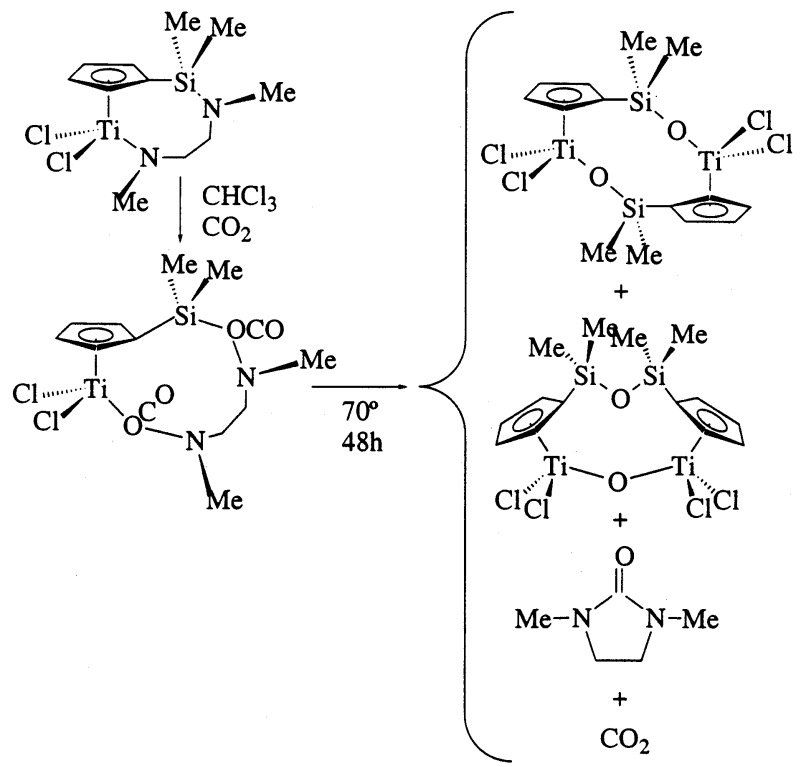

Scheme 49.

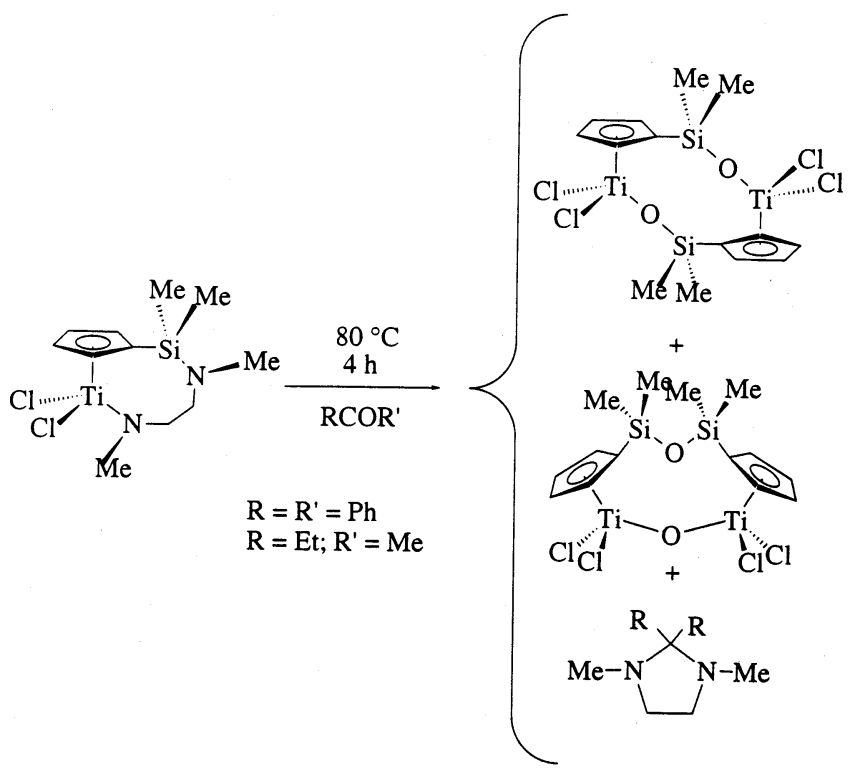

Scheme 50 . 


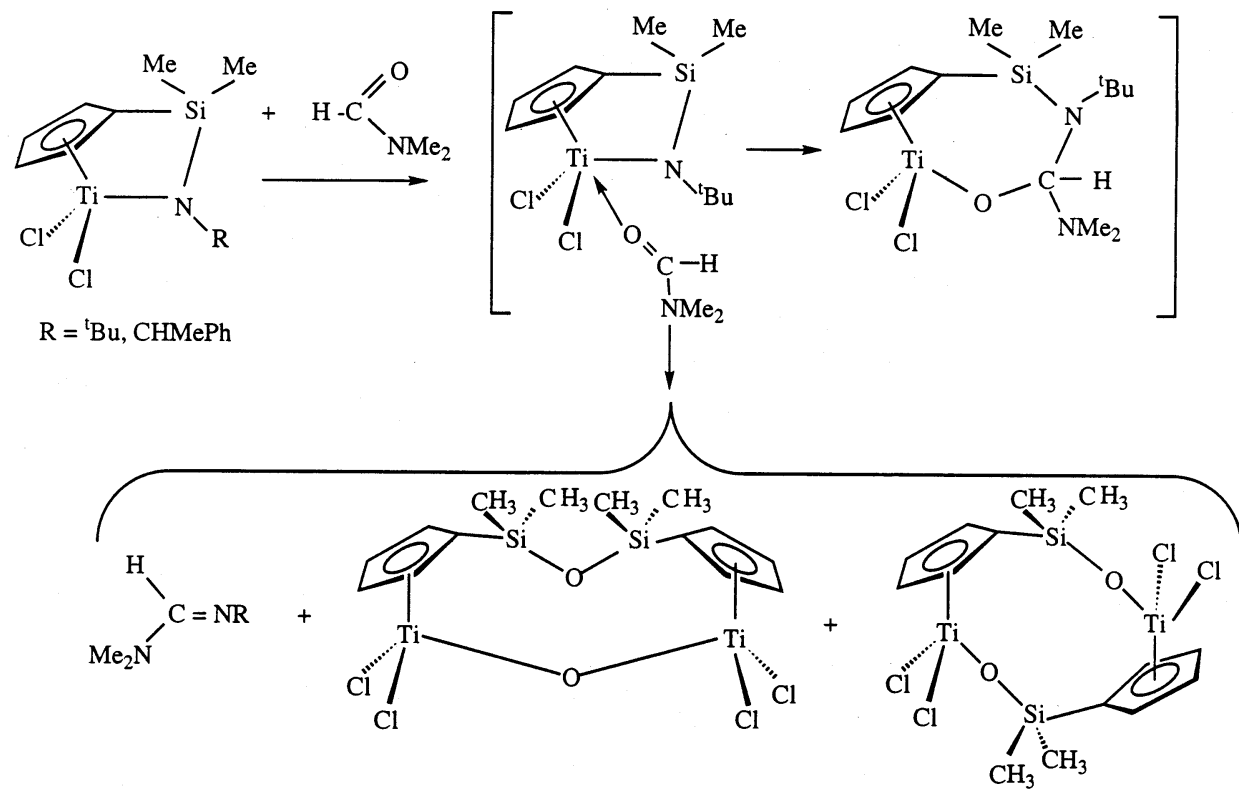

Scheme 51 .

Similar reactions with acyl halides, esters, carbonates and anhydrides have also been observed.

\section{Amino- and amido-silyl-cyclopentadienyl metal complexes (type IV)}

\subsection{Synthetic methods}

Similar methods to those described above to prepare cyclopentadienyl metal complexes containing rings with halo- and oxo-silyl functionalities may also be used to obtain the amino-silyl derivatives.

\subsubsection{Transfer of functionalized cyclopentadienyl rings}

Chloro-silyl-cyclopentadienes are readily transformed into the corresponding amino-silyl-cyclopentadienes by reaction with amines. They are also easily metallated by reaction with strong bases such as LinBu and TlOEt (Scheme 52).

When these amino-silyl-cyclopentadienes contain secondary amino substituents, reaction with two equivalents of the basic reagent can also metallate the amino group to give amido-silyl-cyclopentadienyl dianionic ligands. These were then used to prepare the chelated silyl-amido complexes [47].

\subsubsection{Transformation of chloro-silyl into amido-silyl functionalized} cyclopentadienyl metal complexes

As discussed above, this method requires reactions at the $\mathrm{Si}-\mathrm{Cl}$ bond to be highly selective. 


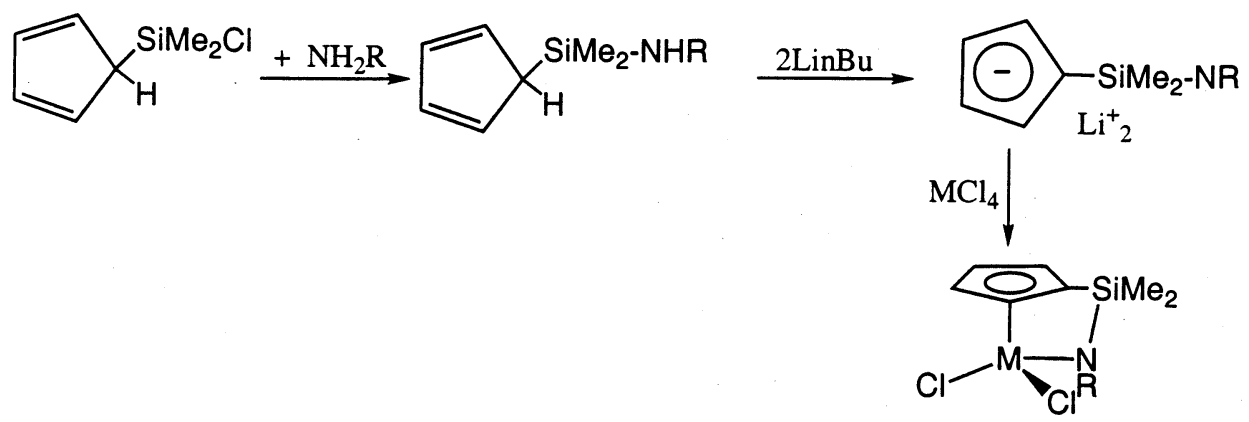

Scheme 52 .

Reactions of chloro-silyl-cyclopentadienyl metal halides with nucleophilic nitrogen donor reagents depend on the polarity and comparative stability of the $\mathrm{M}-\mathrm{Cl}$ and $\mathrm{Si}-\mathrm{Cl}$ bonds and on the nucleophilic character of the reagent used. The trends are similar to those observed in reactions with oxygen donor nucleophiles.

5.1.2.1. Reactions with amines. The reaction is not selective and both the $\mathrm{Ti}-\mathrm{Cl}$ and $\mathrm{Si}-\mathrm{Cl}$ bonds of the monocyclopentadienyl titanium(IV) complex $\operatorname{Ti}\left(\eta^{5}-\right.$ $\left.\mathrm{C}_{5} \mathrm{H}_{4} \mathrm{SiMe}_{2} \mathrm{Cl}\right) \mathrm{Cl}_{3}$ react with $\mathrm{NH}_{2}^{t} \mathrm{Bu}$ to give the disubstituted amido-silyl and amido-titanium compound, always accompanied by the amido-silyl derivative which results from elimination of the ammonium salt $\left[\mathrm{NH}_{3}^{t} \mathrm{Bu}\right] \mathrm{Cl}$. In the presence of the more basic amine, $\mathrm{NEt}_{3}$, total conversion into the amido-silyl complex was observed [46a] (Scheme 53). Similar behaviour was observed when $\mathrm{NH}_{2} \mathrm{CHMePh}$ was used.

However, selective reactions at two of the $\mathrm{M}-\mathrm{Cl}$ bonds takes place with monocyclopentadienyl niobium(V), molybdenum(V) and tungsten(V) halides which are transformed into the corresponding imido complexes [28e, 28f] (Scheme 54).

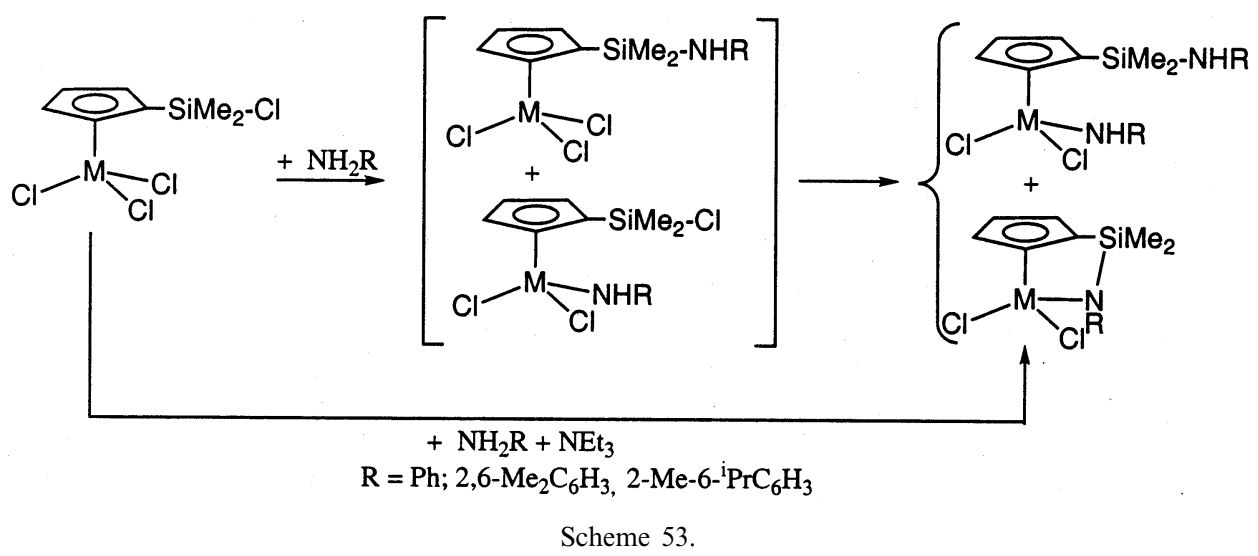




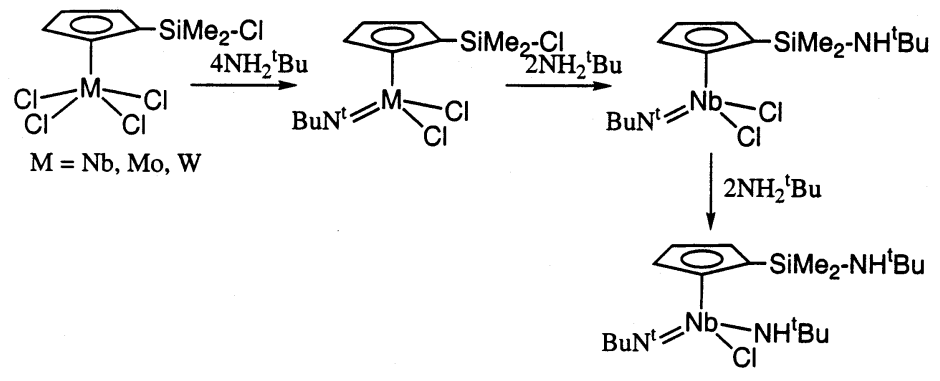

Scheme 54.

In the case of the niobium complex, the presence of the imido group stabilizes the two remaining $\mathrm{Nb}-\mathrm{Cl}$ bonds and the next step of the substitution takes place selectively at the $\mathrm{Si}-\mathrm{Cl}$ bond with the final step at the $\mathrm{Nb}-\mathrm{Cl}$ bond.

5.1.2.2. Reactions with amides LiNR $_{2}$ and LiNHR. Reactions with more polar and stronger nucleophilic primary amides are not selective and both $\mathrm{M}-\mathrm{Cl}$ and $\mathrm{Si}-\mathrm{Cl}$ bonds of the $\mathrm{M}\left(\eta^{5}-\mathrm{C}_{5} \mathrm{H}_{4} \mathrm{SiMe}_{2} \mathrm{Cl}\right) \mathrm{Cl}_{3}(\mathrm{M}=\mathrm{Ti}, \mathrm{Zr})$ compounds react to give unresolvable mixtures unless a stoichiometric amount of the amide is used to give the totally substituted compound. A selective reaction at the $\mathrm{Ti}-\mathrm{Cl}$ bond was only observed with $\mathrm{LiN}\left(\mathrm{SiMe}_{3}\right)_{2}$. Further elimination of $\mathrm{HCl}$ gave the amido-silyl compound when protonated amides were used [30c, 46a] (Scheme 55).

The related zirconium compounds react in a similar way with primary amides to give the amido-silyl complexes in lower yields. However, when secondary amides are used in the presence of the more basic $\mathrm{NEt}_{3}$ the reaction takes place via intermediate coordination of the amine which stabilizes the $\mathrm{Zr}-\mathrm{Cl}$ bond. So the reaction with amides in the presence of $\mathrm{NEt}_{3}$ comprises a preferential reaction at the $\mathrm{Si}-\mathrm{Cl}$ bond to give amino-silyl derivatives which can be isolated [46a] (Scheme 56).
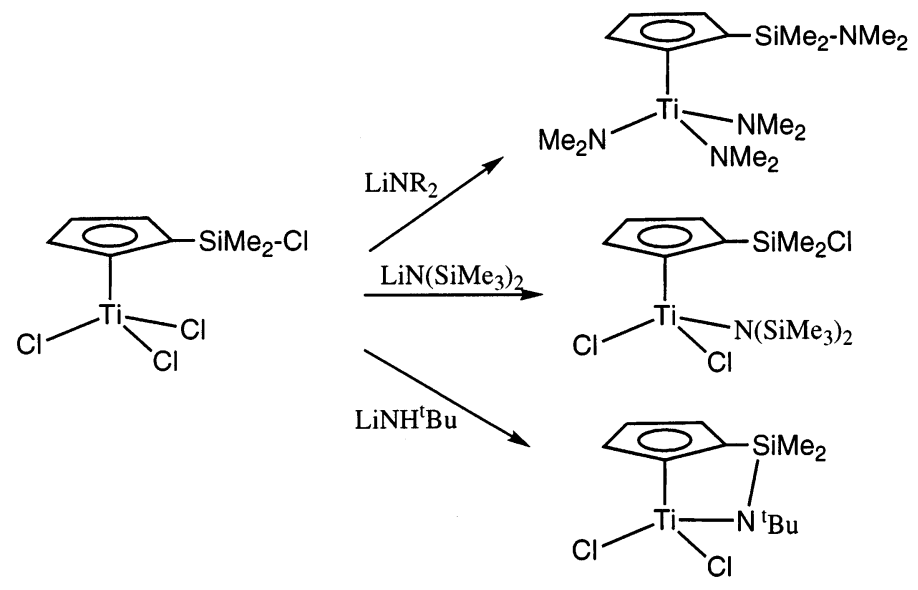

Scheme 55 . 


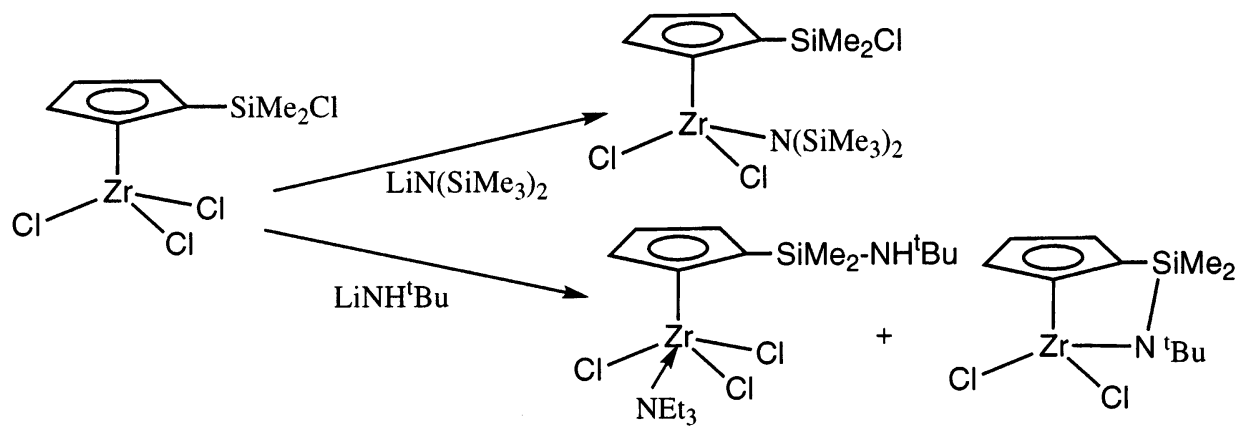

Scheme 56 .

Analogous reactions with the monocyclopentadienyl niobium(V) imido complex take place with elimination of $\mathrm{HCl}$ to give the amido-silyl compound, which can then be totally substituted by a new reaction with the amide. These silyl-amido niobium derivatives also result from reactions of the tetrachloride with a great excess of the amide, or alternatively by heating to temperatures above $140^{\circ} \mathrm{C}$ [28f] (Scheme 57).

Analogous behaviour is also observed with related dibenzyl and chloro-benzyl niobium complexes for which reaction with the lithium amide initially gives the amido niobium derivative which then slowly rearranges at room temperature to the amido-silyl compound by an intermolecular reaction [28f] (Scheme 58).

The differences of reactivity shown in these examples may be used, under appropriate conditions, to transform chloro-silyl into amino-silyl complexes.

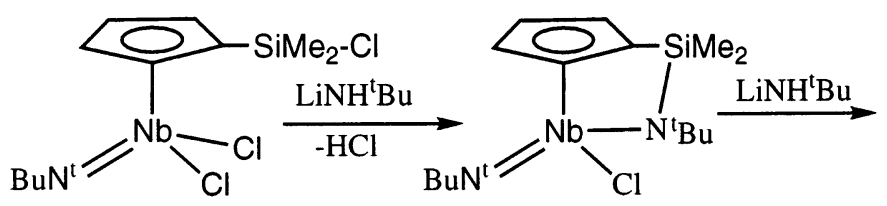

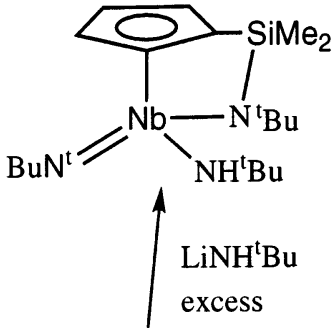<smiles>CS(Cl)(Cl)c1cccc(C(Cl)(Cl)Cl)c1</smiles> 


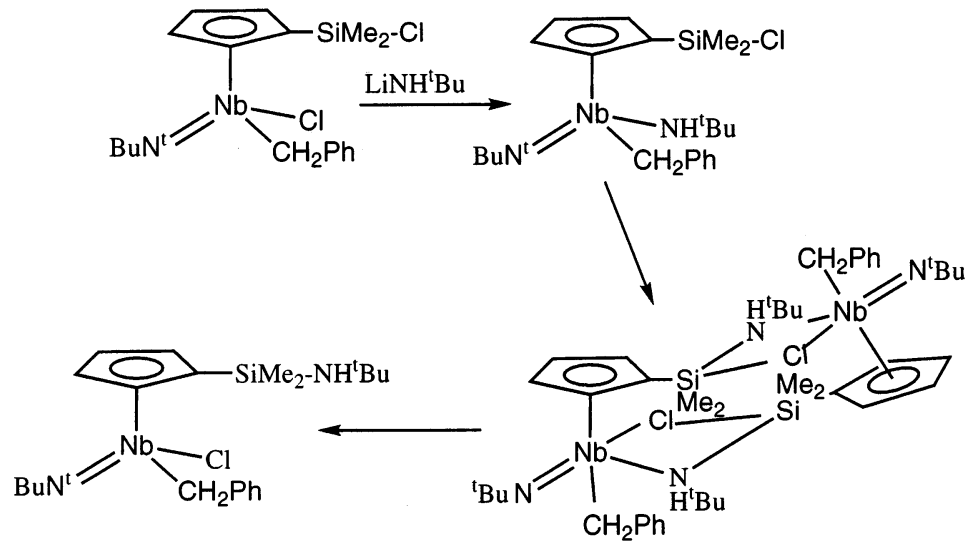

Scheme 58 .

\section{Alkyl-silyl-cyclopentadienyl metal complexes (type V)}

In addition to the silicon-bonded functional group, all of the compounds described in preceding sections contain at least one alkyl substituent. These are not discussed in this review which is mainly concerned with silyl groups containing substituents that can be significant as metal coordinating moieties. Therefore, in this section we will only refer to those compounds in which the alkyl group bonded to silicon acts as the support to introduce different functional groups which can coordinate the metal center, although few of them have been studied.

Compounds with pendant chains functionalized by phosphine ligands have been reported. Examples are the tridentate mixed donor ligand shown in Scheme 59 [48] and the P-H-functionalized phosphinosilyltetramethylcyclopentadienyl ligands and their dilithium salts [48c].

The isolation of $\mathrm{Zr}\left[\mathrm{P}_{2} \mathrm{Cp}\right] \mathrm{Cl}_{3}$ along with a number of hydrocarbyl zirconium derivatives $\mathrm{Zr}\left[\mathrm{P}_{2} \mathrm{Cp}\right] \mathrm{Cl}_{3-x} \mathrm{R}_{x}\left(\mathrm{R}=\mathrm{Me}, \mathrm{CH}_{2} \mathrm{Ph} ; x=1,2\right)$ has been reported. The phosphine moieties coordinate to the metal, anchoring the cyclopentadienyl unit and modulating its reactivity. These complexes exhibit dynamic behaviour, as observed by variable temperature NMR spectroscopy which shows the presence of species with coordinated and uncoordinated phosphine. When a mixture of the mono-benzyl $\mathrm{Zr}\left[\mathrm{P}_{2} \mathrm{Cp}\right] \mathrm{BzCl}_{2}$ and the tri-benzyl $\mathrm{Zr}\left[\mathrm{P}_{2} \mathrm{Cp}\right] \mathrm{Bz}_{3}$ derivatives was pho-

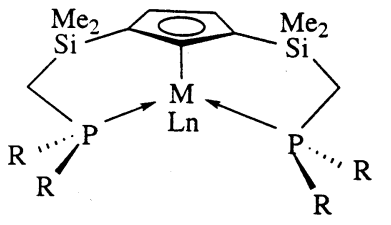

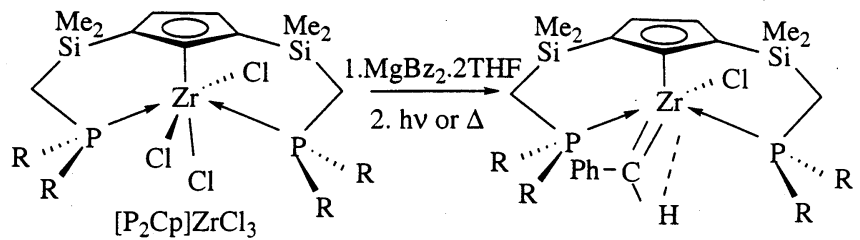


tolized or thermolized, a smooth reaction was observed and the benzylidene $\left[\mathrm{P}_{2} \mathrm{Cp}\right] \mathrm{Zr}=\mathrm{CHPh}(\mathrm{Cl})$ complex was isolated in $85 \%$ yield. This is one of the first examples of authentic alkylidene mononuclear complexes of zirconium formed via an $\alpha$-hydrogen abstraction process.

In the following sections we will only discuss the chemistry of those alkyl-silylcyclopentadienyl metal compounds formed by organic alkyl substituents which can coordinate to the metal center.

\subsection{Silyl-bridged di-and poly-cyclopentadienyl metal complexes}

The presence of a second cyclopentadienyl ring leads to the most important group of complexes of this type.

One of the most widely studied series of electron-deficient early transition metal organometallic compounds is $\mathrm{MCp}_{2}^{*} \mathrm{Cl}_{2}\left(\mathrm{Cp}^{*}=\right.$ unsubstituted or substituted cyclopentadienyl ring) and its derivatives. The two cyclopentadienyl rings in these compounds and their related derivatives typically display a canted arrangement that forms a protective pocket around the metal center. However, under appropriate conditions various investigators have observed that the $\mathrm{Cp}$ ring in these metallocene complexes can actively participate in many different chemical reactions. These processes include $\mathrm{H} / \mathrm{D}$ exchange, ring coupling to give dinuclear fulvalene complexes, ring migration where a cyclopentadienyl ligand simultaneously acts as a $\sigma$ and $\pi$ donor to two metal centers, or ring detachment which accompanies polynuclear metal complexes formation. These widely diverse examples arise from the inherent ability of the ligand to venture across the frontier orbital surface of the metal.

A reasonable strategy to reduce the $\mathrm{Cp}$ participation of the ligand in these side reactions is to link the two rings by an interannular bridge. This stereochemical modification has been successfully employed to moderate the reactivity of a number of cyclopentadienyl compounds.

Several alternatives have been proposed to achieve this objective:

1. an $\mathrm{R}_{2} \mathrm{Si}$ unit bridging the two rings has important effects:

$\circ$ it restricts the mobility of the ring, providing an attractive way to minimize potentially undesirable side reactions.

- varying the alkyl substituent on the silicon atom allows the solubility of the modified metallocenes and their derivatives to be controlled.

$\circ$ the redox behaviour of compounds with this bridging system differs from their unbridged analogues.

o the complexes show higher stability in unusual oxidation states relative to the unbridged metallocene derivatives.

$\circ$ the complexes have applications in stereoregular polymerization of $\alpha$-olefins. 2. siloxane units can be used to bridge the cyclopentadienyl rings.

This strategy has been used to anchor metal complexes that are homogeneous catalysts to polymer supports. This is an area of continuing interest in transition metal chemistry. Cyclopentadienyl ligands are especially efficient as anchoring groups since the metal is strongly bound by the $\eta^{5}$-coordination. This minimizes catalyst leaching under the reaction conditions, and the polymer backbone is 
removed from direct contact with the metal so that undesired side reactions involving $\mathrm{Si}-\mathrm{O}$ bond cleavage are also minimized (see Section 4).

\subsubsection{Synthetic procedures}

6.1.1.1. Transfer of the silyl-cyclopentadienyl ring to a transition metal using an alkali salt. This method, applied to the $\mathrm{CpCp}^{\prime} \mathrm{SiR}_{2}$ system, has been used to synthesize several mononuclear and polynuclear derivatives with attractive properties and applications in several processes.

6.1.1.1.1. Mononuclear compounds. The synthesis of ligand systems with a $\mathrm{Si}-\mathrm{C}$ bond in addition to the $\mathrm{Si}-\mathrm{Cp}$ bond may be carried out by attaching the $-\left(\mathrm{CH}_{2}\right)_{n}-\mathrm{R}$ fragment to the silicon atom. This is achieved via hydrosilylation of the corresponding alkenyl reagent with the silane $\mathrm{R}_{3} \mathrm{Si}-\mathrm{H}$ in the presence of a catalyst (generally a platinum catalyst; Speier reaction) [49]. This method has been used to prepare silanes of the type $\mathrm{MeO}\left(\mathrm{CH}_{2}\right)_{n} \mathrm{Si}(\mathrm{Me}) \mathrm{Cl}_{2}$. The resulting silanes are then reacted with two equivalents of $\mathrm{NaCp}$ to obtain the neutral ligand, which can then be cleanly converted to their dilithium salts by reaction with an excess of $\mathrm{LinBu}$ (Scheme 60).

The lanthanide complexes with these ligands $(\mathrm{R}=\mathrm{OMe})$ were synthesized to investigate the influence of the tethered ether group on their reactivity and catalytic properties in two mechanistically well characterized model processes: 1-hexene hydrogenation and amino-alkene hydroamination/cyclization. The length of the hydrocarbon tether necessary for coordination to the lanthanide center was estimated using theoretical calculations. Depending upon the assumed details of the coordination configuration, a $\mathrm{C}_{3}-\mathrm{C}_{5}$ tether length was judged to be optimal.

The donor functionality has been found to exert a strong influence on the catalytic activity of these complexes. For catalytic conversions of weakly donating substrates, the activity is decreased. Apparently, one or more of the substrates cannot compete with the methoxo group of the ligand for the vacant coordination site on the metal center, resulting in decreased activity compared to the unfunctionalized systems. In contrast, with strong Lewis base substrates the activity increases. Here the methoxo group does not block the metal center because the substrates have a higher Lewis base strength, but rather it may alter the polarity of the medium next to the metal center.

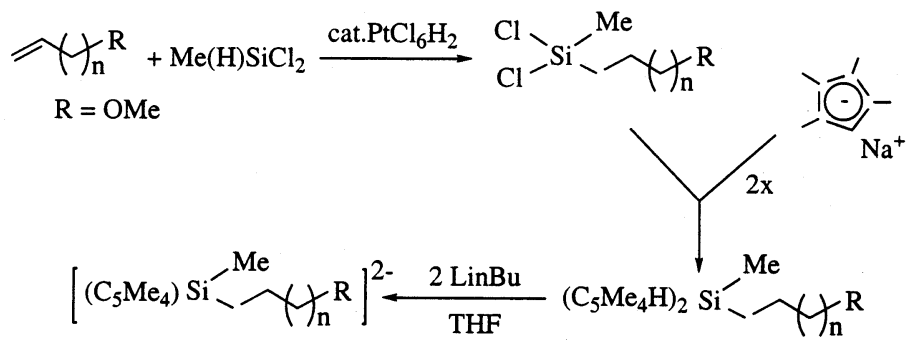

Scheme 60 . 
$\left(\mathrm{C}_{2} \mathrm{H}_{5} \mathrm{O}\right)_{3} \mathrm{Si}\left(\mathrm{CH}_{2}\right) \mathrm{nCl}+\mathrm{NaC}_{5} \mathrm{H}_{5} \longrightarrow\left(\mathrm{C}_{2} \mathrm{H}_{5} \mathrm{O}\right)_{3} \mathrm{Si}\left(\mathrm{CH}_{2}\right) \mathrm{nC}_{5} \mathrm{H}_{5}+\mathrm{NaCl}$

Scheme 61.

Interest has been focused on the preparation of silicon-substituted cyclopentadienyl compounds as modifiers that can functionalize inorganic supports with cyclopentadienyl groups located at varying distances from the support surface. The procedure is illustrated with examples of the compounds $\left(\mathrm{C}_{2} \mathrm{H}_{5} \mathrm{O}\right)_{3} \mathrm{Si}\left(\mathrm{CH}_{2}\right)_{n}\left(\mathrm{C}_{5} \mathrm{H}_{5}\right)(n=1$ and 3) [50] (Scheme 61).

Early transition metal-alkyl complexes that contain cyclopentadienyl ancillary ligands have been involved in many catalytic processes including olefin polymerization and oligomerization.

Stereorigid chiral ansa metallocene complexes have been established as excellent homogeneous catalysts for the stereoespecific polymerization of $\alpha$-olefins to polymers with stereoregular microstructures. Various parameters could control the activity of the catalyst and the stereoespecificity of the polymerization reaction. It has been shown that for the metallocene dichloride complex $C_{\mathrm{s}}$ symmetry is a necessary but not sufficient condition for the production of syndiotactic polyolefins whereas $C_{2}$ symmetry is the required condition for isotacticity. The influence of the bridge in the ansa metallocene on the catalytic olefin polymerization was thought to be minor since it is remote from the coordination sphere of the metal center. However, the nature of the substituent in the bridge could have a strong influence on activity and stereoselectivity in the propylene polymerization reaction.

The effects of substituents in the bridge on polymerization behaviour have been investigated and some ansa-cyclopentadienyl fluorenyl complexes $\mathrm{Zr}\left[\left(\mathrm{C}_{13} \mathrm{H}_{6} \mathrm{R}_{2}\right) \mathrm{EX}_{2^{-}}\right.$ $\left.\left(\mathrm{C}_{5} \mathrm{H}_{4}\right)\right] \mathrm{Cl}_{2}\left(\mathrm{E}=\mathrm{Si}, \mathrm{Ge} ; \mathrm{R}=\mathrm{H},{ }^{t} \mathrm{Bu}\right)$ have been reported [51] (Scheme 62).

These compounds, when activated with methylalumoxane (MAO), show a significant decrease in stereoregularity for propylene polymerization compared to $\mathrm{Zr}\left[\left(\mathrm{C}_{13} \mathrm{H}_{8}\right) \mathrm{CMe}_{2}\left(\mathrm{C}_{5} \mathrm{H}_{4}\right)\right] \mathrm{Cl}_{2}$ and there is no obvious explanation for this behaviour. A comparison of the syndiotacticities of the polypropylene produced using these compounds with those reported for analogous carbon bridged complexes shows that the tacticity decreases in the order $\mathrm{C}>\mathrm{Si}>\mathrm{Ge}$. The presence of $\mathrm{SiMe}_{2}$ or $\mathrm{SiPh}_{2}$ in the ansa position shows only a small difference $(2 \%)$ in syndiotactic block lengths. Differences in activity and molecular weight are more pronounced. The complex with

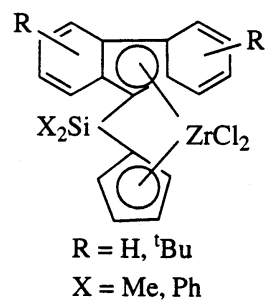

Scheme 62 . 
the $\mathrm{SiMe}_{2}$ unit produces a polymer with a higher molecular weight, while the $\mathrm{SiPh}_{2}$ unit shows a higher activity.

In order to better understand the role played by the bridged system in the ansa metallocene catalyst precursors, rac- and meso- $\mathrm{Zr}\left[\left(\mathrm{CH}_{2}\right)_{4} \mathrm{Si}\left(\mathrm{C}_{9} \mathrm{H}_{6}\right)\right]_{2} \mathrm{Cl}_{2}$ and rac$\mathrm{Zr}\left[\left(\mathrm{CH}_{2}\right)_{4} \mathrm{Si}\left(\mathrm{C}_{9} \mathrm{H}_{10}\right)\right]_{2} \mathrm{Cl}_{2}$ have been synthesized [52] (Scheme 63) and used to polymerize propene and ethene. rac- $\mathrm{Zr}\left[\left(\mathrm{CH}_{2}\right)_{4} \mathrm{Si}\left(\mathrm{C}_{9} \mathrm{H}_{6}\right)\right]_{2} \mathrm{Cl}_{2}$ was used to copolymerize ethene-propene. The polymerizations have been described in detail by Tsai and Chien [53].

The 4-ansa metallocene $\mathrm{M}\left[\eta^{5}-\mathrm{C}_{5} \mathrm{H}_{4} \mathrm{SiMe}_{2} \mathrm{CH}_{2}\right]_{2} \mathrm{Cl}_{2}$ derivatives, in which the ligand framework is stabilized by an interannular 1,1,4,4-tetramethyl-1,4-disilabutylene chelate ring, were prepared by the reaction of $\mathrm{Li}_{2}\left[\mathrm{C}_{5} \mathrm{H}_{4} \mathrm{SiMe}_{2} \mathrm{CH}_{2}\right]_{2}$ with $\mathrm{MCl}_{4}$ ( $\mathrm{M}=\mathrm{Ti}, \mathrm{Zr}, \mathrm{Hf})$ [54] (Scheme 64).

These compounds are the only isolated products obtained following extraction of the reaction residue with dichloromethane. They are monomeric, as evidenced by cryoscopic molecular weight determinations in benzene. Their ${ }^{1} \mathrm{H}-\mathrm{NMR}$ spectra show the presence of an $\mathrm{AA}^{\prime} \mathrm{BB}^{\prime}$ spin system for the cyclopentadienyl protons.

In certain applications, it would be desirable to be able to vary substituents at the bridgehead atom of the ansa-metallocene compounds. For example, a ligand with a $\mathrm{Cl}_{2} \mathrm{Si}$ linkage could be attached to an inorganic support. A bridging group of the type $\mathrm{R}_{2} \mathrm{Si}$ where $\mathrm{R}$ is a long chain alkyl group would impart hydrocarbon solubility to the metallocene compound. Metallocenes linked by silacycloalkanes were obtained via the reaction of a $\mathrm{Cl}_{2} \mathrm{Si}$ bridged complex with $\mathrm{Li}\left(\mathrm{CH}_{2}\right)_{n} \mathrm{Li}[19 \mathrm{~m}]$.

6.1.1.1.2. Dinuclear compounds. Dimetallic complexes have recently received considerable attention because they have the potential to exhibit cooperative electronic

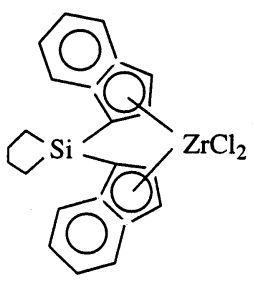

rac- and meso-

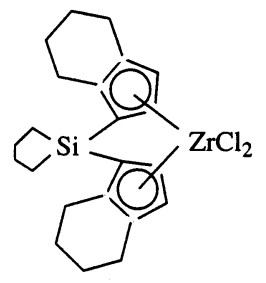

rac-

Scheme 63 .

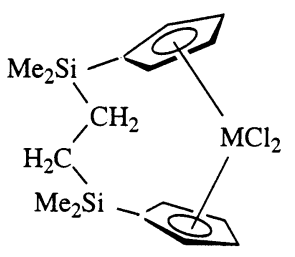

Scheme 64. 
and chemical effects. These effects can strongly influence their reactivity and could be useful in catalysis. Dinuclear metallocenes can be made by linking two $M C p_{2} R_{2}$ units with either one or more bridges, which comprise silicon fragments with a $\mathrm{Si}-\mathrm{Cp}$ bond, between the cyclopentadienyl ligands. The choice of ligand allows the distance between the two metal centers to be controlled.

Rotation around the $\mathrm{Si}-\mathrm{Cp}$ bond in a monobridged dimetallic complex may occur, thus the relative orientation of the two metal centers can vary in an uncontrolled manner. However, two $\mathrm{SiR}_{2}$ bridges between the $\mathrm{Cp}$ rings would result in a less flexible system in which the metals could bind to the same (cis) or opposite (trans) faces of the ligand.

Cooperative reactivity in a catalytic cycle may depend on the orientation (cis or trans) and the relative distance between the metal centers in the dimetallic complexes. The distance may be influenced by the effective length and flexibility of the bridge between the $\mathrm{Cp}$ rings. If this length is too great, the two metal centers may not interact cooperatively. If the length is short, the metal centers may be too sterically crowded to interact.

Two isomers (boat and chair conformations) of 4,4,8,8-tetramethyltetrahydro-4,8disila-s-indacene are known [19a, 20, 21b, 55]. They can be deprotonated under various conditions to give either the monoanionic or dianionic derivative [10i]. The most convenient route is the three-step procedure summarized in Scheme 65 .

The monoanion derivative is obtained as a mixture of enantiomers. Temperaturedependent NMR spectroscopy showed these two monoanion enantiomers to undergo both a degenerate and a nondegenerate silatropic rearrangement with an energy barrier of $E_{\mathrm{a}}=48.5 \mathrm{~kJ} \mathrm{~mol}^{-1}$.

Monobridged and dibridged bimetallic titanium and zirconium complexes $[\mu-$ $\left.\mathrm{X}_{n}\left(\mathrm{C}_{5} \mathrm{R}_{x}\right)_{2}\right]\left[\mathrm{MCpCl}_{2}\right]_{2}\left[\mathrm{X}=\mathrm{SiMe}_{2}(\mathrm{M}=\mathrm{Ti}, \mathrm{Zr} ; n=1(\mathrm{R}=\mathrm{H}, x=4), 2(\mathrm{R}=\mathrm{H}, \mathrm{Me}\right.$, $x=3)) ; \quad \mathrm{X}=\mathrm{Me}_{2} \mathrm{SiCH}_{2} \mathrm{SiMe}_{2} \quad(\mathrm{M}=\mathrm{Ti} ; \quad n=1 ; \quad \mathrm{R}=\mathrm{H}, \quad x=4) ; \quad \mathrm{X}=\mathrm{Me}_{2} \mathrm{SiCH}_{2}-$ $\left.\mathrm{CH}_{2} \mathrm{SiMe}_{2}(\mathrm{M}=\mathrm{Ti}, \mathrm{Zr} n=1 ; \mathrm{R}=\mathrm{H}, x=4)\right]$ have been synthesized using these alkaline salts (Scheme 66). Their catalytic activity in the dehydrocoupling of $\mathrm{PhSiH}_{3}$ to polyphenylsilane has been studied [56].

Deprotonation of dicyclopentadienyl dimethylsilane with $n$-butyllithium followed by reaction with dichlorodisilane and treatment with $\mathrm{LinBu}$ and $\mathrm{ZrCp}^{\prime} \mathrm{Cl}_{3}$ gives similar dinuclear derivatives [57] (Scheme 67).

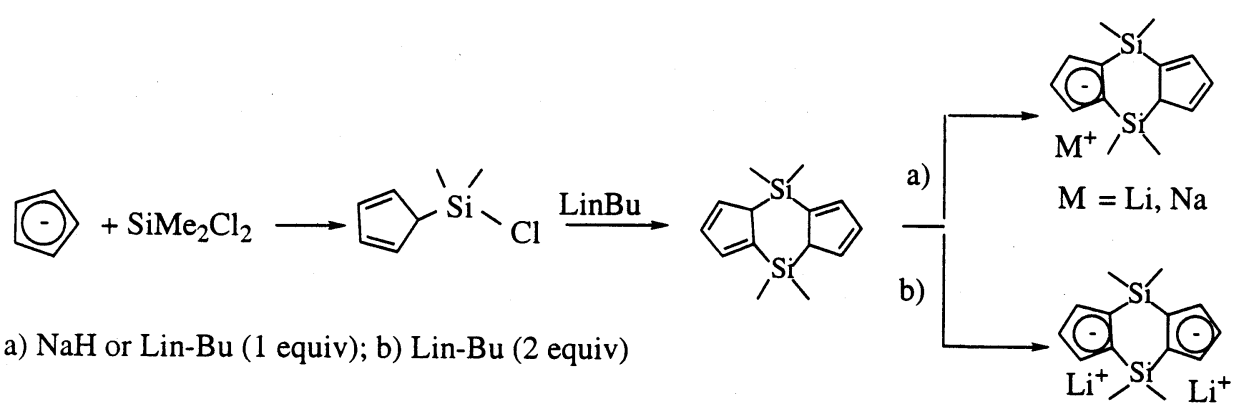



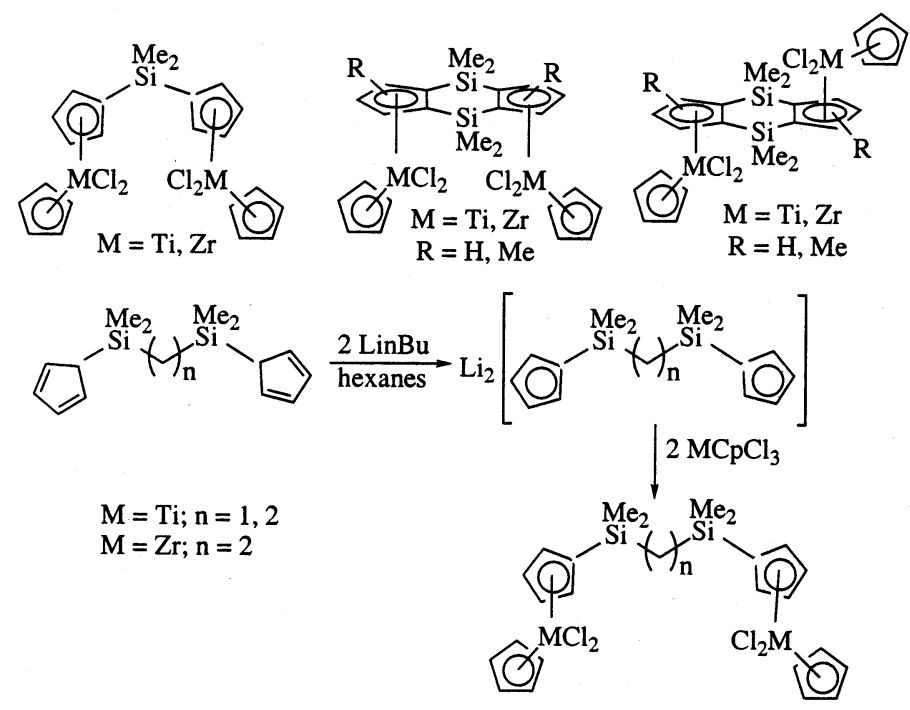

Scheme 66.

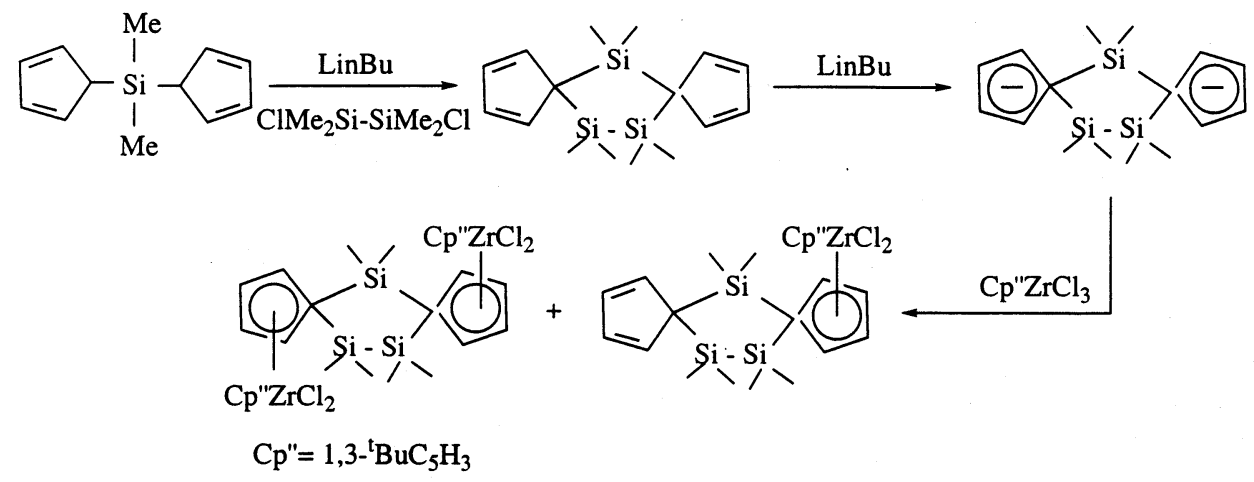

Scheme 67.

6.1.1.1.3. Polynuclear compounds. Polycyclopentadienyl molecules are of interest as polydentate ligands. They can stabilize polynuclear complexes in which novel properties may result from cooperation between the metal centers held in close proximity. Ligands containing two (fulvalene, $\mathrm{CpCH}_{2} \mathrm{Cp}$ ) or three cyclopentadienyl rings are known and examples with a $\mathrm{Cp}-\mathrm{Si}-\mathrm{C}$ unit have been described. They include the $\mathrm{Cp}-\mathrm{Si}-\mathrm{Cp}$ and $\operatorname{aryl}\left(\mathrm{SiMe}_{2} \mathrm{Cp}\right)_{n}(n=2,3)$ ligands.

The synthesis of compounds containing two or three cyclopentadienyl groups linked to an aromatic backbone has been reported [58]. The arylsilyl halide precursors were prepared as outlined in Scheme 68. 


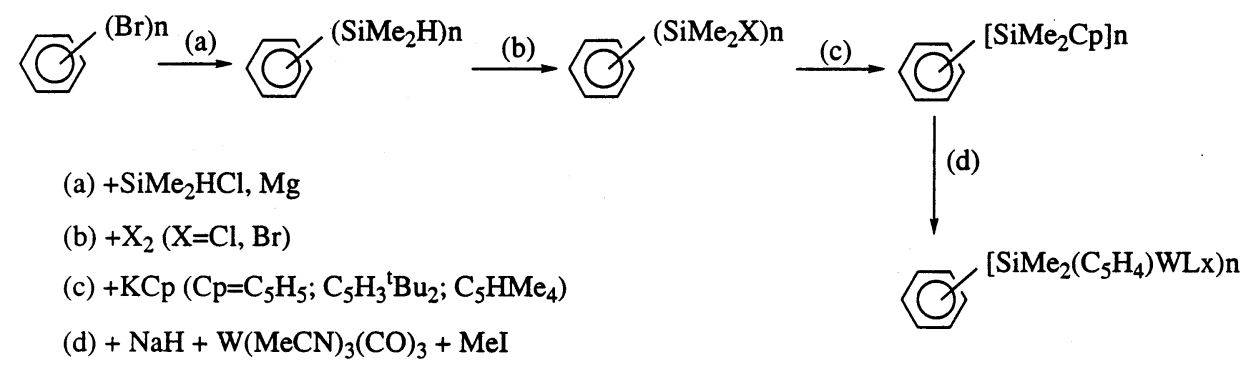

Scheme 68 .

The halide can be replaced by various cyclopentadienides to give aryldimethylsilylcyclopentadienes of the general type $\mathrm{C}_{6} \mathrm{H}_{6-n}\left(\mathrm{SiMe}_{2} \mathrm{C}_{5} \mathrm{H}_{5}\right)_{n}(n=1,2,3)(\mathrm{Scheme}$ 68).

These compounds were used to make, under the appropriate conditions, $\eta^{5}$ bound tungsten complexes containing up to three half-sandwich units within one molecule (Scheme 69).

6.1.1.2. Alcoholysis of silicon-silicon bonds. The selective alcoholysis of the $\mathrm{Si}-\mathrm{Si}$ bond in silyl substituted cyclopentadienyl ferrocene derivatives takes place under mild conditions in the presence of $\mathrm{FeCl}_{3}$ in strictly oxygen-free conditions or in 0.05 $\mathrm{M} \mathrm{HCl}$ (at a higher $\mathrm{HCl}$ concentration desilylation resulted to give ferrocene) [59] (Scheme 70).

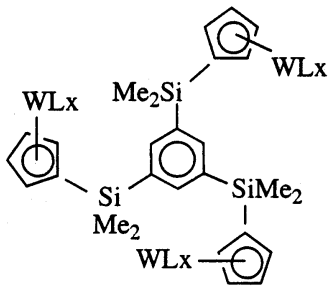

Scheme 69.

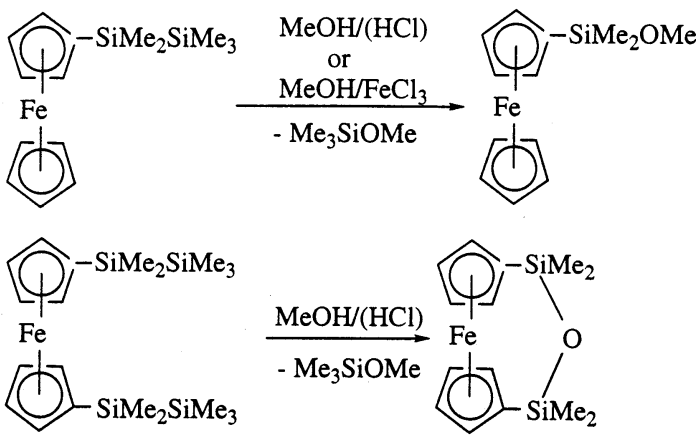

Scheme 70 . 


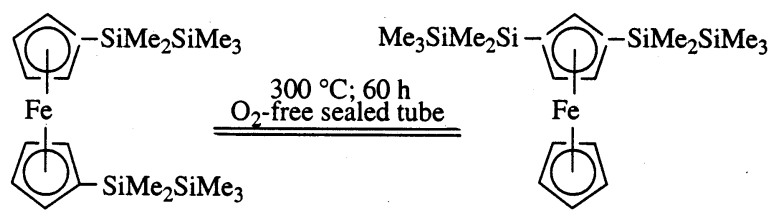

Scheme 71.

Mechanistic studies show the formation of ferricenium ion intermediates arising from a redox reaction. In contrast to the uncharged ferrocenyl group, the ferricenium cationic unit is electron withdrawing which makes the $\beta$ silicon atom susceptible to nucleophilic attack by methanol, with respect to the ferrocene ring.

Compounds of this type show another interesting, although not yet well understood, reaction involving reversible isomerization from a heteroannularly silyl substituted to homoannularly bis-silyl substituted disposition (Scheme 71).

\subsection{Alkenyl-silyl-cyclopentadienyl metal complexes}

In a recent contribution to the study of the cationic $\mathrm{d}^{0}$ dicyclopentadienyl Group 4 metal-alkene complexes as the active species in olefin polymerization processes a cyclopentadienyl ligand that contained a silylallyl pendant chain with a terminal olefinic moiety was used [60]. Compared to similar alkyl pendant chains [61], the higher acidity and fluxionality of the silyl substituent favors coordination of the alkene when the cationic center is formed by reaction of the dialkyl metallocene with $\mathrm{B}\left(\mathrm{C}_{6} \mathrm{~F}_{5}\right)_{3}$.

As shown in Scheme 72 the mixed dicyclopentadienyl dichloro zirconium complex was isolated from the reaction of the lithium salt of the ligand with $\left[\mathrm{ZrCpCl}_{3}\right] \cdot \mathrm{DME}$ and was further alkylated with $\mathrm{Mg}\left(\mathrm{CH}_{2} \mathrm{C}_{6} \mathrm{H}_{5}\right)_{2} \cdot 2 \mathrm{THF}$. Reaction of the dibenzylzirconium derivative with $\mathrm{B}\left(\mathrm{C}_{6} \mathrm{~F}_{5}\right)_{3}$ yielded the alkene-coordinated cation as evidenced by NMR spectroscopy. The four multiplets between $\delta 1.81$ and

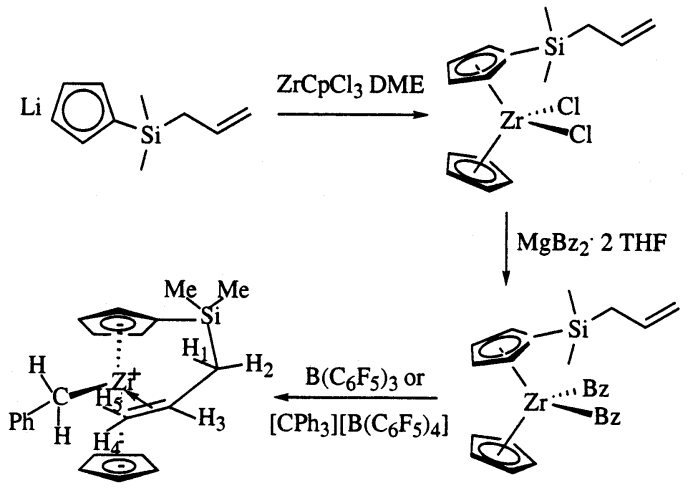

Scheme 72 . 
$\delta 2.78$ were attributed to the terminal olefinic and silicon bonded methylenic protons and the multiplet at $\delta 7.30$ was attributed to the internal olefinic proton. The typical vinylic signals between $\delta 4.90$ and $\delta 5.60$ found for the starting neutral complex were absent. Similar behaviour was observed in the ${ }^{13} \mathrm{C}-\mathrm{NMR}$ spectra. Variable temperature ${ }^{1} \mathrm{H}-\mathrm{NMR}$ spectroscopic studies show intramolecular interconversion between the two enantiomers through a transition state with $C_{\mathrm{s}}$ symmetry for which the kinetic parameters $\left(\log A=14.4 \pm 0.5, E_{\mathrm{a}}=13.4 \pm 0.54 \mathrm{kcal} \mathrm{mol}^{-1}\right.$, $\Delta H^{\#}=12.9 \pm 0.53 \mathrm{kcal} \mathrm{mol}^{-1}, \Delta S^{\#}=5.0 \pm 2.3 \mathrm{cal} \mathrm{K}^{-1} \mathrm{~mol}^{-1}, \Delta G_{298 \mathrm{~K}}^{\#}=11.4$ $\mathrm{kcal} \mathrm{mol}^{-1}$ ) were calculated. A metal-alkene interaction results in delocalized electron density in the $\mathrm{Zr}-\mathrm{C}-\mathrm{C}$ system, favored by the known silicon $\beta$-effect, which is similar to that observed for classical allyl cations.

Similar studies have been extended more recently to other Group 4, 5 and 6 metal compounds [62].

\section{Boron-silyl-cyclopentadienyl metal complexes (type VI)}

The primary synthetic approach to borylated metallocenes is to attach the reactive boryl substituents to neutral cyclopentadienes by $\mathrm{B}-\mathrm{Si}$ or $\mathrm{B}-\mathrm{Sn}$ metathesis prior to metal complexation. Cyclopentadienyl anions are, however, functionally incompatible with $\mathrm{BX}_{2}$ groups which have labile $\mathrm{X}$ ligands such as $\mathrm{Cl}$ or $\mathrm{Br}$. It is possible to avoid this incompatibility by incorporating a trimethylsilyl substituent onto the cyclopentadiene ring. Subsequent reaction with early transition metal halides then affords the desired borylated $\mathrm{Cp}$ complex with elimination of chlorotrimethylsilane.

Alternatively, boryl groups can be attached to the ligands already coordinated to the transition metal [33].

\section{Structural aspects}

All of the metal complexes containing one silyl-cyclopentadienyl ligand characterized by X-ray crystallography belong to the known mono- and di-cyclopentadienyl structural types with no important modifications derived from the presence of the silyl-substituent in the cyclopentadienyl ring.

The monocyclopentadienyl titanium complexes show a three-legged piano-stool structure whereas the second- and third-row metal derivatives have di- or poly-nuclear structures, which expand the coordination sphere to give a pseudo-octahedral geometry. The dicyclopentadienyl complexes show the typical bent ring disposition with the auxiliary ligands located in the dihedral plane.

Representative examples [28b, 28d, 30b, 30c, 45, 46a] are shown in Figs. 1 and 2 for different titanium, zirconium and niobium compounds.

A partial loss of the $\eta^{5}$-character of the cyclopentadienyl ligand due to the redistribution of the electron density in the ring is usually observed. This is shown by differences in metal-carbon and carbon-carbon ring bond distances. The silicon 
atom is essentially located in the ring plane as expected for a $\mathrm{Si}-\mathrm{C}_{\mathrm{sp}^{2}}$ bond, and the distance from the $\mathrm{Si}$ atom to this plane is between 0.06 and $0.10 \mathrm{~A}$.

A remarkable structural feature of these complexes is the absence of compounds with a chelating $\mathrm{Cp}-\mathrm{Si}-\mathrm{O}$ unit. This contrasts with the large number of known examples with amido-cyclopentadienyl ligands containing similar $\mathrm{Cp}-\mathrm{Si}-\mathrm{N}$ units $[3,47]$, which coordinate to the metal centers as chelating ligands. This disposition is favored by the overlap of the amido $\mathrm{sp}^{2}$ nitrogen $\mathrm{p}_{\pi}$ orbital with the appropriate metal and silicon $\mathrm{d} \pi$ orbitals, whereas in the $\mathrm{Cp}-\mathrm{Si}-\mathrm{O}$ fragment, there is better

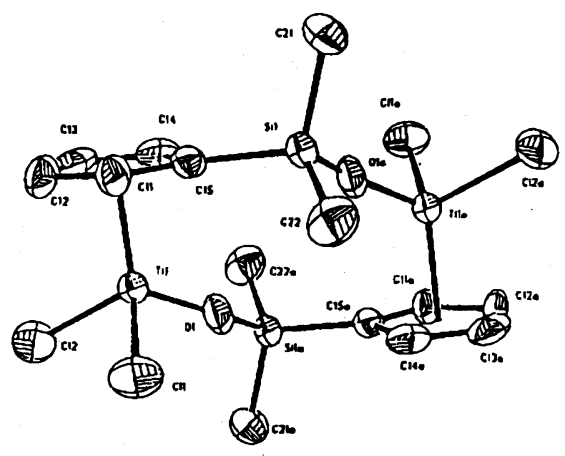

$\left[\mathrm{Ti}\left\{\eta^{5}-\mathrm{C}_{5} \mathrm{H}_{4} \mathrm{SiMe}_{2}(\mu-\mathrm{O})\right\} \mathrm{Cl}_{2}\right]_{2}$

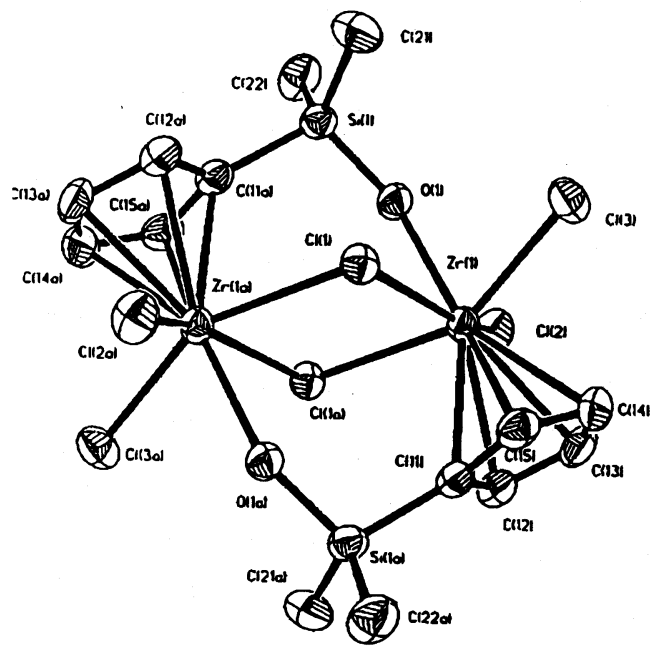

$\left[\mathrm{Zr}\left\{\eta^{5}-\mathrm{C}_{5} \mathrm{H}_{4} \mathrm{SiMe}_{2}(\mu-\mathrm{OH})\right\}(\mu-\mathrm{Cl}) \mathrm{Cl}_{2}\right]_{2}$

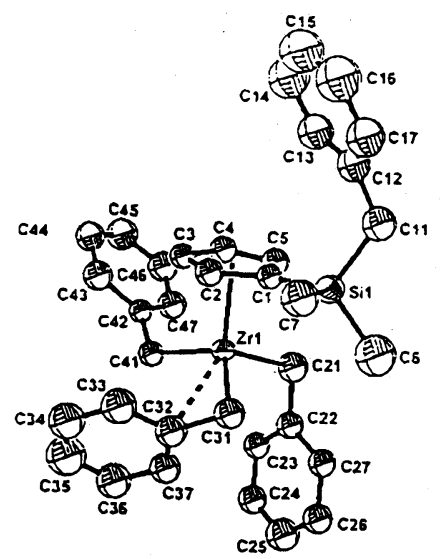

$\left[\mathrm{Zr}\left(\eta^{5}-\mathrm{C}_{5} \mathrm{H}_{4} \mathrm{SiMe}_{2} \mathrm{CH}_{2} \mathrm{Ph}\right)\left(\mathrm{CH}_{2} \mathrm{Ph}\right)_{3}\right]$

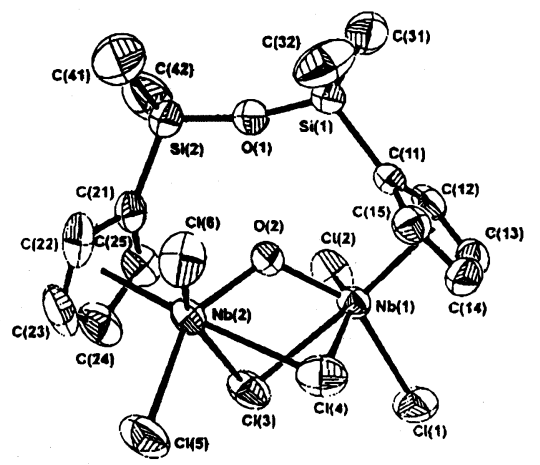

$\left[\mathrm{Nb}_{2}\left\{\left(\eta^{5}-\mathrm{C}_{5} \mathrm{H}_{4} \mathrm{SiMe}_{2}\right)_{2}(\mu-\mathrm{O})\right\}(\mu-\mathrm{Cl})_{2}(\mu-\mathrm{O}) \mathrm{Cl}_{4}\right]$

Fig. 1. 


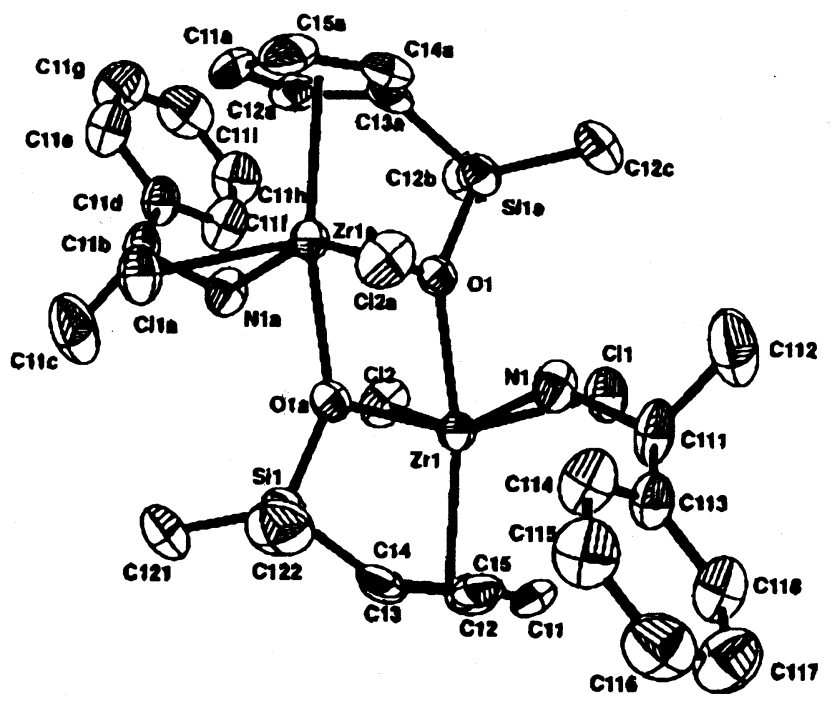

$\left[\mathrm{Zr}\left\{\eta^{5}-\mathrm{C}_{5} \mathrm{H}_{4} \mathrm{SiMe}_{2}(\mu-\mathrm{O})\right\} \mathrm{Cl}_{2}\left\{\mathrm{H}_{2} \mathrm{~N}(\mathrm{CHMe}) \mathrm{P}\right.\right.$

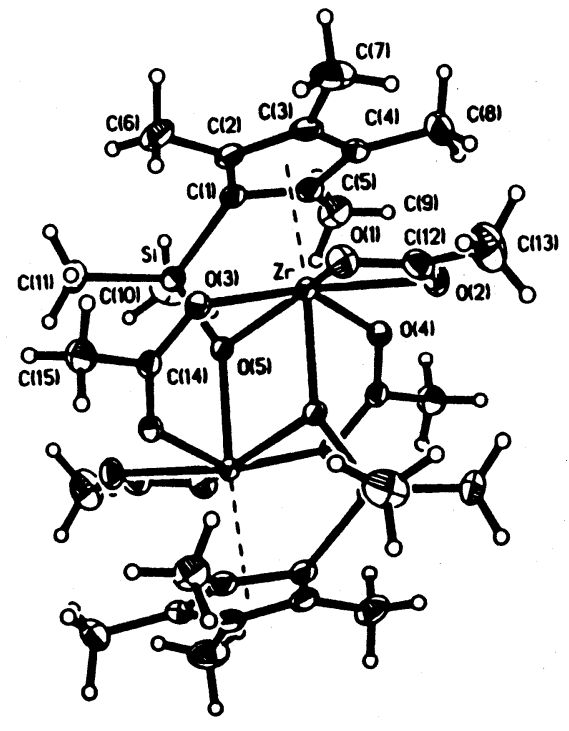

$\left.\left[\mathrm{Zr}\left(\eta^{5}-\mathrm{C}_{5} \mathrm{Me}_{4}\right) \mathrm{SiMe} \mathrm{e}_{2} \mathrm{O}\right\}\left(\eta^{2}-\mathrm{O}_{2} \mathrm{CMe}\right)\left(\mu-\mathrm{O}_{2} \mathrm{CMe}\right)\right]_{2}$

Fig. 2. 
$\pi$-bonding resulting from a linear disposition, which favors the formation of almost linear $\mathrm{Si}-\mathrm{O}-\mathrm{M}$ bridges and gives dinuclear compounds. However, four-membered $\mathrm{Cp}-\mathrm{Si}-\mathrm{O}-\mathrm{M}$ rings can be formed simultaneously in these dimers when bulkier metal atoms demand that additional, essentially single $\sigma$-bonds be formed to complete a pseudo-octahedral environment.

Solution studies by NMR spectroscopy provide the most efficient means to assign the molecular structure of these compounds. ${ }^{1} \mathrm{H}-\mathrm{NMR}$ spectra of all complexes containing the silicon atom located in a molecular plane of symmetry show the expected resonances of the cyclopentadienyl ring protons as two sets of pseudotriplets due to an $\mathrm{AA}^{\prime} \mathrm{BB}^{\prime}$ spin system, and the appropriate signals for the equivalent alkyl groups bonded to the silicon atom. When this plane is not present, the $\mathrm{C}_{5} \mathrm{H}_{4}$ protons are observed as four multiplets indicative of an ABCD spin system, and in the same way the two identical alkyl groups bonded to silicon exhibit diastereotopic behaviour and give two groups of signals in the ${ }^{1} \mathrm{H}-\mathrm{NMR}$ spectra. Characteristic ranges for ${ }^{1} \mathrm{H}$ chemical shifts, governed by the nature of the $\mathrm{X}$ substituent, for silicon bonded methyl groups in the $\mathrm{Cp}-\mathrm{SiMe}_{2}-\mathrm{X}$ unit have been observed.

$$
\begin{aligned}
& \mathrm{X}=\mathrm{H}: 0.10<\delta^{1} \mathrm{H}<0.30 \\
& \mathrm{X}=\mathrm{Cl}: 0.45<\delta{ }^{1} \mathrm{H}<0.80 \\
& \mathrm{X}=\mathrm{O}: 0.20<\delta^{1} \mathrm{H}<0.40 \\
& \mathrm{X}=\mathrm{N}: 0.00<\delta^{1} \mathrm{H}<0.40
\end{aligned}
$$

Similarly, the ${ }^{13} \mathrm{C}-\mathrm{NMR}$ data are consistent with these spectroscopic characteristics.

The value of $\Delta \delta=\delta_{\mathrm{d}}-\delta_{\mathrm{p}}\left(\delta_{\mathrm{d}}\right.$ and $\delta_{\mathrm{p}}$ being the chemical shifts of the distal and proximal protons with respect to the silyl-bonded Cipso of the cyclopentadienyl ring, respectively) has been used as a spectroscopic parameter to distinguish the coordination modes of the silyl-substituted cyclopentadienyl ligands. Lower values of $\Delta \delta$ can be attributed to non-bridging coordination or to the presence of large interannular bridges which allow less constrained geometry than shorter interannular bridges. The electronic and steric features shown by the ansa-derivatives with large interannular bridges are similar to those found for non-bridged analogues with substituted cyclopentadienyl ligands. In both types of complexes similar values of $\Delta \delta$ have been obtained, indicating in this case that this spectroscopic parameter cannot be used to distinguish between the dispositions of the two cyclopentadienyl ligands. However, the relative ${ }^{13} \mathrm{C}$ chemical shifts of the cyclopentadienyl ring $\mathrm{C}_{i p s o}$ can be used to distinguish between different types of coordination. It has been observed that in chelating compounds, this resonance appears at higher fields than the proximal and distal carbon resonances of the same ring, while for a bridging coordination mode in dinuclear derivatives or for unbridged mononuclear substituted metallocene analogues, the reverse was observed. This feature has been explained, in the first case, as the result of a redistribution of the $\pi$-electron density of the ring caused by the silicon atom. This causes the $\mathrm{C}_{\mathrm{ipso}}$ atom to be shielded but 
the remaining ring carbon atoms to be deshielded. In contrast, complexes with an interannular hydrocarbon link do not present this spectroscopic behaviour for the $\mathrm{C}_{\text {ipso }}$ atom.

\section{Acknowledgements}

Financial support by DGICYT (Project PB97-0776) is gratefully acknowledged.

\section{References}

[1] (a) P.L. Pauson, T.J. Kealy, Nature 168 (1951) 1039. (b) S.A. Miller, T.A. Tebboth, J.F. Tremaine, J. Chem. Soc. (1952) 632.

[2] F.G.A. Stone, G. Wilkinson, E.W. Abel (Eds.), Comprehensive Organometallic Chemistry, Pergamon, London, 1982.

[3] (a) P. Jutzi, J. Organomet. Chem. 400 (1990) 1. (b) N.J. Coville, K.E. du Plooy, W. Pick1, Coord. Chem. Rev. 116 (1992) 1. (c) R. Poli, Chem. Rev. 91 (1991) 509. (d) R.L. Halterman, Chem. Rev. 92 (1992) 965. (e) N.J. Long, Metallocenes. An Introduction to Sandwich Complexes, Blackwell Science, Oxford, 1998. (f) A. Togni, R.L. Halterman (Eds.), Metallocenes. Synthesis, Reactivity, Aplications, vol. 1, Wiley-VCH, Weinheim, 1998.

[4] (a) M. Bottril, P.D. Gavens, J.W. Kelland, J. McMeeking, in: G. Wilkinson, F.G.A. Stone, E.W. Abel (Eds.), Comprehensive Organometallic Chemistry, Pergamon, Oxford, 1982. (b) A. Togni, R.L. Halterman (Eds.), Metallocenes. Synthesis, Reactivity, Aplications, vol. 2, WileyVCH, Weinheim, 1998.

[5] (a) P.C. Möhring, N.J. Coville, J. Organomet. Chem. 479 (1994) 1. (b) H.H. Brintzinger, D. Fischer, R. Mulhaupt, R. Rieger, R.M. Waymouth, Angew. Chem. Int. Ed. Engl. 34 (1995) 1143. (c) M. Bochmann, J. Chem. Soc. Dalton Trans. (1996) 255.

[6] (a) H. Koepf, P. Koepf-Maier, Angew. Chem. Int. Ed. Engl. 18 (1979) 477. (b) P. Koepf-Maier, H. Koepf, Chem. Rev. 87 (1987) 1137. (c) P. Koepf-Maier, H. Koepf, J. Organomet. Chem. 342 (1988) 277).

[7] (a) F. Nief, L. Ricard, F. Mathey, Organometallics 8 (1989) 1473 and references therein. (b) D.W. Macomber, W.P. Hart, M.D. Rausch, Adv. Organomet. Chem. 21 (1982) 1.

[8] (a) J.C. Stevens, F.J. Timmers, D.R. Wilson, G.F. Schmidt, P.N. Nickias, R.K. Rosen, G.W. Knight, S. Lai, Eur. Pat. Appl. EP 416815, Dow, 1991, Chem. Abstr. 115 (1991) 93163. (b) J.M. Canich, G.G. Hlatky, H.W. Turner, USA Patent 542236, Exxon, 1990.

[9] A. Cano, T. Cuenca, P. Göómez-Sal, A. Manzanero, P. Royo, J. Organomet. Chem. 526 (1996) 227 and references therein.

[10] (a) N.M. Sergeyev, G.I. Avramenko, A.V. Kisin, V.A. Korenevsky, Y.A. Ustynyuk, J. Organomet. Chem. 32 (1971) 55. (b) E.W. Abel, M.O. Dunster, J. Organomet. Chem. 33 (1971) 161. (c) P. Jutzi, R. Sauer, J. Organomet. Chem. 50 (1973) C29. (d) A. Bonny, S.R. Stobart, P.C. Angus, J. Chem. Soc. Dalton Trans. (1978) 938. (e) A. Bonny, S.R. Stobart, J. Chem. Soc. Dalton Trans. (1980) 224. (f) A.D. McMaster, S.R. Stobart, Inorg. Chem. 19 (1980) 1178. (g) E.M. Schulman, A.E. Merbach, M. Turin, R. Wedinger, W.J. le Noble, J. Am. Chem. Soc. 105 (1983) 3988. (h) P. Jutzi, Chem. Rev. 86 (1986) 983. (i) J. Hiermeier, F.H. Köhler, G. Müller, Organometallics, 10 (1991) 1787. (j) V.S. Shriro, Y.A. Strelenko, Y.A. Ustynyuk, N.N. Zemlyansky, K.A. Kocheshkov, J. Organomet. Chem. 117 (1976) 321.

[11] V.I. Koshutin, L.N. Maksimova, V.I. Emyashev, V.A. Smirrnov, Zh. Obshch. Kim. 46 (1976) 146. 
[12] G. Ciruelo, T. Cuenca, R. Gómez, P. Gómez-Sal, A. Martín P. Royo, results not published.

[13] G. Ciruelo, T. Cuenca, A. Fernández, P. Gómez-Sal, P. Royo, results not published.

[14] E. Colomer, R.J.P. Corriu, R. Pleixats, J. Organomet. Chem. 381 (1990) C1.

[15] K. Sünkel, S. Schubert, J. Hofmann, J. Organomet. Chem. 541 (1997) 199.

[16] K. Sünkel, J. Hofmann, Organometallics 11 (1992) 3923.

[17] H. Lang, S. Blau, A. Muth, K. Weiss, U. Neugebauer, J. Organomet. Chem. 490 (1995) C32.

[18] M. Dössmar-Wolf, Gmelin Handbook of Inorganic Chemistry, Organoiron Compounds Part A, Ferrocene 9, 8th ed., Springer-Verlag, Berlin, 1989, pp. 305.

[19] (a) R.L. Schaaf, P.T. Kan, C.T. Lenk, E.P. Deck, J. Org. Chem. 25 (1960) 1986. (b) I.M. Shologon, M.K. Romantsevich, Zh. Obshch. Khim. 36 (1966) 1846 (Chem. Abstr. 66 (1967) 66, 76075). (c) I.M. Shologon, M.K. Romantsevich, S.V. Kul'kova, Zh. Obshch. Kim. 37 (1967) 2315 (Chem. Abstr. 68 (1969) 73299). (d) J. Okuda, Chem. Ber. 123 (1990) 1649. (e) R.E. Spence, W.E. Piers, Organometallics, 14 (1995) 4617. (f) Y. Mu, W.E. Piers, D.C. MacQuarrie, M.J. Zaworotko, V.G. Young, Organometallics, 15 (1996) 2720. (g) D. Stern, M. Sabat, T.J. Marks, J. Am. Chem. Soc. 112 (1990) 9558. (h) P. Jutzi, T. Heideman, B. Neuman, H.G. Stammler, J. Organomet. Chem. 472 (1994) 27. (i) C.M. Fendrick, L.D. Schertz, V.W. Day, T.J. marks, Organometallics 7 (1988) 1828. (j) I.V. Borisova, Yu. N. Luzikov, N.N. Zemlyansky, Yu. A. Ustynyuk, I.P. Beletskaya, J. Organomet. Chem. 268 (1984) 11. (k) A.H. Cowley, E.A.V. Ebsworth, S.K. Mehrotra, D.W.H. Rankin, M.D. Walkinshaw, J. Chem. Soc. Chem. Commun. (1092) 1099. (1) P. Jutzi, H. Saleske, D. Bühl, H. Grohe, J. Organomet. Chem. 252 (1983) 29. (m) Y.-X. Chen, M.D. Rausch, J.C.W. Chien, Organometallics 12 (1993) 4607. (n) L.H. Sommer, N.S. Marans, J. Am. Chem. Soc. 73 (1951) 5135. (o) Y.-X. Chen, M.D. Rausch, J.C.W. Chien, J. Organomet. Chem. 497 (1995) 1. (p) I.V. Borisova, N.N. Zemlyansky, V.K. Belsky, N.D. Kolosova, N.A. Sobolev, Y.N. Luzikov, Y.A. Untynyuk, I.P. Beletskaya, J. Chem. Soc. Chem. Commun. (1982) 1090. (q) I.V. Borisova, N.N. Zemlyansky, Y.N. Luzikov, Y.A. Untynyuk, I.V.K. Bel'skii, N.D. Kolosova, M.M. Shtern, I.P. Beletskaya, Dokl. Akad. Nauk SSSR 269 (1983) 369 (Chem. Abstr. 99 (1983) 105383).

[20] P.R. Jones, J.M. Rozell Jr., B.M. Campbell, Organometallics 4 (1985) 1321.

[21] (a) P.R. Jones, T.F.O. Lim, R.A. Pierce, J. Am. Chem. Soc. 102 (1980) 4970. (b) T.J. Barton, G.T. Burns, E.V. Arnold, J. Clardy, Tetrahedron Lett. 22 (1981) 7.

[22] T.J. Barton, C.R. Tully, J. Organomet. Chem. 172 (1979) 11.

[23] S.P. Constantine, P.B. Hitchcock, G.A. Lawless, G.M. de Lima, J. Chem. Soc. Chem. Commun. (1996) 1101.

[24] (a) G. Hidalgo, M. Mena, F. Palacios, P. Royo, R. Serrano, J. Organomet. Chem. 340 (1988) 37. (b) J.I. Amor, T. Cuenca, M. Galakhov, P. Royo, J. Organomet. Chem. 497 (1995) 127. (c) M.J. Bunker, A. DeCian, M.L.H. Green, J.J.E. Moreau, N. Siganporia, J. Chem. Soc. Chem. Commun. (1980) 2155. (d) S.L. Shaw, R.J. Morris, J. Huffmann, J. Organomet. Chem. 489 (1995) C4. (e) P. Foster, J.C.W. Chien, M.D. Rausch, Organometallics 15 (1996) 2404. (f) E.C. Lund, T. Livinghouse, Organometallics 8 (1990) 2426. (g) J.H. Wengrovius, R.R. Schrock, J. Organomet. Chem. 205 (1981) 319. (h) P.T. Wolczanski, J.E. Bercaw, Organometallics 1 (1982) 793. (i) C.H. Winter, X.-X. Zhou, D.A. Dobbs, M.J. Heeg, Organometallics 10 (1991) 210. (j) P. Jutzi, A. Seufert, J. Organomet. Chem. 169 (1979) 373. (k) E. Abel, S. Moorhouse, J. Organomet. Chem. 29 (1971) 227. (1) T.E. Ready, J.C.W. Chien, M.D. Rausch, J. Organomet. Chem. 519 (1996) 21. (m) N.E. Schore, J. Am. Chem. Soc. 101 (1979) 7410. (n) F. Nief, F. Mathey, J. Chem. Soc. Chem. Commun. (1988) 770.

[25] A.M. Cardoso, R.H. Clark, S. Moorhouse, J. Chem. Soc. Dalton Trans. (1980) 1156.

[26] (a) P. Jutzi, M. Kuhn, J. Organomet. Chem. 173 (1979) 221. (b) K. Rufanov, E. Avtonomonov, N. Kaznnova, V. Kotov, A. Khvorost, D. Lemenovskii, J. Lorberth, J. Organomet. Chem. 536/537 (1997) 361.

[27] (a) J.M. Rozell Jr, P.R. Jones, Organometallics 4 (1985) 2206. (b) J. Cano, P. Royo, unpublished results. 
[28] (a) J.M. Rozell Jr., P.R. Jones, Organometallics 4 (1985) 11. (b) S. Ciruelos, T. Cuenca, P. Gómez-Sal, A. Manzanero, P. Royo, Organometallics 14 (1995) 177. (c) A.V. Churakov, D.A. Lemenovskii, L.G. Kuz'mina, J. Organomet. Chem. 489 (1995) C81. (d) S. Ciruelos, T. Cuenca, R. Gómez, P. Gómez-Sal, A. Manzanero, P. Royo, Polyhedron 7 (1998) 1055. (e) F.J. de la Mata, P. Giner, P. Royo, J. Organomet. Chem. 572 (1999) 155. (f) M.I. Alcalde, M.P. Gómez-Sal, P. Royo, Organometallics 18 (1999) 546.

[29] E.W. Abel, S. Moorhouse, J. Organomet. Chem. 28 (1971) 211.

[30] (a) B. Royo, P. Royo, L.M. Cadenas, J. Organomet. Chem. 551 (1998) 293. (b) M.I. Alcalde, P. Gómez-Sal, A. Martín, P. Royo, Organometallics 17 (1998) 1144. (c) G. Ciruelo, T. Cuenca, R. Gómez, P. Gómez-Sal, A. Martín, G. Rodríguez, P. Royo, J. Organomet. Chem. 547(1998) 287.

[31] (a) G. Trouvé, D.A Laske, A. Meetsma, J.H. Teuben, J. Organomet. Chem. 511 (1996) 255. (b) H. Plenio, A. Warnecke, J. Organomet. Chem. 544 (1997) 133. (c) D.M. Antonelli, M.L.H. Green, P. Mountford, J. Organomet. Chem. 438 (1992) C4.

[32] (a) R. Gómez-García, P. Royo, J. Organomet. Chem., in press. (b) R. Gómez García, P. Royo, 583 (1999) 86.

[33] (a) P.A. Deck, T.S. Fisher, J.S. Downey, Organometallics 16 (1997) 1193. (b) M.D. Curtis, J.J. D’Errico, N.N. Duffy, P.S. Epstein, L.G. Bell, Organometallics 2 (1983) 1808.

[34] C. Martín. Doctoral Thesis, University of Alcalá, Spain, 1998.

[35] H. Sinn, W. Kaminsky, H.J. Vollmer, R. Woldt, Angew. Chem. Int. Ed. Engl. 19 (1980) 390.

[36] Y. Mu, W.E Piers, L.R. Macgillivray, M.J. Zaworotko, Polyhedron 14 (1) (1995) 1.

[37] (a) U. Siemeling, J. Organomet. Chem. 429 (1992) C14. (b) U. Siemeling, J. Chem. Soc. Chem. Commun. (1992) 1335.

[38] (a) T.A. Herzog, D.L. Zubris, J.E. Bercaw, J. Am. Chem. Soc. 118 (1996) 11988. (b) W. Mengele, J. Diebold, C. Troll, W. Röll, H.-H. Brintzinger, Organometallics 12 (1993) 1931. (c) U. Siemeling, P. Jutzi, B. Neumann, H.-G. Stammler, M.B. Hursthouse, Organometallics 11 (1992) 1328.

[39] A. Cano, T. Cuenca, P. Gómez-Sal, B. Royo, P. Royo, Organometallics 13 (1994) 1688.

[40] W. Song, K. Shackett, J.C.W. Chien, M.D. Rausch, J. Organomet. Chem. 501 (1995) 375.

[41] H. Naderer, E. Siebel, R.D. Fischer, J. Organomet. Chem. 518 (1996) 181.

[42] (a) B. Liang, Y. Li, G. Xie, Macromol. Rapid Commun. 17 (1996) 193. (b) H. Yasuda, E. Ihara, Macromol. Chem. Phys. 196 (1995) 2417.

[43] J. Gräper, G. Paolucci, R.D. Fischer, J. organomet. Chem. 501 (1995) 211.

[44] T. Mise, M. Maeda, T. Nakajuma, K. Kobayashi, I. Shimizu, Y. Yamamoto, Y. Wakatsuki, J. Organomet. Chem. 473 (1994) 155.

[45] L. Kloppenburg, J.L. Petersen, Organometallics 15 (1996) 7.

[46] (a) S. Ciruelos, T. Cuenca, R. Gómez, P. Gómez-Sal, A. Manzanero, P. Royo, Organometallics 15 (1996) 5577. (b) E. Rodríguez, Tesis Licenciatura, Univ. de Alcalá, Fac. Ciencias, 1998. (c) A. Rodrİguez, Tesis Licenciatura, Univ. Alcalá, Fac. Ciencias, 1998.

[47] (a) J. Okuda, S. Verch, T.P. Spaniol, R. Stürner, Chem. Ber. 129 (1996) 1429. (b) A.L. McKnight, R.M. Waymouth, Chem. Rev. 98 (1998) 2587.

[48] (a) M.D. Fryzuk, S.S.H. Mao, M.J. Zaworotko, L.R. MacGillivray, J. Am. Chem. Soc. 115 (1993) 5336. (b) M.D. Fryzuk, S.S.H. Mao, P.B. Duval, S.J. Rettig, Polyhedron 14 (1995) 11. (c) T. Koch, E. Hey-Hawkins, Eur. J. Chem. (1998) submitted.

[49] P.W. Roesky, C.L. Stern, T.J. Marks, Organometallics 16 (1997) 4705.

[50] A. Reissov, M. Capka, Synth. React. Inorg. Met. Org. Chem. 16 (5) (1986) 707.

[51] K. Patsidis, H.G. Alt, W. Milius, S. Palackal, J. Organomet. Chem. 509 (1996) 63.

[52] H.J.G. Luttikhedde, R.P. Lenio, J.H. Näsman, M. Ahlgrén, T. Pakkanen, J. Organomet. Chem. 486 (1995) 193.

[53] W.-M. Tsai, J.C.W. Chien, J. Polym. Sci. Part A Polym. Chem. 32 (1994) 149.

[54] H. Lang, D. Seyferth, Organometallics 10 (1991) 347.

[55] (a) Y. Nakadaira, H. Sakaba, H. Sakurai, Chem. Lett. 9 (1980) 1071. (b) N.N. Zemlyanskii, I.V. Borisova, Yu.N. Luzikov, Yu.A. Ustynyuk, N.D. Kolosova, I.P. Beletskaya, J. Org. Chem. USSR (Engl. Transl.) 17 (1981) 1174. (c) I.M. Shologon, M.K. Romantsevich, J. Org. Chem. USSR (Engl. Transl.) 36 (1966) 1836. 
[56] (a) J.L. Huhmann, J.Y. Corey, N.P. Rath, J. Organomet. Chem. 533 (1997) 61. (b) J.Y. Corey, J.L. Huhmann, N.P. Rath, Inorg. Chem. 34 (1995) 3203.

[57] P. Jutzi, I. Mieling, B. Neumann, H.-G. Stammler, J. Organomet. Chem. 541 (1997) 9.

[58] H. Plenio, J. Organomet. Chem. 435 (1992) 21.

[59] M. Kumada, J. Organomet. Chem. 500 (1995) 195.

[60] M.V. Galakjov, G. Heinz, P. Royo, Chem. Commun. (1998) 17.

[61] (a) J. Okuda, K.E. du Plooy, P.J. Toscano, J. Organomet. Chem. 495 (1995) 195. (b) K.A. Butakoff, D.A. Lemenovskii, P. Mountford, L.G. Kuz'mina, A.V. Churakov, Polyhedron 15 (1996) 489.

[62] (a) J. Cano, G. Martínez, P. Nicolás, S. Acebrón, P. Royo, unpublished results. 